Portland State University

PDXScholar

$12-8-2020$

\title{
Wildfire Risk Assessment for a Municipal Watershed in Western Oregon, USA: Methods for Projecting the Impact of Mid-21st Century Climate Change on Wildfire Hazard
}

Andy McEvoy

Portland State University

Follow this and additional works at: https://pdxscholar.library.pdx.edu/open_access_etds

Part of the Natural Resources Management and Policy Commons Let us know how access to this document benefits you.

\section{Recommended Citation}

McEvoy, Andy, "Wildfire Risk Assessment for a Municipal Watershed in Western Oregon, USA: Methods for Projecting the Impact of Mid-21st Century Climate Change on Wildfire Hazard" (2020). Dissertations and Theses. Paper 5631.

https://doi.org/10.15760/etd.7503

This Thesis is brought to you for free and open access. It has been accepted for inclusion in Dissertations and Theses by an authorized administrator of PDXScholar. Please contact us if we can make this document more accessible: pdxscholar@pdx.edu. 
Wildfire Risk Assessment for a Municipal Watershed in Western Oregon, USA:

Methods for Projecting the Impact of Mid- $21^{\text {st }}$ Century Climate Change on

Wildfire Hazard

\title{
by
}

Andy McEvoy

A thesis submitted in partial fulfillment of the

requirements for the degree of

\author{
Master of Science \\ in \\ Environmental Science and Management
}

\author{
Thesis Committee: \\ Max Nielsen-Pincus, Chair \\ Andrés Holz \\ Kelly Gleason
}

Portland State University

2020 
(C) 2020 Andy McEvoy 


\begin{abstract}
In the western United States, climate change is projected to lead to significant changes in regional wildfire regimes. Historically, forests west of the Cascade crest in Oregon and Washington, USA (westside) have been characterized by low-frequency wildfire events, but climate change projections indicate that wildfire could become a more common disturbance, altering ecological processes and impairing ecosystem services like surface water quality and quantity. Wildfire risk assessments based on simulation models have been used in high frequency fire regimes to evaluate contemporary and future risk, but present unique challenges in westside forests because characteristic low annual burn probabilities result in determinations of low risk. In this thesis, I evaluated wildfire hazard in the Clackamas River watershed (Clackamas), a municipal watershed in western Oregon, under contemporary and projected mid-century climate conditions using the large fire simulator, FSim. In Chapter One, I modeled four climate scenarios from the Coupled Model Intercomparison Project (CMIP5) under RCP 8.5. Results demonstrated that climate change will likely lead to significant changes in fire size, frequency, and fire season length, but a wide range of future conditions is possible. In Chapter Two, I explored the challenges to communicating risk from low probability, high consequence events and presented a framework for evaluating the impact of climate change on surprising, impactful wildfires. Results demonstrated the plausibility of surprising wildfires under contemporary conditions, and showed that surprising wildfires will be increasingly plausible under hotter and drier conditions. The
\end{abstract}


modeled changes in westside fire regimes indicate that historic and contemporary fire regime characteristics are not a complete guide for future disturbance regimes. The combination of probabilistic and surprise fire analysis demonstrated the need for robust risk mitigation and adaptation strategies in the face of a range of plausible futures. 


\section{ACKNOWLEDGEMENTS}

I am grateful for the support and guidance of my committee, Dr. Max-NielsenPincus, Dr. Andrés Holz, and Dr. Kelly Gleason as well as from Dr. Cody Evers. Dr. Arielle Catalano provided the downscaled climate projections which made this project possible. This work was initiated as part of a larger climate resiliency study of the Clackamas River watershed, and I am grateful for the support and contributions from teammates including Portland State's Institute for Sustainable Solutions, the Clackamas River Water Providers, and Clackamas Water and Environmental Services. Finally, I am eternally grateful for the bottomless patience and unbounded support from my wife, Liz Mortati. 


\section{TABLE OF CONTENTS}

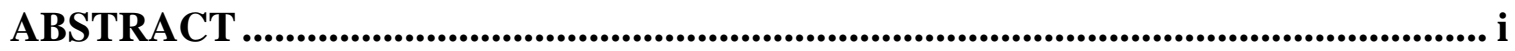

ACKNOWLEDGEMENTS ............................................................................ii

LIST OF TABLES

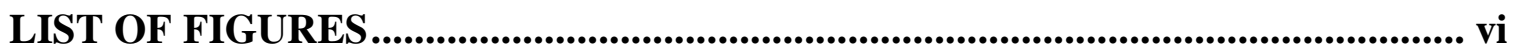

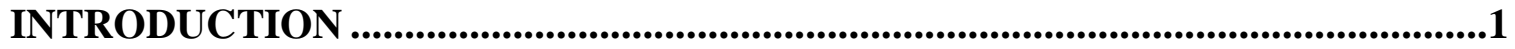

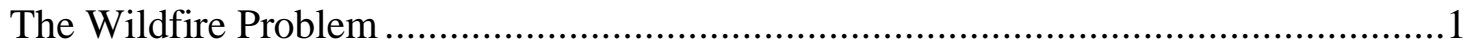

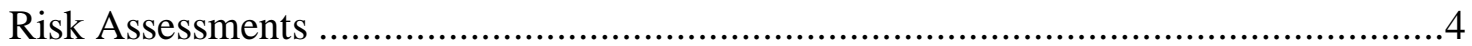

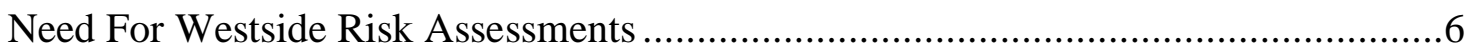

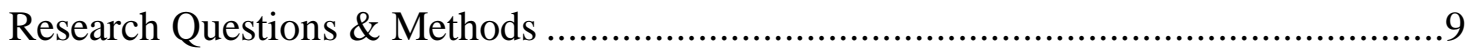

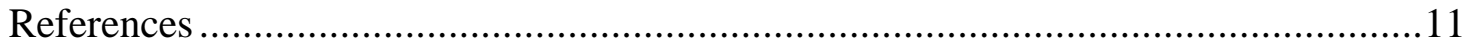

CHAPTER 1: Projected Impact Of Mid-21 ${ }^{\text {st }}$ Century Climate Change On Wildfire Hazard In The Clackamas River Watershed Outside Portland, Oregon U.S.A .......17

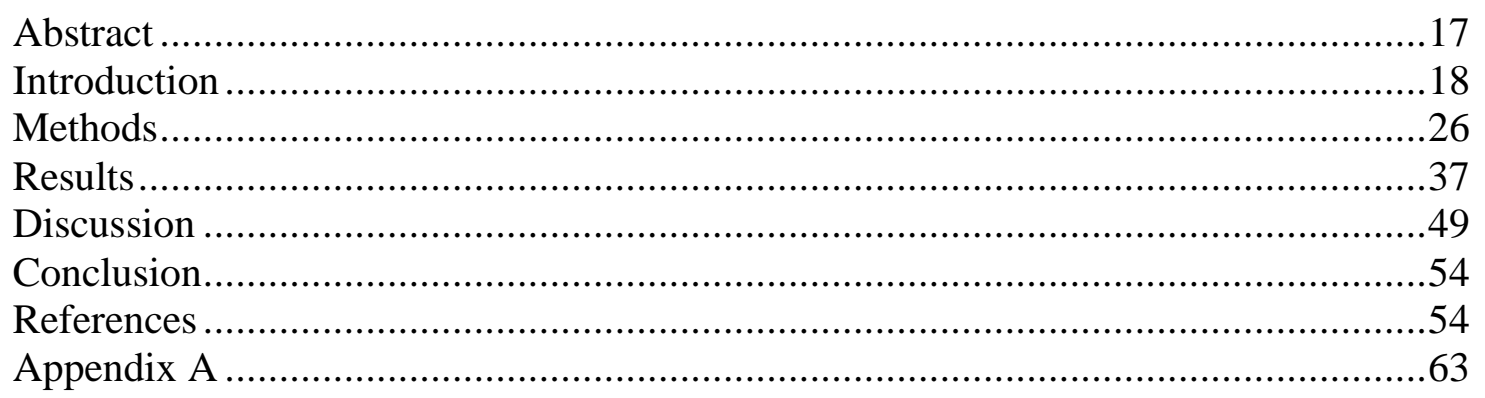

CHAPTER 2: New Perspectives On Wildfire Risk Assessments In Low Frequency Fire Regimes .....................................................................................................................64

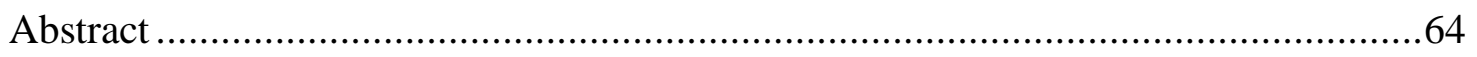

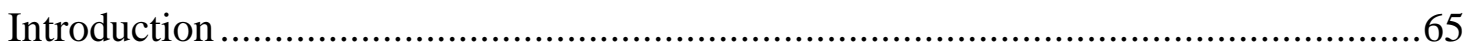

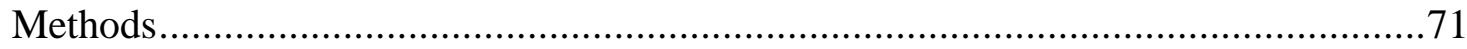

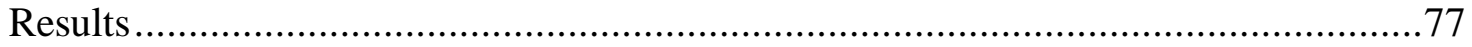

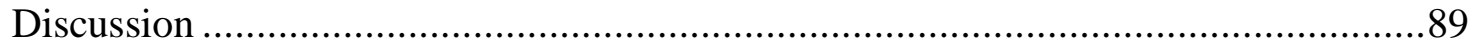

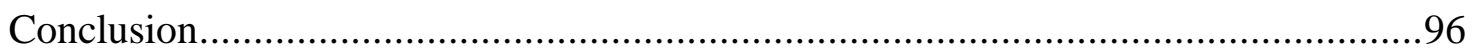

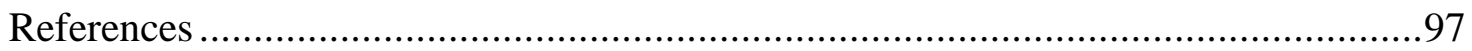

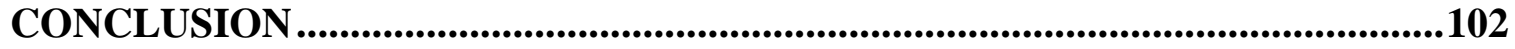

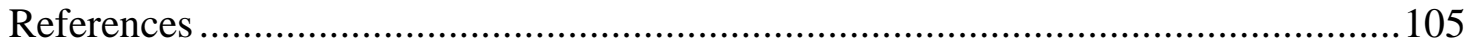




\section{LIST OF TABLES}

Table 1. Major land manager groups in the clackamas and associated land cover. Rows may not sum to $100 \%$ because of miniscule amounts of other landcover including non- burnable (i.e. rock, ice and certain types of row crops), water, grasslands and exotic plants

Table 2. Simulated mean fire size of all fires and the mean annual number of large fires, fires greater than $100 \mathrm{ha}$. Range and standard error are shown below mean values. Conditional area burned is the size of the study area effected in those years that fires were simulated - not all years experienced fire. 30 -year area burned is the estimated cumulative extent of wildfire between 2040 - 2069. Mid-century fire size and frequency distributions were compared to baseline distributions using dunn's tests and in call instances, mid-century distributions were significantly different from baseline (all p-values $<0.0001$ ).

Table 3. Results from a generalized pareto distribution (gpd) model of 99th percentile fire sizes under each climate scenario. The threshold of fire sizes for consideration was set at the 99th percentile of each scenario's fire size distribution. 100- and 1000year return intervals (ri) refer to the fire size (ha) with a 0.01 and 0.001 probability of occurrence. Shape parameters close to 0 indicate that fire size distributions are light-tailed exponential and negative values indicate that fire sizes are finite.

Table 4. Watershed-wide average integrated wildfire hazard and hazard components under each climate scenario. Range and standard error are shown below each average value

Table 5. Count of the total number of surprise fires under each scenario and broken down by surprise type. Percentages in parentheses indicate the percent of all simulated fires in each scenario that were characterized as surprises. The total is not the sum of the categories because some fires satisfied multiple definitions of surprise

Table 6. Number of ignitions resulting in a surprise fire under each climate scenario by land manager where ignition occurred. 


\section{LIST OF FIGURES}

Figure 1. U.S. Forest Service "Forest to Faucets" (USDA Forest Service, 2011) compares the importance of forests to surface drinking water on a relative scale of 0 100. Forests are especially important to drinking water in westside landscapes (left) which have experienced few to no significant wildfires in the past 20 years (National Interagency Fire Center, 2019). The largest wildfire in recent history in the Clackamas River watershed (right) was the 36 Pit fire in 2014 which burned just over 2,200 ha on the Mt. Hood National Forest, but adjacent to private land (Oregon Department of Forestry, 2015).

Figure 2. Extent of FSim modeling. The model extent was divided into two fire occurrence areas (FOAs) in order to distinguish between very different fire environments on either side of the Cascade crest. Each FOA was associated with a unique weather station from which empirical observations were used in the baseline scenarios, and modified to reflect projected future climate conditions. The FOA defines the area within which FSim simulated ignitions and is significantly larger than the analysis area, the Clackamas River watershed, in order to allow for fires that ignite outside the analysis area but eventually burn into it.

Figure 3. Average monthly temperature and relative humidity departure from historical (1970 - 1999) predicted by the four GCMs selected to model future fire weather conditions. These four GCMs represent a full range of predicted climate futures and were downscaled over the study area. Additional figures and explanation of model selection in Appendix A...................................................................................3

Figure 4. Mean daily ERC values for each future (2040 - 2069) climate scenario, shown in red, compared to baseline ERC values, shown in black. Dashed gray lines reflect the 80th, 90th, 97th, ERC percentiles based on baseline climate $1992-2015$. Numbers above the dashed lines indicate the number of days additional to baseline during which fire weather exceeds each fire danger rating......

Figure 5. Number of simulated fires as a function of day of year for mid-century scenarios (red) and baseline (black). Vertical dotted lines indicate the start and end of the large fire season, the period during which fires greater than 100 ha account for more than $90 \%$ of the annual area burned on average.

Figure 6. Integrated wildfire hazard (IWH) is the product of annual burn probability (BP) and mean fireline intensity (MFI). All three metrics are mapped under baseline climate conditions using a quantile method.

Figure 7. Burn probability and mean fireline intensity at each pixel in the study area under baseline (gray) and future scenarios (red). Diagonal lines demarcate integrated wildfire hazard classes .46 
Figure 8. Average annual burn probability in the Clackamas under baseline (1992-2015) and four mid-century (2040-2069) scenarios. HadGEM is the warmest and driest future scenario, followed by CNRM. Both MIROCCHEM and MIROC5 project small increases in summer relative humidity and are less hot than HadGEM and CNRM, but are still warmer than baseline conditions. Non burnable pixels indicate water, rock/ice, high density urban areas, and agriculture. Results are classified using a quantile method.

Figure 9. Integrated wildfire hazard is the product of annual burn probability and mean fireline intensity. Baseline wildfire hazard (upper left) under climate conditions based on empirical climate data 1992-2015. The four mid-century scenarios (right) are based on projected climate scenarios. HadGEM is the warmest and driest future scenario, followed by CNRM. Both MIROCCHEM and MIROC5 project small increases in summer relative humidity and are less hot than HadGEM and CNRM, but are still warmer than baseline conditions. Non-burnable pixels indicate water, rock/ice, high density urban areas, and agriculture. Results are classified using a quantile method.

Figure 10. Projected average annual change in temperature and relative humidity between the end of the $21^{\text {st }}$ century (2070-2099) and the historical reference period (1970-1999) under RCP 8.5 from eighteen GCMs from CMIP5. Circled models were used to model mid-century (2040-2069) wildfire characteristics: HadGEM (upper left), MIROCCCHEM (upper right), CNRM (lower left), MIROC5 (lower right).

Figure 11. Annual burn probability for Oregon and Washington (left) adapted from the 2018 Pacific Northwest Quantitative Risk Assessment. The Clackamas River watershed (right) land management and notable fires from the 200-2018 National Interagency Fire Center. The largest wildfire in recent history in the Clackamas River watershed (right) was the 36 Pit fire in 2014 which burned just over 2,200 ha on the Mt. Hood National Forest, but adjacent to private land. Also shown is the Eagle Creek fire from 2017 which burned about 20,000 ha in the Columbia River Gorge.

Figure 12. Average monthly temperature and relative humidity departure from historical $(1970$ - 1999) projected by the two GCMs selected to model future fire weather conditions. These two GCMs represent a full range of projected climate futures and were downscaled over the study area.

Figure 13. Burn probabilities in the Clackamas River watershed under baseline (left) and two mid-century climate scenarios. Burn probability values are mapped using a quantile method with the percentiles based on the range of burn probabilities from all three scenarios 
Figure 14. Count of all simulated surprise fires from 10,000 iterations in each climate

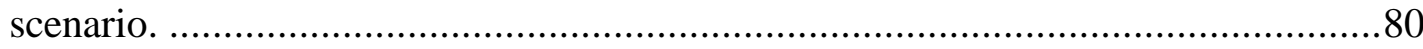

Figure 15. Ignition location of out-of-season surprise fires in each climate scenario with fires igniting after September $22^{\text {nd }}$ on the top row and fires igniting before June $23^{\text {rd }}$ on the bottom row.

Figure 16. Surprise fire occurrence under all three climate scenarios. Conditional surprise probability is the probability of a surprising fire of any kind (top) or an extremely large fire (bottom) given that a fire does occur. Non-burnable pixels are shown in gray.

Figure 17. Ignition location of all surprise fires (top) and only fires greater than 20,000

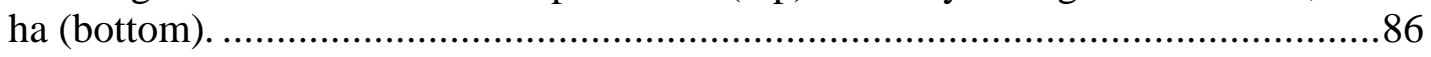

Figure 18. Boxplot of location surprise ignition by day of year. ..................................87 


\section{INTRODUCTION}

\section{THE WILDFIRE PROBLEM}

The distribution of wildfire and its impact on Earth systems is spatially and temporally heterogeneous (Archibald et al., 2013; Whitlock et al., 2010). Driven strongly by climate, but also human activity, global patterns of fire frequency and fire regime characteristics have been changing and are projected to continue changing in the future (Krawchuk et al., 2009). In some fire regimes, human communities will be increasingly exposed to negative wildfire consequences either through direct interaction between infrastructure and fire, or because novel fire regime characteristics interrupt and impair essential ecosystem services (Bowman et al., 2017).

In the United States, the future annual footprint of wildfire is projected to increase as are the consequences and costs associated with wildfire (Abatzoglou and Kolden, 2013; Stavros et al., 2014b; Fairbrother and Turnley, 2005). Over the past several decades in the United States, social and ecological costs associated with wildfire have increased even as more and more resources have been allocated to mitigate risk (Calkin et al., 2015; Hoover, 2017). A century of aggressive suppression policies has led to consequential fire regime shifts in some parts of the country and in all parts of the country an expectation that homes, communities, resources and assets can usually be protected from harmful fires (Calkin et al., 2014). Wildfire risk management is challenged by complex social-ecological interactions and frequently by competing strategies for mitigation (Fischer et al., 2016). At the same time that the U.S. has been experiencing superlatively negative wildfire consequences, there has been a mounting 
recognition that at least part of the problem is that we have excluded wildfire from many landscapes and have not benefitted from the risk mitigation and adaptation opportunities provided by natural fire regimes (Schoennagel et al., 2017). Balancing negative and positive consequences of wildfire is a national challenge, but perspectives and strategies are strongly influenced by local socio-ecological conditions, making it hard to advance a cohesive strategy (Steelman, 2016).

Changing the trajectory of wildfire consequences is not a simple matter. The occurrence and consequences of wildfires are part of a coupled human-natural system wherein complex interactions and feedbacks between human decisions and ecological processes drive changes in fire regimes (Spies et al., 2014). The particularly negative consequences of recent wildfires illustrates what Fischer et al. (2016) called a socioecological pathology; short-term human decision-making over the past century has led to long term unintended changes in ecological systems and processes, such that risk to many human communities has actually increased. In the United States, the pathology is largely attributable to human-caused changes in vegetation and expansion of human communities into fire-prone landscapes. Aggressive suppression policies over the past century have dramatically reduced the ecological footprint of wildfire (Parks et al., 2015). Consequently, in many landscapes like ponderosa pine ecosystems, vegetation has taken on a new structure that facilitates larger, harder to control wildfires (Schoennagel et al., 2004). In grasslands, grazing and land use changes have promoted the rapid spread of flammable invasive vegetation which facilitates and is adapted to frequent, severe wildfires (Balch et al., 2013). Also contributing to the pathology, human development is 
quickly expanding into fire-prone landscapes and thereby contributing to increased ignitions and fire potential, as well as increasing the consequences of wildfires when they impact infrastructure, impair ecosystem services, and degrade air quality (Theobald and Romme, 2007; Balch et al., 2017; Spracklen et al., 2009). Once set in motion, changes in vegetation structure and human development are not simple to reverse. On National Forests in the western U.S. alone, efforts to augment vegetation via fuel treatments have been severely challenged by the pace and scale required to make an impact and by the difficulty of prioritizing treatments to address highly stochastic wildfire occurrence (Schoennagel and Nelson, 2011; Barros et al., 2019;). Likewise, human communities cannot simply be unbuilt or evacuated, nor is it easy to convince residents exposed to wildfire risk to adopt risk mitigation behaviors (Brenkert-Smith et al., 2006).

The intractable problem of a wildfire socioecological pathology has led to calls for new paradigms for resource management, land use planning and wildfire governance. Understanding and treating wildfire as a social ecological system (SES) requires that society learn to co-exist with wildfire on the landscape instead of resorting to exclusion practices. Much attention has been given to reducing our reliance on fuel treatments as the primary risk reduction tool and employing them as strategically as possible when they are required (Barros et al., 2019). In place of or additional to fuel treatments, SES perspectives advocate for increased application of fire as way to restore native fire regimes and achieve community risk reduction (Moritz et al., 2011; North et al., 2012). Increased fire may come from prescribed burning, but also by strategically allowing unintentional ignitions to burn when fire managers feel it is safe. (Moritz et al., 2014). 
Importantly, effectively addressing the wildfire problem requires that human

communities adapt which may mean tolerating more fire on the landscape or it may mean taking specific actions to make infrastructure as resilient as possible (Calkin et al., 2014). None of the above changes will be possible unless wildfire governance systems adopt more flexible approaches to risk management that are responsive to local conditions and incentivize informed risk taking (Steelman, 2016).

\section{RISK ASSESSMENTS}

Characterizing wildfire risk is a prerequisite for informed decisions about how best to mitigate risk, but in complex SESs defining risk is not straightforward. Most definitions of risk include two parts, the probability of a particular outcome and an evaluation of the impact of the outcome should it occur. Wildfires are spatiotemporally stochastic; accurately identifying the probability of a wildfire at any location is incredibly challenging. In most disciplines risk describes the probability and impact of negative consequences, but as described above wildfire occurrence is not an inherently negative event. Therefore, wildfire risk management must account for both negative and positive consequences of wildfire.

Wildfire risk management science has developed new tools and strategies to characterize and communicate wildfire risk and inform risk governance and adaptation strategies. In particular, Monte Carlo based wildfire simulation models have created new opportunities to evaluate contemporary fire occurrence and behavior, project changes in the future, and test mitigation strategies (Parisien et al., 2019). Monte Carlo simulation uses spatially explicit inputs detailing the fuel, topography, weather, and ignitions to 
simulate thousands of statistically plausible iterations of a single fire season. The simulations produce fire perimeter polygons from which we can then derive descriptive pixel-based assessments of the likelihood of a wildfire occurring (burn probability) and the intensity at which it is likely to burn. Burn probability and intensity are combined to evaluate wildfire hazard. Wildfire hazard helps managers address the challenges of stochasticity by illustrating and quantifying where on the landscape and under what climate conditions fires are most likely to occur. However, hazard does not address the impact of wildfire to highly valued resources and assets (HVRAs) such as communities, timber resources, drinking water supply, or recreation sites. Exposure analysis overlays hazard information with spatial occurrence of HVRAs and describes the probability that a fire of a certain intensity will impact an HVRA. In the effects analysis process, the exposure of an HVRA is combined with some measure of susceptibility of the HVRA, in order to quantify the consequence, positive or negative, of wildfire. Frequently, managers are interested in multiple, spatially coincident HVRAs in which case the results of effects analysis for each HVRA in the study area is combined to quantify a spatially explicit and composite measure of wildfire risk. It is during the effects analysis that both the positive and negative consequences of wildfire are accounted for. The reader is directed to Scott et al. (2013) for more comprehensive description of probabilistic wildfire modeling and risk analysis.

Burn probability based risk assessments are arguably the foundation of modern wildfire risk management (Parisien et al., 2019). The results are most frequently reported as raster map products that illustrate variation in the likelihood and net impact of wildfire. 
The resulting maps are usually interpretable by a wide audience, facilitating their integration in all manner of natural resource planning applications. Probabilistic risk assessments are used at national (Finney et al., 2011), regional (Gilbertson-Day et al., 2018), and even local scales (“Oregon Explorer: Wildfire Risk,” n.d.) to identify where risk is highest and what HVRAs are exposed to the most loss or benefit so that resources can be deployed strategically to maximize net benefits and minimize net losses. In addition to evaluating the potential risk to an HVRA, simulation results can be used to determine the source of the risk. In other words, for any given HVRA managers and planners can identify locations where ignitions occur and result in fires that impact the HVRA. From the perspective of addressing and correcting the socioecological pathology of wildfire, probabilistic models can be used to help us understand the relationship between wildfire, climate, and vegetation and to test mitigation strategies. They have been used to evaluate the tradeoff between community risk reduction and habitat conservation (Ager et al., 2010), to assess the impact of various development scenarios on wildfire occurrence (Hulse et al., 2016), to model the impact of different levels of suppression (Riley et al., 2018) and to evaluate the effect of different fuel treatment locations on community wildfire exposure (Scott et al., 2016).

\section{NEED FOR WESTSIDE RISK ASSESSMENTS}

In the western United States, probabilistic risk assessments have generally been conducted at national and regional scales, or have been focused on frequent fire regimes. Focusing on large landscapes is ecologically and socially appropriate. The state and federal agencies responsible for wildfire management operate across large landscapes and 
need to be able to strategically invest in pre-fire planning and resource allocation. Using a probabilistic lens, risk reduction can be maximized by focusing on locations with the highest probability of wildfire impacts to either reduce losses or increase benefits. Furthermore, in frequent fire regimes it is apparent that human activities have interrupted frequent, low to moderate severity fire occurrence and inadvertently increased the potential for large, high severity fires (Parks et al., 2015; Schoennagel et al., 2004). In contrast, westside low frequency fire regimes have received little to no direct attention in probabilistic assessments. For one, the socioecological pathology is not as obvious in westside landscapes. Forest structure and composition has changed significantly over the past centuries in westside landscapes as indigenous fire applications were interrupted and timber management became the dominant disturbance agent (Donato et al., 2020; Haugo et al., 2019; DeMeo et al., 2018). The precise impact of those changes on wildfire occurrence and impacts to HVRAs is not obvious, however, because of naturally long fire return intervals, frequently in excess of 200 years. Additionally, the exceedingly low probability of a fire occurring in any given year means that the westside region is classified as low risk or at least lower risk than fire prone regions east of the Cascades.

Westside fire regimes are generally controlled by climate conditions, and in light of regional projected climate change over the remainder of the $21^{\text {st }}$ century, it is increasingly important that we better understand the drivers and magnitude of westside fire risk. Long return intervals in westside landscapes, where fuel is generally abundant, are primarily the result of regional climate (Gedalof et al., 2005; Littell et al., 2009). The westside of the Cascades receives abundant precipitation through fall and early spring 
and experiences a dry season during the summer. However, snow melt and periodic dryseason rain ordinarily prevent vegetation and fuels from being sufficiently dry to combust or facilitate a spreading fire (Agee, 1993). Historically, westside wildfires have occurred during anomalously dry summers, and are driven largely by seasonal drought patterns (Littell et al., 2016). Very large wildfires in the region appear to be driven by drought in the few weeks leading up to an ignition and the persistence of hot, dry conditions during the event (Stavros et al., 2014a). There is evidence that fire events have historically been regionally synchronous over decades-long time scales, demonstrating the governing role of regional climate in westside fire regimes (Weisberg and Swanson, 2003). westside wildfire exposure is expected to increase as a result of climate change (Sheehan et al., 2015a). Summer temperatures are projected to increase in westside forests (Mote and Salathé, 2010). There is less agreement on projected changes in future precipitation timing and amount, but most models project decreased summer precipitation (Holden et al., 2018; Schoof, 2015). It is not abundantly clear what the impact of increased wildfire risk exposure will be on HVRAs in westside forests. On one hand, post-wildfire landscapes may provide the most likely opportunity for otherwise highly stationary vegetation to adapt to novel climate conditions (Halofsky et al., 2018a). On the other hand, many HVRAs in westside forests, such as drinking water supply, timber resources, and endangered wildlife habitat, are most often negatively impacted by wildfire, thereby justifying continued fire suppression (Halofsky et al., 2018b). 


\section{RESEARCH QUESTIONS \& METHODS}

Westside-specific risk assessments are essential for evaluating the potential consequences of increased wildfire activity and testing mitigation or adaptation strategies. The purpose of this thesis was to demonstrate two unique methods of evaluating contemporary and future wildfire risk exposure in a westside landscape. Both chapters are based on Monte Carlo simulations of wildfire occurrence in the Clackamas River watershed (Clackamas) east of Portland, Oregon. Using the large fire simulator, FSim, and methods based on Riley and Loehman (2016), I simulated wildfire occurrence and characteristics under contemporary climate conditions as well as under four unique climate scenarios for the period 2040-2069.

The Clackamas extends from the Cascade crest in Mt. Hood National Forest down to the river's confluence with the Willamette River in Oregon City. The Clackamas is the second largest surface water source for the Portland metro area, serving more than 300,000 people. The Clackamas also contains productive, actively managed private timber lands, is home to aquatic and terrestrial federally endangered species, and valued for motorized and non-motorized recreation opportunities.

In Chapter One I evaluated contemporary and future wildfire hazard in the Clackamas using a probabilistic, integrated hazard measure developed by Scott et al. (2012). By modeling wildfire hazard under contemporary conditions this work aims to reduce knowledge gaps that are the inevitable result of low annual burn probability. The Clackamas has experienced few large fires in memorable history and while managers and stakeholders have strong convictions about where wildfire hazard is highest, simulations are a robust way to test those convictions and develop a more complete, measurable 
assessment of relative hazard across the watershed. Furthermore, establishing contemporary hazard is essential in order to contextualize and evaluate the projected change in hazard under climate change scenarios. In Chapter One, I used projected changes in temperature and relative humidity from four Global Circulation Models (GCMs) under Representative Concentration Pathway (RCP) 8.5 for the time period 2040-2069. I selected four GCMs that describe the bounds of plausible projected changes in temperature and relative humidity and are therefore anticipated to model the projected range in mid-century fire regime characteristics. For each climate scenario, I evaluated the length and timing of the fire season, fire size and number, and annual area burned and mapped the resulting wildfire hazard. The results are directly applicable to a range of natural resource and planning applications, and provide a foundation for additional exposure and effects analyses.

In Chapter Two, I demonstrated a novel method for evaluating the plausibility and characteristics of surprising wildfires in the Clackamas under contemporary and future climate scenarios. Probabilistic risk assessments, like that in Chapter One, have the advantage of being relatively easy to communicate with a wide audience because raster maps are interpretable and it is common to talk about risk in probabilistic terms across many disciplines. However, there is strong evidence from various research disciplines indicating that individuals do not interpret risk probabilities as rationally as might be expected and that, in particular, individuals struggle to incorporate low probabilities into decisions of risk (Kahneman and Tversky, 1979; Kunreuther et al., 2001). In Chapter Two, I described novel risk assessment methods that add to probabilistic assessments in 
order to clarify sources of uncertainty and improve risk decision-making regarding low probability, high consequence events. Specifically, I outlined the value of characterizing surprising fires, fires which would be highly consequential if they did occur but are considered implausible by managers and relevant stakeholders. Surprising events are often a source of discovery, expanding our understanding of SESs, as well as catalysts for social and ecological change (Lindenmayer et al., 2010). Based on informal conversations with managers, scientists and relevant stakeholders I developed three definitions of surprising fires in the Clackamas based on fire season, fire size, and location. My approach is similar to Hulse et al. (2016), but I demonstrated a method for combining surprise analysis with probabilistic analysis using the results of Monte Carlo simulations. I used the same modeling framework as in Chapter One, but only analyzed the occurrence and characteristics of surprising fires under contemporary and two future climate scenarios instead of four. I selected the hottest and driest as well as the least warm and wettest project future scenarios. The results provide managers and planners with spatially explicit evaluations of the plausibility of seemingly impossible wildfires, and illustrate the changes in frequency and magnitude of consequential fires that are projected to occur over the next fifty years.

\section{REFERENCES}

Abatzoglou, J.T., Kolden, C.A., 2013. Relationships between climate and macroscale area burned in the western United States. Int. J. Wildland Fire 22, 1003. https://doi.org/10.1071/WF13019

Agee, J.K., 1993. Fire Ecology of Pacific Northwest Forests. Island Press, Washington, D.C.

Ager, A.A., Vaillant, N.M., Finney, M.A., 2010. A comparison of landscape fuel treatment strategies to mitigate wildland fire risk in the urban interface and 
preserve old forest structure. Forest Ecology and Management 259, 1556-1570. https://doi.org/10.1016/j.foreco.2010.01.032

Archibald, S., Lehmann, C.E.R., Gomez-Dans, J.L., Bradstock, R.A., 2013. Defining pyromes and global syndromes of fire regimes. Proceedings of the National Academy of Sciences 110, 6442-6447. https://doi.org/10.1073/pnas.1211466110

Balch, J.K., Bradley, B.A., Abatzoglou, J.T., Nagy, R.C., Fusco, E.J., Mahood, A.L., 2017. Human-started wildfires expand the fire niche across the United States. Proceedings of the National Academy of Sciences 114, 2946-2951. https://doi.org/10.1073/pnas.1617394114

Balch, J.K., Bradley, B.A., D’Antonio, C.M., Gómez-Dans, J., 2013. Introduced annual grass increases regional fire activity across the arid western USA (1980-2009). Global Change Biology 19, 173-183. https://doi.org/10.1111/gcb.12046

Barros, A.M., Ager, A.A., Day, M.A., Palaiologou, P., 2019. Improving long-term fuel treatment effectiveness in the National Forest System through quantitative prioritization. Forest Ecology and Management 433, 514-527. https://doi.org/10.1016/j.foreco.2018.10.041

Bowman, D.M.J.S., Williamson, G.J., Abatzoglou, J.T., Kolden, C.A., Cochrane, M.A., Smith, A.M.S., 2017. Human exposure and sensitivity to globally extreme wildfire events. Nat Ecol Evol 1, 0058. https://doi.org/10.1038/s41559-016-0058

Brenkert-Smith, H., Champ, P.A., Flores, N., 2006. Insights Into Wildfire Mitigation Decisions Among Wildland-Urban Interface Residents. Society \& Natural Resources 19, 759-768. https://doi.org/10.1080/08941920600801207

Calkin, D.E., Cohen, J.D., Finney, M.A., Thompson, M.P., 2014. How risk management can prevent future wildfire disasters in the wildland-urban interface. Proceedings of the National Academy of Sciences 111, 746-751. https://doi.org/10.1073/pnas.1315088111

Calkin, D.E., Thompson, M.P., Finney, M.A., 2015. Negative consequences of positive feedbacks in US wildfire management. For. Ecosyst. 2, 9. https://doi.org/10.1186/s40663-015-0033-8

Donato, D.C., Halofsky, J.S., Reilly, M.J., 2020. Corralling a black swan: natural range of variation in a forest landscape driven by rare, extreme events. Ecol Appl 30. https://doi.org/10.1002/eap.2013

Fairbrother, A., Turnley, J.G., 2005. Predicting risks of uncharacteristic wildfires: Application of the risk assessment process. Forest Ecology and Management 211, 28-35. https://doi.org/10.1016/j.foreco.2005.01.026

Finney, M.A., McHugh, C.W., Grenfell, I.C., Riley, K.L., Short, K.C., 2011. A simulation of probabilistic wildfire risk components for the continental United States. Stoch Environ Res Risk Assess 25, 973-1000. https://doi.org/10.1007/s00477-011-0462-z

Fischer, A.P., Spies, T.A., Steelman, T.A., Moseley, C., Johnson, B.R., Bailey, J.D., Ager, A.A., Bourgeron, P., Charnley, S., Collins, B.M., Kline, J.D., Leahy, J.E., Littell, J.S., Millington, J.D., Nielsen-Pincus, M., Olsen, C.S., Paveglio, T.B., Roos, C.I., Steen-Adams, M.M., Stevens, F.R., Vukomanovic, J., White, E.M., 
Bowman, D.M., 2016. Wildfire risk as a socioecological pathology. Frontiers in Ecology and the Environment 14, 276-284. https://doi.org/10.1002/fee.1283

Gedalof, Z., Peterson, D.L., Mantua, N.J., 2005. Atmospheric, Climatic, And Ecological Controls on Extreme Wildfire Years in the Northwestern United States.

Ecological Applications 15, 154-174. https://doi.org/10.1890/03-5116

Gilbertson-Day, J., Stratton, R.D., Scott, J.H., Vogler, K.C., Brough, A., 2018. Pacific Northwest Quantitative Wildfire Risk Assessment: Methods and Results.

Halofsky, J.S., Conklin, D.R., Donato, D.C., Halofsky, J.E., Kim, J.B., 2018a. Climate change, wildfire, and vegetation shifts in a high-inertia forest landscape: Western Washington, U.S.A. PLoS ONE 13, e0209490. https://doi.org/10.1371/journal.pone.0209490

Halofsky, J.S., Donato, D.C., Franklin, J.F., Halofsky, J.E., Peterson, D.L., Harvey, B.J., 2018 b. The nature of the beast: examining climate adaptation options in forests with stand-replacing fire regimes. Ecosphere 9, e02140. https://doi.org/10.1002/ecs2.2140

Haugo, R.D., Kellogg, B.S., Cansler, C.A., Kolden, C.A., Kemp, K.B., Robertson, J.C., Metlen, K.L., Vaillant, N.M., Restaino, C.M., 2019. The missing fire: quantifying human exclusion of wildfire in Pacific Northwest forests, USA. Ecosphere 10, e02702. https://doi.org/10.1002/ecs2.2702

Holden, Z.A., Swanson, A., Luce, C.H., Jolly, W.M., Maneta, M., Oyler, J.W., Warren, D.A., Parsons, R., Affleck, D., 2018. Decreasing fire season precipitation increased recent western US forest wildfire activity. Proc Natl Acad Sci USA 115, E8349-E8357. https://doi.org/10.1073/pnas.1802316115

Hoover, K., 2017. Wildfire Management Funding: Background, Issues, and FY2018 Appropriations (No. R45005). Congressional Research Service.

Hulse, D., Branscomb, A., Enright, C., Johnson, B., Evers, C., Bolte, J., Ager, A., 2016. Anticipating surprise: Using agent-based alternative futures simulation modeling to identify and map surprising fires in the Willamette Valley, Oregon USA. Landscape and Urban Planning 156, 26-43. https://doi.org/10.1016/j.landurbplan.2016.05.012

Kahneman, D., Tversky, A., 1979. Prospect Theory: An Analysis of Decision under Risk. Econometrica 47, 263. https://doi.org/10.2307/1914185

Krawchuk, M.A., Moritz, M.A., Parisien, M.-A., Van Dorn, J., Hayhoe, K., 2009. Global Pyrogeography: the Current and Future Distribution of Wildfire. PLoS ONE 4, e5102. https://doi.org/10.1371/journal.pone.0005102

Kunreuther, H., Novemsky, N., Kahneman, D., 2001. Making Low Probabilities Useful. Journal of Risk and Uncertainty 23, 103-120. https://doi.org/10.1023/A:1011111601406

Lindenmayer, D.B., Likens, G.E., Krebs, C.J., Hobbs, R.J., 2010. Improved probability of detection of ecological "surprises." Proceedings of the National Academy of Sciences 107, 21957-21962. https://doi.org/10.1073/pnas.1015696107

Littell, J.S., McKenzie, D., Peterson, D.L., Westerling, A.L., 2009. Climate and wildfire area burned in western U.S. ecoprovinces, 1916-2003. Ecological Applications 19, 1003-1021. https://doi.org/10.1890/07-1183.1 
Littell, J.S., Peterson, D.L., Riley, K.L., Liu, Y., Luce, C.H., 2016. A review of the relationships between drought and forest fire in the United States. Glob Change Biol 22, 2353-2369. https://doi.org/10.1111/gcb.13275

Moritz, M.A., Batllori, E., Bradstock, R.A., Gill, A.M., Handmer, J., Hessburg, P.F., Leonard, J., McCaffrey, S., Odion, D.C., Schoennagel, T., Syphard, A.D., 2014. Learning to coexist with wildfire. Nature 515, 58-66.

https://doi.org/10.1038/nature13946

Moritz, M.A., Hessburg, P.F., Povak, N.A., 2011. Native Fire Regimes and Landscape Resilience, in: The Landscape Ecology of Fire51, Ecological Studies. Springer Netherlands, pp. 51-86.

Mote, P.W., Salathé, E.P., 2010. Future climate in the Pacific Northwest. Climatic Change 102, 29-50. https://doi.org/10.1007/s10584-010-9848-Z

North, M., Collins, B.M., Stephens, S., 2012. Using Fire to Increase the Scale, Benefits, and Future Maintenance of Fuels Treatments. Journal of Forestry 110, 392-401. https://doi.org/10.5849/jof.12-021

Oregon Explorer: Wildfire Risk [WWW Document], n.d. URL https://oregonexplorer.info/topics/wildfire-risk?ptopic=62 (accessed 6.21.20).

Parisien, M.-A., Dawe, D.A., Miller, C., Stockdale, C.A., Armitage, O.B., 2019. Applications of simulation-based burn probability modelling: a review. Int. J. Wildland Fire 28, 913. https://doi.org/10.1071/WF19069

Parks, S.A., Miller, C., Parisien, M.-A., Holsinger, L.M., Dobrowski, S.Z., Abatzoglou, J., 2015. Wildland fire deficit and surplus in the western United States, 19842012. Ecosphere 6, art275. https://doi.org/10.1890/ES15-00294.1

Riley, K., Thompson, M., Scott, J., Gilbertson-Day, J., 2018. A Model-Based Framework to Evaluate Alternative Wildfire Suppression Strategies. Resources 7, 4. https://doi.org/10.3390/resources7010004

Riley, K.L., Loehman, R.A., 2016. Mid-21st-century climate changes increase predicted fire occurrence and fire season length, Northern Rocky Mountains, United States. Ecosphere 7, e01543. https://doi.org/10.1002/ecs2.1543

Schoennagel, T., Balch, J.K., Brenkert-Smith, H., Dennison, P.E., Harvey, B.J., Krawchuk, M.A., Mietkiewicz, N., Morgan, P., Moritz, M.A., Rasker, R., Turner, M.G., Whitlock, C., 2017. Adapt to more wildfire in western North American forests as climate changes. Proceedings of the National Academy of Sciences 114, 4582-4590. https://doi.org/10.1073/pnas.1617464114

Schoennagel, T., Nelson, C.R., 2011. Restoration relevance of recent National Fire Plan treatments in forests of the western United States. Frontiers in Ecology and the Environment 9, 271-277. https://doi.org/10.1890/090199

Schoennagel, T., Veblen, T.T., Romme, W.H., 2004. The Interaction of Fire, Fuels, and Climate across Rocky Mountain Forests. BioScience 54, 661. https://doi.org/10.1641/0006-3568(2004)054[0661:TIOFFA]2.0.CO;2

Schoof, J.T., 2015. High-resolution projections of 21 st century daily precipitation for the contiguous U.S. J. Geophys. Res. Atmos. 120, 3029-3042.

https://doi.org/10.1002/2014JD022376 
Scott, J., Helmbrecht, D., Thompson, M.P., Calkin, D.E., Marcille, K., 2012. Probabilistic assessment of wildfire hazard and municipal watershed exposure. Nat Hazards 64, 707-728. https://doi.org/10.1007/s11069-012-0265-7

Scott, J.H., Thompson, M.P., Calkin, D.E., 2013. A wildfire risk assessment framework for land and resource management (No. RMRS-GTR-315). U.S. Department of Agriculture, Forest Service, Rocky Mountain Research Station, Ft. Collins, CO. https://doi.org/10.2737/RMRS-GTR-315

Scott, J.H., Thompson, M.P., Gilbertson-Day, J.W., 2016. Examining alternative fuel management strategies and the relative contribution of National Forest System land to wildfire risk to adjacent homes - A pilot assessment on the Sierra National Forest, California, USA. Forest Ecology and Management 362, 29-37. https://doi.org/10.1016/j.foreco.2015.11.038

Sheehan, T., Bachelet, D., Ferschweiler, K., 2015. Projected major fire and vegetation changes in the Pacific Northwest of the conterminous United States under selected CMIP5 climate futures. Ecological Modelling 317, 16-29. https://doi.org/10.1016/j.ecolmodel.2015.08.023

Spies, T.A., White, E.M., Kline, J.D., Fischer, A.P., Ager, A., Bailey, J., Bolte, J., Koch, J., Platt, E., Olsen, C.S., Jacobs, D., Shindler, B., Steen-Adams, M.M., Hammer, R., 2014. Examining fire-prone forest landscapes as coupled human and natural systems. E\&S 19, art9. https://doi.org/10.5751/ES-06584-190309

Spracklen, D.V., Mickley, L.J., Logan, J.A., Hudman, R.C., Yevich, R., Flannigan, M.D., Westerling, A.L., 2009. Impacts of climate change from 2000 to 2050 on wildfire activity and carbonaceous aerosol concentrations in the western United States. J. Geophys. Res. 114, D20301. https://doi.org/10.1029/2008JD010966

Stavros, E.N., Abatzoglou, J., Larkin, N.K., McKenzie, D., Steel, E.A., 2014a. Climate and very large wildland fires in the contiguous western USA. Int. J. Wildland Fire 23, 899. https://doi.org/10.1071/WF13169

Stavros, E.N., Abatzoglou, J.T., McKenzie, D., Larkin, N.K., 2014b. Regional projections of the likelihood of very large wildland fires under a changing climate in the contiguous Western United States. Climatic Change 126, 455-468. https://doi.org/10.1007/s10584-014-1229-6

Steelman, T., 2016. U.S. wildfire governance as social-ecological problem. E\&S 21, art3. https://doi.org/10.5751/ES-08681-210403

Theobald, D.M., Romme, W.H., 2007. Expansion of the US wildland-urban interface. Landscape and Urban Planning 83, 340-354. https://doi.org/10.1016/j.landurbplan.2007.06.002

Tom DeMeo, Ryan Haugo, Chris Ringo, Jane Kertis, Steve Acker, Mike Simpson, Mark Stern, 2018. Expanding Our Understanding of Forest Structural Restoration Needs in the Pacific Northwest. Northwest Science 92, 18-35.

Weisberg, P.J., Swanson, F.J., 2003. Regional synchroneity in fire regimes of western Oregon and Washington, USA. Forest Ecology and Management 172, 17-28. https://doi.org/10.1016/S0378-1127(01)00805-2 
Whitlock, C., Higuera, P.E., McWethy, D.B., Briles, C.E., 2010. Paleoecological Perspectives on Fire Ecology: Revisiting the Fire-Regime Concept TOECOLJ 3, 6-23. https://doi.org/10.2174/1874213001003020006 


\title{
CHAPTER 1: Projected Impact of mid-21 ${ }^{\text {st }}$ Century Climate Change on Wildfire Hazard in the Clackamas River Watershed outside Portland, Oregon U.S.A
}

\author{
ABSTRACT \\ Projected changes in future wildfire regimes are expected to alter existing eco- \\ hydrological processes and lead to significant management challenges across the globe.
} Across the United States, the majority of the population depends on surface sources of freshwater, and in the western U.S. in particular, forests are vital to the maintenance of water quality and quantity. Projected increases in wildfire occurrence and severity threaten surface sources of freshwater due to post-fire erosion, altered stream chemistry, and changes in timing and magnitude of peak flow. We evaluated impacts of climate change on wildfire hazard in a municipal watershed outside Portland, Oregon, USA. Using the large fire simulator FSim, we simulated wildfire occurrence and characteristics under contemporary conditions (1992-2015) and four mid-century (2040-2069) scenarios. The four scenarios were selected from the Coupled Model Intercomparison Project phase $5, \mathrm{RCP} 8.5$ to represent a range of potential changes in temperature and relative humidity. Results indicated a wide range of future changes to wildfire regime characteristics are possible, from moderate increases in fire frequency to novel disturbance regimes. All mid-century scenarios demonstrated the potential for large fires to occur in the lower watershed in close proximity to high density communities. Projected changes in temperature and relative humidity led to longer fire seasons and more severe fire weather in three of the four scenarios. Our analysis results are consistent with other studies which have also projected longer fire seasons and increased annual area affected by wildfire in westside forests. Contemporary and future wildfire hazard assessments are the foundation 
for subsequent exposure and risk analysis, as well as the development of risk mitigation and climate adaptation strategies. In particular, water resource managers will need to carefully consider what it means to adapt to climate change in low frequency fire regimes without sacrificing adequate water provision to communities.

\section{INTRODUCTION}

Projected changes in future wildfire regimes are expected to alter existing ecohydrological processes and lead to significant management challenges across the globe (Hallema et al., 2018). Historically, especially large fires or years in which there was an extraordinary number of fires have been linked to decreased water quality, altered water supply, and significant risks of flooding and landslides (de la Barrera et al., 2018; Moody et al., 2008; Rhoades et al., 2019). In forested watersheds, post-fire changes in soil and water chemistry can persists for years after the actual fire, impairing water quality and treatability of drinking water sources (Emelko et al., 2016; Hohner et al., 2019). Wildfires can also have long-lasting and far-reaching impacts on annual water yield and seasonal timing associated with high (or low) water levels (Emelko et al., 2011). The particular impact of climate change on hydrological processes will, in part, reflect regional changes in wildfire regimes. In many parts of the world, climate change is projected to lead to increased annual area burned and higher severity fires (Dennison et al., 2014; Krawchuk et al., 2009). Future wildfire impacts to hydrology will also be mediated in regionally specific ways by complex interactions between climate, hydrology, topography, vegetation and social factors related to land and water management (Hallema et al., 2017; Moody et al., 2013). 
Regions dependent on surface sources of freshwater are particularly susceptible to negative consequences of increased wildfire frequency, extent and severity. Much of the United States relies on surface water sources, but in the western states more than $50 \%$ of the available freshwater originates in forested watersheds susceptible to wildfire (Brown et al., 2008). Water quality and quantity in landscapes west of the Cascade crest in Oregon and Washington, USA (westside) are particularly dependent on forests and forest-based ecological processes, and the majority of residents in Oregon and Washington live in the westside and rely on surface water sources (Figure 1). For example, the Bull Run watershed collects precipitation in an entirely forested basin and is the primary water source for millions of residents in Portland, Oregon and the surrounding metro area (Portland Water Bureau, 2020). Throughout western Oregon more than two million residents depend on water that originates in the heavily forested Cascades (Haller and Moryc, 2018). Similarly, nearly all of Seattle, Washington's freshwater originates in mountain watersheds of the western Cascades.

Historically, westside fire regimes have been dominated by centuries long return intervals and punctuated by anomalously dry conditions during which wildfires can occur (Agee, 1993). Proximity to the ocean and the orographic effect of coastal and Cascade mountain ranges graces westside forests with generally abundant water and moderate climate. Even during mostly dry summers, soil moisture is relatively high compared to other regions of the western United States, in large part because of water released slowly from high elevation snowmelt and glaciers. As a result, vegetation is rarely sufficiently dry enough to facilitate wildfire combustion, let alone the prolonged active spreading that 
leads to large fires. The past century is speckled with memorable wildfires that left their mark on both the landscape and the communities living there. The Yacolt fire (1902) killed thirty-eight individuals and burned over 200,00 ha in the Columbia River Gorge; the Tillamook Burn (1933 through 1951) - which was actually four fires over the course of twenty years - consumed over 141,00 ha of timber in Oregon's coast range; and recently the Eagle Creek fire (2017) burned approximately 22,000 ha and threatened Bull Run Reservoir, the primary drinking water source for Portland, OR.

While infrequent, large, high severity fires may stand out in the cultural memory of westside landscapes, evidence increasingly points to a much more complex mosaic of fire size, frequency, and severity (Bakker et al., 2019; Hessburg et al., 2016; Reilly et al., 2017; Tepley et al., 2013). Shades of variation and complexity in westside fire regimes appear to be at least partly explained by anthropogenic forces. Throughout the Holocene growing human populations appear to have locally and regionally augmented otherwise climate-driven trends in fire activity (Walsh et al., 2015). Amidst the increasingly complex backdrop it can be hard to discern whether the relative absence of large fires in recent history in westside forests is a result of fire suppression and land management as is the case in more arid parts of the western U.S., or whether recent fire occurrence is consistent with the regional fire regime and reflects the top down control imposed by seasonally dry, but generally wet climate (Parks et al., 2015; Schoennagel et al., 2004).

Climate change is expected to lead to novel fire regime changes and thus novel challenges to maintaining ecosystem services in westside forests. Summer temperatures are projected to increase (Mote and Salathé, 2010) and while there is less agreement on 
future annual precipitation patterns, precipitation during the fire season is expected to decrease (Dalton and Shell, 2013; Holden et al., 2018; Schoof, 2015). In fact, average annual temperatures in western Oregon and Washington increased by nearly $1^{\circ} \mathrm{C}$ over the $20^{\text {th }}$ century (Abatzoglou and Barbero, 2014; Mote et al., 2003). Recent droughts, like those in western Oregon in 2014 and 2015 when the region experienced anomalously low snowpack, may be a harbinger of what is to become more common. During the winter of 2014, winter temperatures were $2-4^{\circ} \mathrm{C}$ warmer than average, and snow water equivalent was reduced by as much as 30\% (Cooper et al., 2016). Reduced snowpack and warmer winter temperatures led to earlier peaks in summer streamflow and summer drought conditions in western Oregon (Jung and Chang, 2011; Tague and Grant, 2009). In westside forests where fuel is generally abundant and wildfire has historically been limited by infrequent occasions of sufficiently dry fuel for combustion, increasingly hot and dry conditions will lead to increased fire activity (Abatzoglou and Kolden, 2013; Cansler and McKenzie, 2014; Holden et al., 2018; Littell et al., 2009; Reilly et al., 2017; Stavros et al., 2014b; Westerling, 2006). Climate has historically been a strong driver of fire seasonality (Heyerdahl et al., 2008; Littell et al., 2009) and the projected changes in temperature and precipitation will likely intensify future fire weather in the peak season, as well as expand the fire season into spring and autumn. Intensifying fire weather and more days each year during which an ignition may result in a spreading fire will lead to more fires and increased annual area burned (McKenzie et al., 2004; McKenzie and Littell, 2017). 
While contemporary wildfire in westside forests is not necessarily considered the primary threat to these ecosystems and the benefits we derive from them, climate change may significantly alter fire regime characteristics such that wildfire impairs ecosystem services. The indirect impacts of climate change on forests as a result of wildfire, drought, and pests are expected to be the primary pathway by which forest resilience is compromised (Spies et al., 2018). In this context, resilience is the capacity of forests to maintain provision of ecosystem services even in the face of novel disturbance frequency and magnitude. The additive interaction of extreme weather events with impacts from wildfire and insect outbreaks is more plausible under projected future climate conditions and could result in vegetation phase transitions - i.e forested to non-forested (Buma, 2015).

Surface drinking water sources may suffer from a number of climate-wildfire related changes such as post-fire debris slides triggered by rain-on-snow events (Wondzell and King, 2003). Rain-on-snow events are expected to become more common in westside forests and if the burned area increases as well, there may be significant impacts to downstream water sources (Jennings and Jones, 2015). Climate induced soil moisture stress and reduced snowpack may enable more frequent wildfires in higher elevations of westside landscapes, leading to reduced downstream water yield where human communities most need it (Nolin, 2012). Large wildfires at high elevations and the resulting changes in forest structure and presence of char can lead to significant changes in snow accumulation and snowmelt timing (Gleason and Nolin, 2016). 
At the same time, wildfire is an essential disturbance agent across the western U.S. and has enormous social and environmental benefits (Keane et al., 2008; Pausas and Keeley, 2019). Wildfire, whether natural or prescribed, can help reduce risk exposure in nearby communities (Schoennagel et al., 2017), and is essential to creating or maintaining climate-adapted landscapes (Hessburg et al 2016). After a century of wildfire suppression and industrial forest management, westside forest structure is outside the historic range of variability (Haugo et al., 2019). Mid-seral, even aged stands are overly abundant while early- and late-seral structures are underrepresented (Haugo et al., 2015). Wildfire may help move forest structures back into alignment with historical ranges of variability, as well as help otherwise highly stationary forests adapt to climate change (Halofsky et al., 2020; J. S. Halofsky et al., 2018a).

Effective prioritization of wildfire management and mitigation of wildfire risk requires consideration of both costs and benefits of wildfire (Ager et al., 2015; Vogler et al., 2015). Doing so is a challenge for managers in westside forests where may have little experience with recent large wildfires, and climate change is likely to result in novel fire regime characteristics. Although managers must always work in an environment of incomplete historical knowledge to make decisions about an uncertain future, westside forests compound the challenge managers face as historical conditions may not serve as a reliable reference for future wildfire risk.

Probabilistic wildfire hazard and risk assessments are increasingly common tools, providing managers with necessary information to understand wildfire regimes even in the absence of experience, mitigate negative wildfire impacts, protect human 
communities, achieve resource benefits with fire, and direct resources to achieve management goals (Scott et al., 2012; Calkin et al., 2014; Thompson et al., 2016; Ager et al., 2016). In westside forests, models may be especially helpful by supplying a baseline to which the impact of climate change on wildfire characteristics can be compared. Burn probability, or the annual likelihood of fire occurring at any location on the landscape, is the foundation of wildfire risk assessments, allowing managers to evaluate the relationships between fire occurrence and landscape features (Parisien et al., 2019; Scott et al., 2013b). Probabilistic models have been used to evaluate existing burn probabilities (e.g. Calkin et al., 2010), as well as the impact of fuel treatments or management decisions on burn probability (Ager et al., 2010), and to predict changes in burn probability resulting from climate change (Flannigan et al., 2009; Riley and Loehman, 2016b). Burn probability can also be combined with a measure of fire behavior, like fire intensity, to characterize wildfire hazard, allowing managers to infer fire behavior, and the risk to resources and assets of value (Parisien et al., 2019; Scott et al., 2013b)

It is difficult to contextualize risk posed by highly stochastic, but disproportionately impactful events (Donato et al., 2020; Halofsky et al., 2020; Taleb, 2010). Characterizing wildfire hazard in westside forests is challenged by the nature of contemporary fire regimes. Other studies have probabilistically assessed wildfire hazard and risk in westside forests, but only as part of larger regional studies that also included fire-prone areas east of the Cascades (Gilbertson-Day et al., 2018). When east- and westside regions are compared in the same assessment, wildfire exposure appears to be low in westside forests because of low burn probabilities in any given year. The apparent 
lack of risk confounds managers who know that while the chance of fire occurring in any given year is low, the consequences should one occur can be profound.

The primary objective of this study was to evaluate the impact of mid- $21^{\text {st }}$ century climate change on wildfire hazard in the Clackamas River watershed east of Portland, Oregon. We applied an integrated wildfire hazard metric described in Scott et al. (2012) and fire modeling methods based on Riley and Loehman (2016) to establish contemporary wildfire hazard and compare it to wildfire hazard under a range of potential climate conditions for 2040-2069. The secondary objective was to address challenges of characterizing wildfire hazard in westside forests. Our work adapts probabilistic hazard assessments in two notable ways. First, in addition to evaluating hazard based on annualized exposure metrics, we assess the impact of wildfire over a thirty year period in mid-century similar to Riley et al. (2018). In low-frequency fire regimes, the average annual area burned is not a particularly instructive metric. Top-down climate controls are such that wildfire occurrence is generally synchronized during particularly dry years (Weisberg and Swanson, 2003). To better capture the impact of climate change on wildfire occurrence we assessed occurrence and impact during thirty-year window. Second, similar to average annual area burned, assessing average fire size has limited application. Changes in average fire size do capture the impact of climate change on fire characteristics, but in this study we also assess changes in very large wildfires to describe the impact of climate change on large, highly impactful wildfire events. 


\section{METHODS}

\section{Study Area}

Our study area is the Clackamas River watershed ("Clackamas"), in Clackamas County, Oregon just east of Portland. Portland is the largest metro area in Oregon with 2.5-3 million residents, only slightly smaller than the Seattle metro area. The Clackamas, 244,002 ha, provides drinking water to over 300,000 residents and is the second largest surface drinking water source for the Portland region. As is true throughout westside forests, surface drinking water is one of the most highly valued resources (GilbertsonDay et al., 2018) and health of forests is vital to maintaining drinking water quality and quantity (Figure 1). Drinking water is not the only valued resource in the Clackamas. The Mt. Hood National forest makes up about two-thirds of the watershed and manages forests for timber value as do private industrial timber companies that own and manage forests in the middle watershed (Table 1). The Mt Hood National Forest, and the Clackamas River in particular, is also a popular motorized and non-motorized recreation region. The Clackamas is also within the area covered under the Northwest Forest Plan and is the site of numerous long-term conservation efforts including portions of three wilderness areas as well as spotted owl and salmon recovery plans, and efforts to maintain and increase old growth forests (Spies et al., 2018). Land ownership and management in the Clackamas is heavily segmented (Figure 1), and human communities, the primary beneficiaries of the watershed many ecosystem services, are concentrated in the lower watershed in the Portland metro area and surrounding low-density rural development. Clackamas County's population is expected to grow by nearly 270,000 
individuals in the next fifty years, placing increasing demand on land and water resources (Jurjevich et al., 2017).
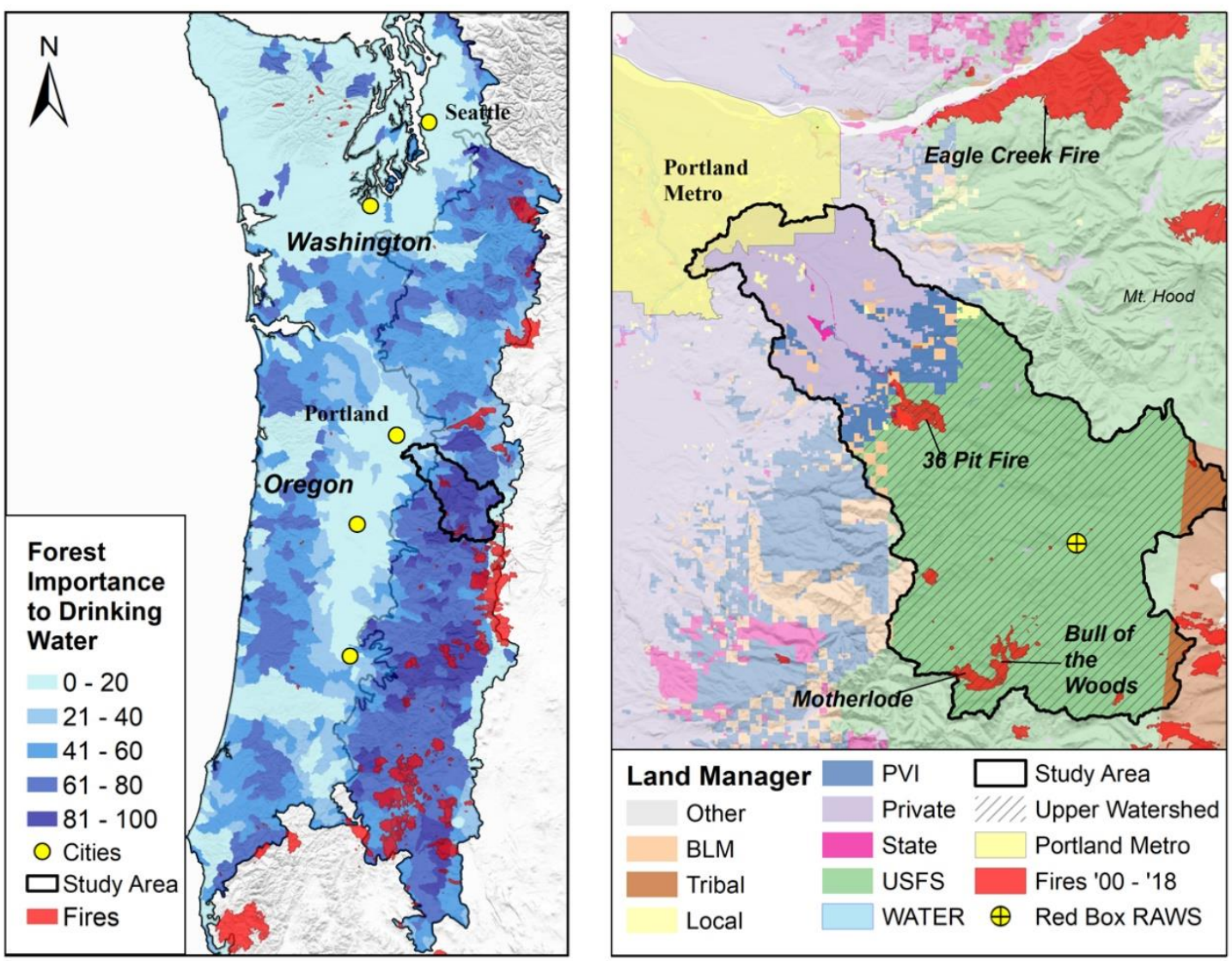

Figure 1. U.S. Forest Service "Forest to Faucets" (USDA Forest Service, 2011) compares the importance of forests to surface drinking water on a relative scale of 0-100. Forests are especially important to drinking water in westside landscapes (left) which have experienced few to no significant wildfires in the past 20 years (National Interagency Fire Center, 2019). The largest wildfire in recent history in the Clackamas River watershed (right) was the 36 Pit fire in 2014 which burned just over 2,200 ha on the Mt. Hood National Forest, but adjacent to private land (Oregon Department of Forestry, 2015).

The Clackamas is in a moist forest region wherein potential vegetation is largely characterized by western hemlock (Simpson, 2013). Potential vegetation types indicate that Clackamas forest types are adapted to infrequent (> 200 year fire return intervals) but 
stand replacing fires, as well as to moderately frequent fires (50-150 year return intervals) of mixed severity (Spies et al., 2018). However, existing species assemblages and forest structure today are most likely the result of human land management, predominantly the legacy of intensive forest management during the $20^{\text {th }}$ century which favored even-aged, single species, relatively young stands (Haugo et al., 2015). The vast majority of the watershed is coniferous forests (Table 1) including Douglas-fir (Pseudotsuga menziesii), western hemlock (Tsuga heterophylla) and Pacific silver fir (Abies amibilis) as well as other conifers in smaller extents. Infrequent wildfires are largely the result of regional climate patterns. The watershed receives over $150-200 \mathrm{~cm}$ of precipitation on average annually, the vast majority of which falls between October and April each year (Gedalof et al., 2005; Graves and Chang, 2007). Summers are generally dry, and, as a result of groundwater storage, seasonal variations in drought are highly dependent on snowpack levels and snowmelt timing (Tague and Grant, 2009). Although annual temperatures are moderate, late summer temperatures regularly exceed $32^{\circ} \mathrm{C}$ during same period of time when water resources are most scarce.

Table 1. Major land manager groups in the Clackamas and associated land cover. Rows may not sum to $100 \%$ because of miniscule amounts of other landcover including non-burnable (i.e. rock, ice and certain types of row crops), water, grasslands and exotic plants.

\begin{tabular}{rrcccccc}
\hline Manager & $\begin{array}{c}\text { Total } \\
\text { Area } \\
\text { (ha) }\end{array}$ & $\begin{array}{c}\text { Percent of } \\
\text { Study Area }\end{array}$ & $\begin{array}{c}\text { Non- } \\
\text { vegetated }\end{array}$ & Developed & Agricultural & Hardwood & Conifer \\
\hline \hline USFS & 167,663 & $69 \%$ & $1 \%$ & $0 \%$ & $0 \%$ & $0 \%$ & $98 \%$ \\
Private & 47,358 & $19 \%$ & $1 \%$ & $14 \%$ & $36 \%$ & $12 \%$ & $34 \%$ \\
PVI & 14,130 & $6 \%$ & $1 \%$ & $1 \%$ & $1 \%$ & $7 \%$ & $85 \%$ \\
Federal & 6,878 & $3 \%$ & $0 \%$ & $0 \%$ & $5 \%$ & $0 \%$ & $88 \%$ \\
BLM & 5,697 & $2 \%$ & $0 \%$ & $0 \%$ & $0 \%$ & $7 \%$ & $90 \%$ \\
Local & 1,490 & $1 \%$ & $2 \%$ & $8 \%$ & $20 \%$ & $5 \%$ & $59 \%$ \\
State & 691 & $0 \%$ & $6 \%$ & $12 \%$ & $12 \%$ & $16 \%$ & $51 \%$ \\
\end{tabular}


Few large wildfires have been recorded in the Clackamas in recent history, a fact which reflects both the local fire regime as well as a century of aggressive suppression efforts. Fire regimes in the Clackamas are dominated by long return intervals and mixed severity. Fifty-five percent of the watershed, predominately at mid-elevations, has return intervals longer than 200 years. In the upper watershed, where lightning strikes are more common, the return intervals are between 35 and 200 years. The upper watershed is bounded on the east by the Cascade crest, east of which the landscape is drier and more fire prone. Despite thousands of recorded ignitions in the Clackamas, nearly $75 \%$ of which are caused by human-activities (Short, 2017) there have been only a handful of large fire events in recent history. The 36 Pit fire occurred in the middle of the watershed in 2014 and was just over 2,000 hectares. The B \& B complex in 2003 near the southeast of the watershed was over 30,000 hectares, some of which burned into the Clackamas. In 2017, the Eagle Creek fire burned north of the Clackamas in the Columbia River Gorge National Scenic Area and encroached on Bull Run, Portland's primary surface drinking water source.

\section{Wildfire Modeling}

We used the large fire simulator, FSim (Finney et al., 2011), to model the effect of climate change on wildfire characteristics and hazard in the Clackamas during 2040 2069 (mid-century) and to compare it to simulated contemporary (baseline) wildfire characteristics and hazard. FSim models the interaction of fuel, topography, weather and spatial ignition patterns on a daily time-step to simulate fire occurrence, growth and 
suppression in a statistically plausible fire season. Simulations are generated in four modules - weather generation, fire occurrence, fire growth, and fire extinction - which have been described in detail in previous publications (Finney et al., 2011; and Riley and Loehman, 2016). The four modules in FSim operate on three primary inputs: daily weather, spatial historic fire occurrence patterns, and landscape characteristics. Although the study area is the Clackamas, we simulated fire behavior across a significantly larger fire occurrence area (FOA), in order to account for large fires that ignite outside, but grow into the Clackamas. Specifically, we simulated two FOAs, one centered on Clackamas but restricted to west of the Cascade crest and another adjacent to the Clackamas but on the east side of the Cascade crest. The fire regime and fire-climatefuel relationships are vastly different east of the Cascades and required separate simulations. The majority of recent wildfires that have affected westside landscapes have occurred right along the Cascade crest and have spread west as a result of easterly winds coming off the Columbia River. Notably, the B \& B complex in 2003 straddled the Cascade crest just south of the Clackamas and burned approximately 37,000 hectares. In 2017, the Eagle Creek fire ignited in the Columbia River Gorge and spread west, burning just over 20,000 hectares. The simulation process was identical for both FOAs although the simulations were run in parallel, not simultaneously. Analysis was restricted to the Clackamas.

Climate and Weather - We used daily weather records (1992-2015) from the Remote Automated Weather Station (RAWS), one in each FOA. The RAWS data was processed in Fire Family Plus software (Bradshaw and McCormick, 2009) to compute a distribution 
of daily Energy Release Component (ERC) values based on Fuel Model G (Finney et al., 2011). ERC quantifies the amount of energy released at the flaming front of an active fire and is a proxy for fuel moisture (Cohen and Deeming, 1985). FSim uses ERC to determine on what days a fire may ignite, how many fires may ignite, and when fires do ignite FSim uses ERC values in conjunction with wind speed/direction and landscape features to simulate how a fire grows and is extinguished.

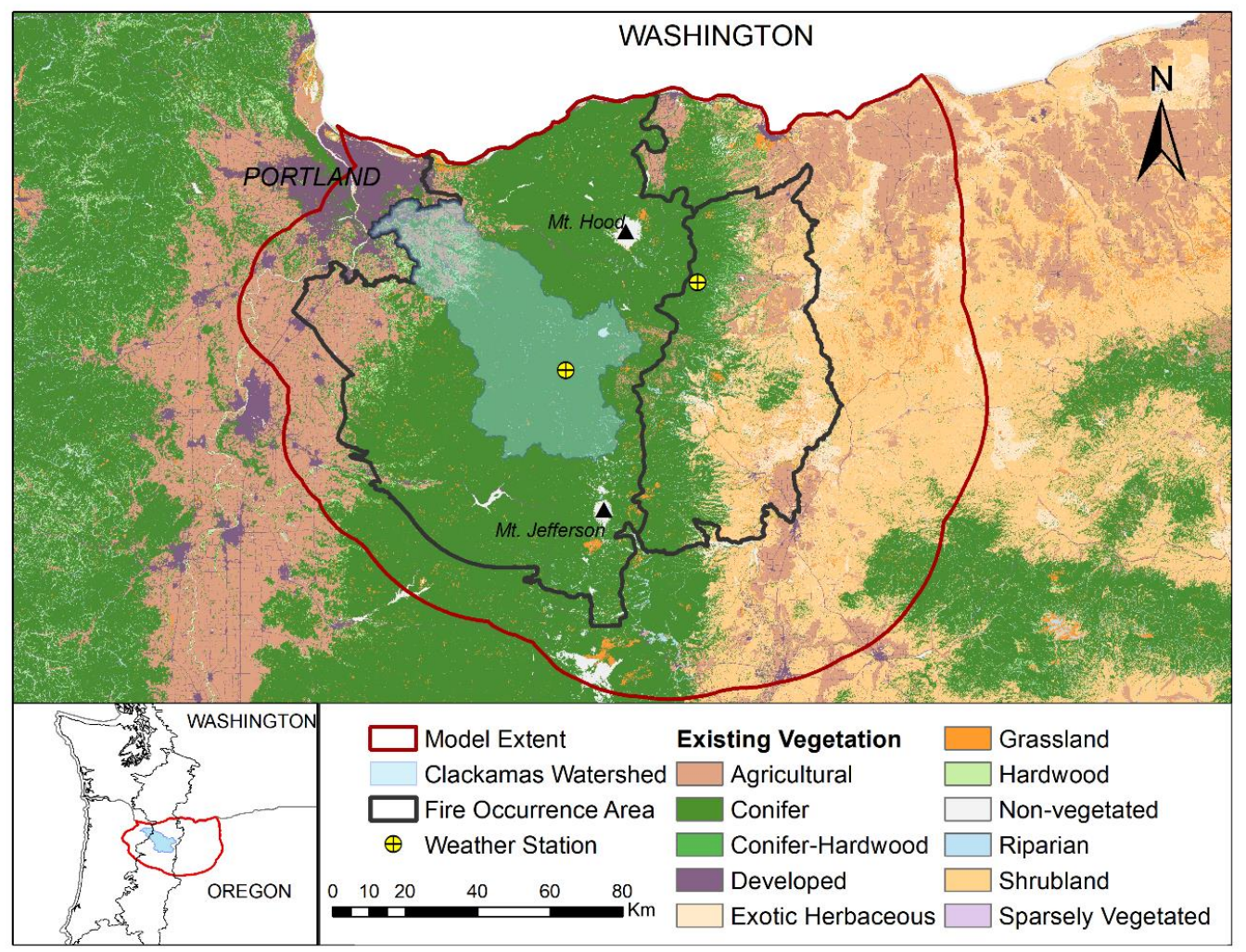

Figure 2. Extent of FSim modeling. The model extent was divided into two fire occurrence areas (FOAs) in order to distinguish between very different fire environments on either side of the Cascade crest. Each FOA was associated with a unique weather station from which empirical observations were used in the baseline scenarios, and modified to reflect projected future climate conditions. The FOA defines the area within which FSim simulated ignitions and is significantly 
larger than the analysis area, the Clackamas River watershed, in order to allow for fires that ignite outside the analysis area but eventually burn into it.

Future fire behavior was simulated by adapting baseline ERC distributions according to modeled changes in temperature and relative humidity from four Global Climate Models (GCMs) from Coupled Model Intercomparison Project phase 5 (CMIP 5). Each model was downscaled from native to $4 \mathrm{~km}$ resolution using the Multivariate Adaptive Constructed Analogs (MACA) method (Abatzoglou and Brown, 2012). Only RCP 8.5 scenarios were considered. We selected models based on changes in temperature and relative humidity compared between historical (1970-1999) and mid-century CMIP5 data. Among the nineteen models in CMIP5, CNRM-CM5 (CNRM), HadGEM-ES365 (HadGEM), MIROC5, and MIROC-ESM-CHEM (MIROCCHEM) represent the outer 
boundaries of possible changes in mid-century temperature and relative humidity.
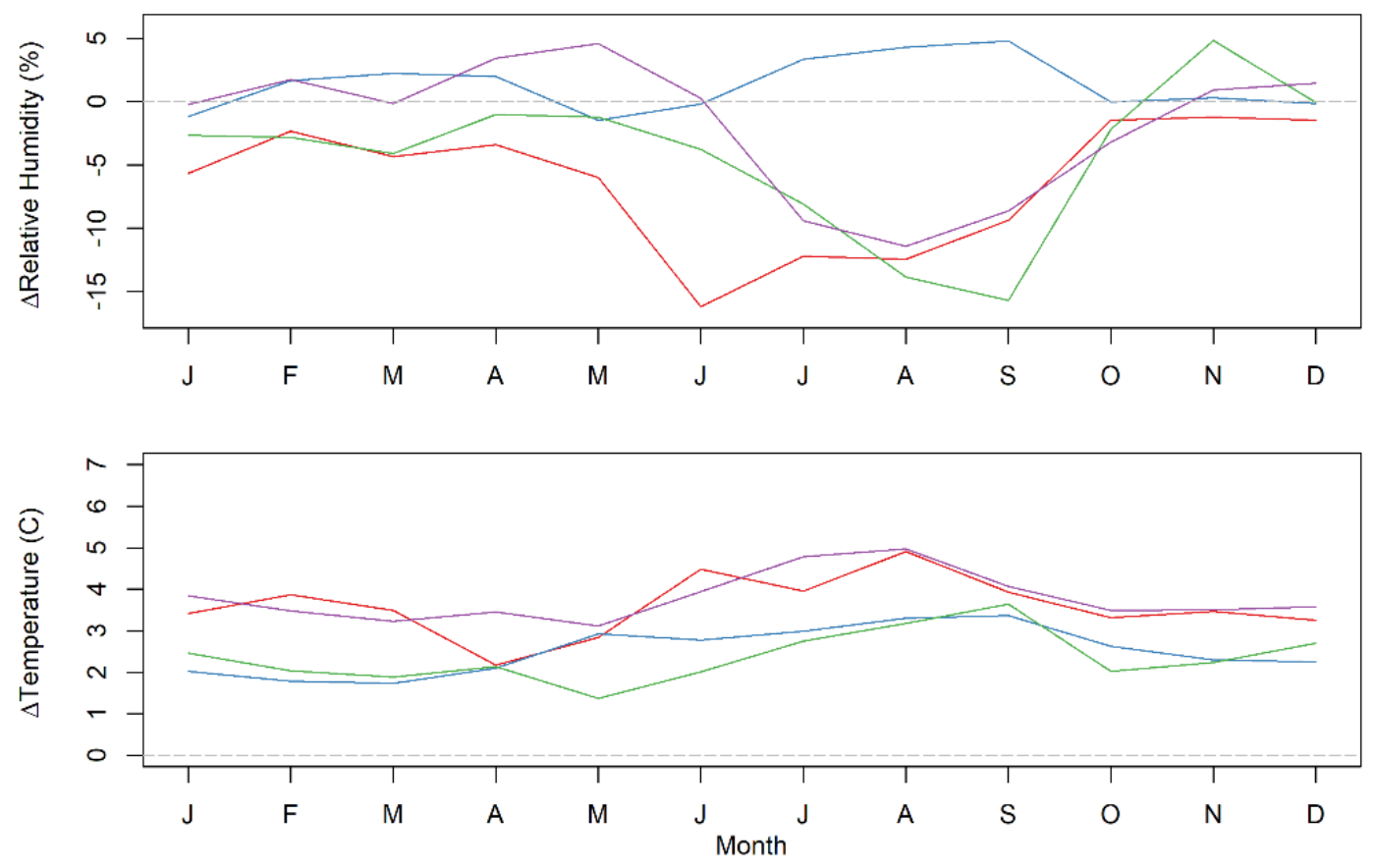

- HadGEM - CNRM MIROCCHEM " MIROC5

Figure 3. Average monthly temperature and relative humidity departure from historical (1970 1999) predicted by the four GCMs selected to model future fire weather conditions. These four GCMs represent a full range of predicted climate futures and were downscaled over the study area. Additional figures and explanation of model selection in Appendix A.

Historic Ignitions - Using Fire Family Plus (Bradshaw and McCormick, 2009), we generated a logistic relationship between daily ERC values and large fire ignitions (Andrews et al., 2003; Finney et al., 2011) from the Fire Program Analysis, Fire Occurrence Database (FPA_FOD, Short, 2017). As FSim moves on a daily time-step through each simulation, it samples from ERC distribution described above and then uses the logistic relationship between ERC and historic ignitions to determine on what days a 
fire may ignite. The relationship between ERC and ignition probability is generally positive, and above $80^{\text {th }}$ percentile ERC values large fires become significantly more common (Riley et al., 2013). Historic ignitions in the Clackamas were also the source of an ignition density raster which quantifies the conditional, relative likelihood of an ignition occurring anywhere in the study area. On those days exceeding $80^{\text {th }}$ percentile ERC, FSim refers to the logistic equation and ignition density raster to determine if, and where a fire will ignite.

Landscape and Fuels - We used a raster stack of eight files which described fuels and topography and which FSim reads in order to simulate fire growth and extinction. All of the rasters were downloaded from LANDFIRE (LANDFIRE, 2014), and resampled from $30 \mathrm{~m}$ to $90 \mathrm{~m}$ resolution. The same landscape files were used in baseline and midcentury scenarios.

Model Calibration -The spatially explicit large fire record for the Clackamas is so sparse given the long fire return intervals that it is not possible to calculate an accurate historic burn probability to which the model could be calibrated. Instead, the baseline FSim model was calibrated so that simulation results closely matched recent historical mean fire size and mean annual area burned derived from observed fires in the FPA_FOD dataset for 1992-2015. We manipulated the rate of spread algorithm and the relationship between ERC and the number of large fires in FSim to achieve calibration targets. The fire record includes the influence of suppression efforts with respect to large fire frequency and large fire size distributions. We used the suppression algorithm built into 
FSim to account for contemporary levels of suppression in both the baseline and midcentury simulations.

\section{Data Analysis}

FSim produces spatial fire perimeters for each of the simulated fires, as well burn probability and mean fireline intensity rasters for each scenario. For each scenario, we merged fire perimeters from the two FOAs, and removed the overburn for each simulation error. Overburn occurred when fires from the same simulation year burned the same pixel(s); the fire perimeter which ignited earlier in the year was maintained and overburnt pixels were removed from the subsequent fire. All analysis was performed based on over-burn corrected fire perimeters including new burn probability rasters generated from the over-burn corrected fire perimeters. Under baseline conditions and in the least warm mid-century scenarios overburn was less than 5\%, but it the hot and dry mid-century scenarios it was as high as $12 \%$. Mean fireline intensity is not affected by overburn so there was no need to calculate new rasters. All spatial and quantitative analysis was performed in R statistical software 3.5 (R Core Team, 2018).

Fire season timing and length was measured using both daily ERC values as well as large occurrence. Our treatment of ERC and fire season is similar to that in Riley and Loehman (2016), which used the relationship between ERC and National Fire Danger Rating System classifications to measure fire season. $80^{\text {th }}$ percentile ERC values were used as the bottom threshold for "moderate fire danger" and an indication of active fire season. The $80^{\text {th }}$ percentile was derived from baseline climate data and was applied to all mid-century scenarios because the fuel moisture thresholds to fire occurrence are not expected to change. We also compared the number of daily average ERC values 
exceeding the $90^{\text {th }}$ ("high fire danger") and $97^{\text {th }}$ percentile ("extreme fire danger"). Daily ERC distributions were created in Fire Family Plus (Bradshaw and McCormick, 2009) as described previously. In addition, we assessed changes in fire season by identifying the average period of time in each scenario during which large fires (> 100 ha) account for $90 \%$ of the annual area burned.

Using the overburn-corrected perimeters we calculated average annual number of large fires, average large fire size, and average annual area burned to evaluate the impact of changes in temperature and relative humidity associated with potential future climate change impacts. Fire size and annual area burned distributions from all five scenarios were compared to one another using a Kruskal-Wallace test followed by Dunn's Multiple Comparison test with an alpha of 0.5 .

In addition to annual metrics, we included two unique fire characteristic analyses. First, we sub-sampled 300 thirty-year samples of fire perimeters for each climate scenario in order to evaluate the variation in annual area burned during the thirty-year climate period. FSim uses a Monte Carlo simulation approach in which each iteration is assigned a year and represents a statistically plausible annual fire season and, because the weather module is dynamic and ignitions are stochastic, each iteration is unique. Riley et al. (2018) presented a method for subsampling the 10,000 iterations to create statistically plausible multidecadal scenarios. Similar to Riley et al. (2018), each iteration was assigned a "fire year" and within each thirty-year sample, we assumed that the same pixel would not burn more than once every five years and removed overlapping portions of fire perimeters when they were within five years of each other. A multidecadal analysis is 
particularly useful in low frequency fire regimes in contrast to metrics like annual averages which may reveal trends over time, but have little managerial application.

Second, studies in other parts of the world have demonstrated the value in assessing trends over time in the frequency and magnitude of extremely large fires (Cumming, 2001; Moritz, 1997). In addition to evaluating climate change impacts on average fire size, we used a generalized Pareto distribution model to evaluate trends in the size and return intervals of extremely large $\left(99^{\text {th }}\right.$ percentile) fires. Generalized Pareto models have been used to evaluate probabilities in the tails of highly skewed distributions in which, like wildfire, extremely rare events are highly impactful (Jiang and Zhuang, 2011). Extreme event analysis was performed in R using the 'extRemes' package (Gilleland, 2020).

Scott et al. (2012) introduced metric that quantifies wildfire exposure hazard as the product of burn probability and mean fireline intensity at each pixel in the study area. This method has the advantage of being quantitative and easily comparable across space and time. We calculated integrated hazard for all burnable pixels for each climate scenario and determined the change in hazard that results from climate change. All spatial analyses are presented using a quantile method.

\section{RESULTS}

\section{Fire Season}

Three of the four modeled scenarios predict that the fire season as measured by ERC will expand by mid-century (Figure 4). Only MIROC5, the least warm and wettest of the GCMs, did not predict a change in fire season length. Under baseline conditions, there are on average 70 moderate fire danger days, days during which ERC exceeds the 
$80^{\text {th }}$ percentile ERC value. MIROCCHEM projected 94 days, CNRM projected 97, and HadGEM projected 99 days on average each year during which ERC values will be above the $80^{\text {th }}$ percentile. Under HadGEM climate conditions ERC values exceeded the $80^{\text {th }}$ percentile earlier in the season but peaked in August and September similar to baseline conditions. In contrast MIROCCHEM and CNRM models illustrated the potential for a similar start to fire season compared to today, but the peak might not come until late September or October.

Annual average daily ERC values in Figure 4 illustrate a clear start and finish to the fire season, but in any given ERC values are far more dynamic, rising and falling above/below the $80^{\text {th }}$ percentile at different times of the season. As a consequence, large fires can occur over a longer period of time then is illustrated in Figure 4. When fire season is defined as the period during which large fires account for $90 \%$ of annual area burned, the season is longer than when measured by ERC (Figure 5). Under baseline conditions the large fire season accounted for $42 \%$ of the year (154 days), under MIROC5 it was 156 days, under HadGEM it was 165 days, under CNRM it was 174 days, and under MIROCCHEM the large fire season was $48 \%$ of the year (175 days). In addition to predicting longer fire seasons, HADGEM, CNRM, and MIROCCHEM also predict more intense fire weather throughout the season. Under baseline conditions ERC values exceeded $97^{\text {th }}$ percentile extreme fire danger conditions on just eleven days in an average year and under MIROC5 that decreased to only five days on average. However, the number of extreme fire danger days increased under MIROCCHEM (to 47 days), CNRM (to 52 days) and HadGEM (to 73 days). Under HadGEM conditions, more days 
are projected to be extreme fire danger days than there were moderate fire danger days under baseline climate.
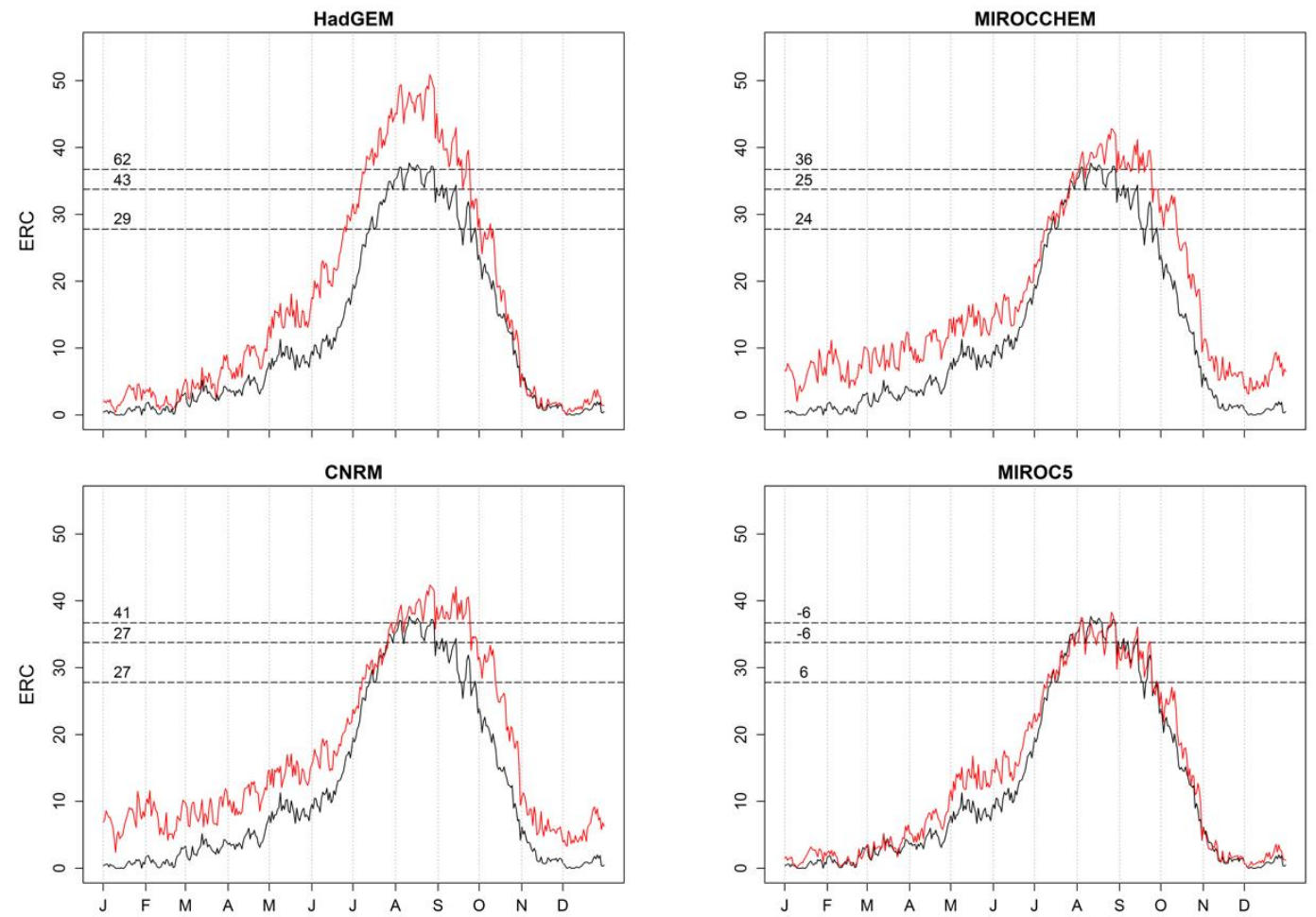

Figure 4. Mean daily ERC values for each future $(2040$ - 2069) climate scenario, shown in red, compared to baseline ERC values, shown in black. Dashed gray lines reflect the 80th, 90th, 97th, ERC percentiles based on baseline climate $1992-2015$. Numbers above the dashed lines indicate the number of days additional to baseline during which fire weather exceeds each fire danger rating. 

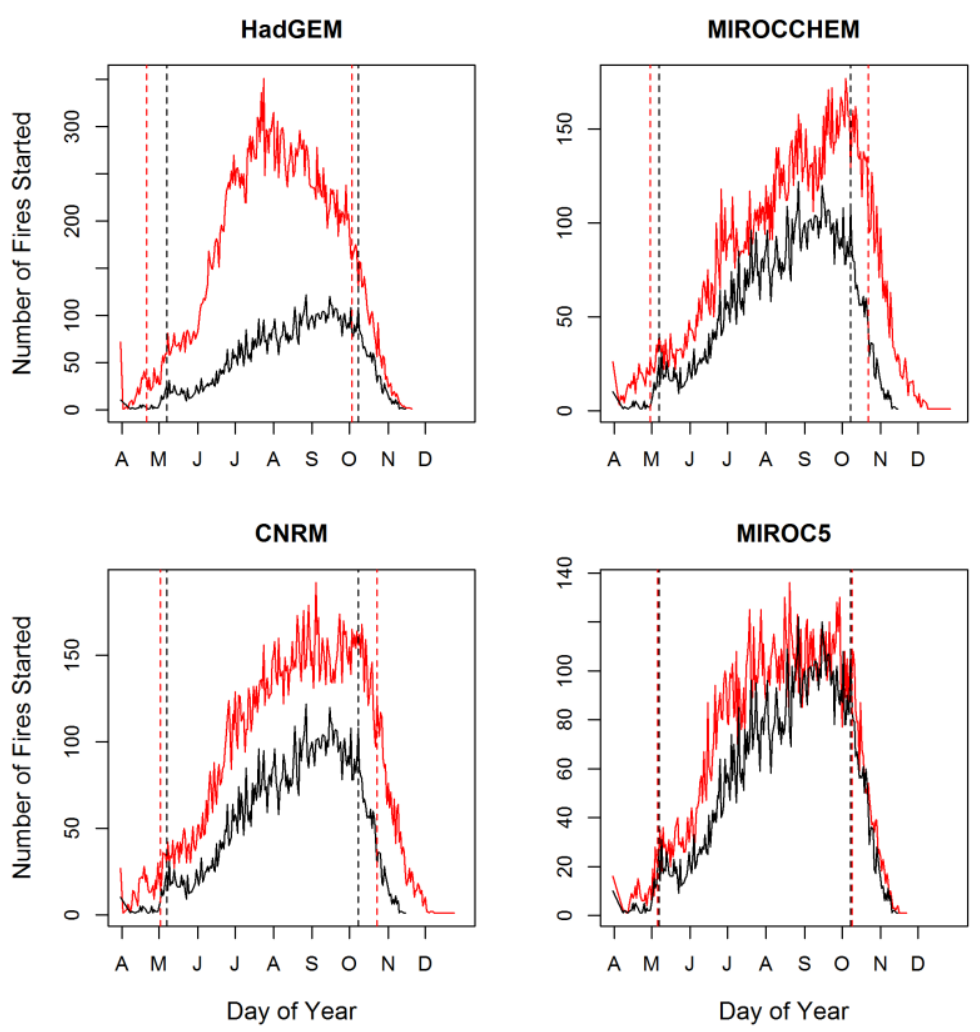

Figure 5. Number of simulated fires as a function of day of year for mid-century scenarios (red) and baseline (black). Vertical dotted lines indicate the start and end of the large fire season, the period during which fires greater than 100 ha account for more than $90 \%$ of the annual area burned on average.

\section{Fire Characteristics}

In response to longer fire seasons and longer continuous stretches of fire-

conducive weather within each season, the average annual number and size of simulated large fires increased under each of the climate scenarios compared to baseline (Table 2). Increased large fire occurrence in mid-century simulations mirrors seasonal ERC patterns (Figure 4). Under all mid-century climate conditions there were more opportunities for ignitions to occur, and higher potential for ignitions to turn into large fires. The size and probability of extremely large wildfire events also increased under mid-century 
conditions. The largest fire simulated under baseline conditions was 37,509 ha. The largest fire size increased significantly under MIROC5 to 42,899 ha (p-value $<0.0001$ ), under MIROCCHEM to 45,051 ha (p-value $<0.0001$ ), under HadGEM to 68,152 ha (pvalue $<0.0001$ ), and under CNRM to 71,646 ha (p-value $<0.0001)$.

Table 2. Simulated mean fire size of all fires and the mean annual number of large fires, fires greater than 100 ha. Range and standard error are shown below mean values. Conditional area burned is the size of the study area effected in those years that fires were simulated - not all years experienced fire. 30-year area burned is the estimated cumulative extent of wildfire between 2040 - 2069. Mid-century fire size and frequency distributions were compared to baseline distributions using Dunn's tests and in call instances, mid-century distributions were significantly different from baseline (all p-values $<0.0001$ ).

\begin{tabular}{|c|c|c|c|c|}
\hline Scenario & $\begin{array}{c}\text { Mean Fire Size } \\
\text { (ha) }\end{array}$ & $\begin{array}{c}\text { Mean } \\
\text { Annual \# } \\
\text { Large Fires }\end{array}$ & $\begin{array}{l}\text { Annual Area } \\
\text { Burned (ha) }\end{array}$ & $\begin{array}{l}\text { 30yr Area } \\
\text { Burned (ha) }\end{array}$ \\
\hline Baseline & 587 & 0.36 & 1,177 & 18,745 \\
\hline range & $<1-37,509$ & $0-9$ & $<1-56,656$ & $194-95,110$ \\
\hline SE & \pm 19.01 & \pm 0.009 & \pm 35.7 & 854 \\
\hline MIROC5 & 794 & 0.54 & 1,837 & 32,194 \\
\hline range & $<1-42,899$ & $0-7$ & $<1-61,730$ & $3,439-133,842$ \\
\hline SE & \pm 21.16 & \pm 0.010 & \pm 50.2 & 1,125 \\
\hline MIROCCHEM & 864 & 0.73 & 2,295 & 43,278 \\
\hline range & $<1-45,051$ & $0-11$ & $<1-86,162$ & $6,201-184,097$ \\
\hline SE & \pm 20.21 & \pm 0.012 & \pm 62.5 & 1,451 \\
\hline CNRM & 999 & 0.89 & 2,828 & 55,514 \\
\hline range & $<1-71,646$ & $0-11$ & $<1-90,732$ & $4,674-142,224$ \\
\hline SE & \pm 20.85 & \pm 0.012 & \pm 67.2 & 1,498 \\
\hline HadGEM & 1,759 & 1.88 & 7,542 & 137,616 \\
\hline range & $<1-68,152$ & $0-12$ & $<1-102,730$ & $31,745-262,257$ \\
\hline SE & \pm 23.57 & \pm 0.015 & \pm 125 & 2,275 \\
\hline
\end{tabular}


Extremely large wildfires are fires exceeding $99^{\text {th }}$ percentile fire size in each scenario. Compared to baseline conditions, the number and size of extremely large fires increased under all mid-century climate scenarios (Table 3). Under baseline conditions the average extremely large fire was $15,789 \mathrm{ha}(\mathrm{sd}=5,808)$. Under MIROC5 the average extremely large fire increased to 19,917 ha (sd = 6,193; Mann-Whitney p-value $<$ 0.0001). Under MIROCCHEM the average extremely large fire increased to 22,104 ha (sd =6,628; Mann-Whitney p-value $<0.0001)$. Under CNRM the average extremely large fire increased to 23,254 ha ( $\mathrm{sd}=7,392$; Mann-Whitney $\mathrm{p}$-value $<0.0001)$. Finally, under HadGEM the average extremely large fire increased to 30,746 ha $(\mathrm{sd}=7,334$; Mann-Whitney p-value $<0.0001)$. A generalized Pareto model illustrated that $99^{\text {th }}$ percentile fire sizes increased by more than a factor of two (Table 3). Likewise, fires with a 0.01 probability of occurrence are increasingly larger (Table 3 ).

Table 3. Results from a generalized Pareto distribution (GPD) model of 99th percentile fire sizes under each climate scenario. The threshold of fire sizes for consideration was set at the 99th percentile of each scenario's fire size distribution. 100- and 1000-Year return intervals (RI) refer to the fire size (ha) with a 0.01 and 0.001 probability of occurrence. Shape parameters close to 0 indicate that fire size distributions are light-tailed exponential and negative values indicate that fire sizes are finite.

\begin{tabular}{rrrrrr}
\hline $\begin{array}{c}\text { Peak Over Threshold } \\
\text { Results }\end{array}$ & Baseline & MIROC5 & MIROCCHEM & CNRM & HadGEM \\
\hline \hline Threshold (ha), $\mu$ & 9,861 & 13,199 & 14,597 & 16,011 & 22,651 \\
Number of fires & 114 & 148 & 195 & 219 & 350 \\
Shape, $\xi$ & 0.00 & -0.09 & -0.01 & 0.03 & -0.01 \\
100 Year RI (ha) & 10,537 & 15,974 & 19,789 & 21,526 & 33,452 \\
1000 Year RI (ha) & 25,853 & 30,493 & 34,469 & 38,460 & 49,645 \\
\hline
\end{tabular}

Annualized metrics are useful for illustrating the effect of climate change on fire characteristics, but results demonstrate that fire occurrence will continue to vary intra- 
and inter-annually. In all future scenarios there were iterations during the 10,000

simulations during which no fires were simulated because ERC never exceeded $80^{\text {th }}$ percentile values, or because simulated ignitions occurred but were located in unburnable pixels (i.e. water or urbanized areas). We can interpret iterations without fire as "fire free years". Under baseline conditions, $43 \%$ of iterations included no fires. However, climate change is projected to decrease the number of fire free years in mid-century. Under MIROC5 36\% of iterations were fire free, 27\% under MIROCCHEM, 23\% under CNRM and only $18 \%$ under HadGEM.

\section{Area Burned}

Excluding fire free years, under baseline conditions approximately 1,200 ha burned annually on average (Table 2). The annual average area burned increased modestly under MIROC5 (to 1,837 ha) and even more under MIROCCHEM (to 2,295 ha) and CNRM (to 2,828 ha). However, under HadGEM climate conditions the average annual area burned increased $540 \%$ to 7,542 ha or approximately $3 \%$ of the watershed. When we sub-sampled the 10,000 iterations in each scenario and created thirty-year samples we learned that increasingly more of the watershed will be exposed to wildfire during the mid-century. Under baseline conditions approximately $8 \%$ of the watershed is projected to experience wildfire in a thirty-year period. From 2040-2069, the MIROC5 scenario projected $13 \%$ of the watershed would be affected, $18 \%$ under MIROCCHEM, and $23 \%$ under CNRM. Under HadGEM, $56 \%$ of watershed could be affected on by fire over the course of thirty years. 

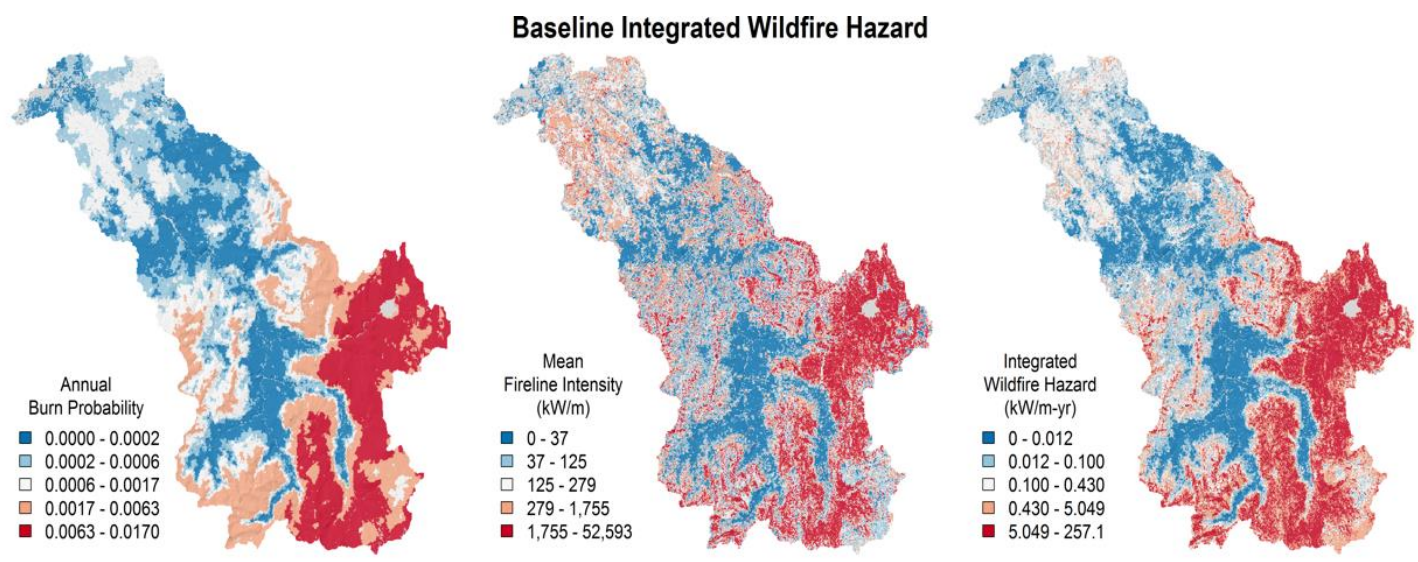

Figure 6. Integrated wildfire hazard (IWH) is the product of annual burn probability (BP) and mean fireline intensity (MFI). All three metrics are mapped under baseline climate conditions using a quantile method.

\section{Wildfire Hazard}

Wildfire hazard under baseline conditions is concentrated at higher elevations in the upper watershed where both burn probability and mean fireline intensity are highest (Figure 6). High burn probabilities in the upper watershed reflect ignition patterns, fire size, and terrain. Ignitions are more likely in the upper watershed where summer lightning storms are more common compared to lower elevations, and where many other sources of ignitions - like recreation - are concentrated. Likewise, the upper watershed is dominated by wilderness areas and management priorities other than timber production. Comparatively continuous, dense fuels and steep terrain facilitate large fires when ignitions occur under the right weather conditions. High fuel loads in the upper watershed produce more intense fires with higher potential for crowning and torching.

Increases in wildfire hazard under all mid-century climate scenarios were driven by increased burn probability (Figure 7). Increased fire size and more frequent wildfires resulted in $226 \%, 357 \%, 476 \%$ average watershed-wide increases in burn probability in 
MIROC5, MIROCCHEM, and CNRM, respectively (Figure 8). However, under the hot and dry conditions of HadGEM burn probability increased on average by $1,663 \%$.

Despite large changes in burn probability the actual annual likelihood of wildfire remains less than $1 \%$ across the entire watershed in all mid-century scenarios except for HadGEM where the watershed-wide average probability of wildfire in any given year exceeds $2 \%$

(Table 4, Figure 8). The distribution of mid-century burn probabilities across the watershed is similar to the spatial pattern in baseline conditions but under hotter and drier conditions, the lower and upper watershed became increasingly fire prone (Figure 8).

Table 4. Watershed-wide average integrated wildfire hazard and hazard components under each climate scenario. Range and standard error are shown below each average value

\begin{tabular}{|c|c|c|c|}
\hline Scenario & $\begin{array}{l}\text { Burn Probability } \\
\text { (fraction) }\end{array}$ & $\begin{array}{c}\text { Mean Intensity } \\
(\mathrm{kW} / \mathrm{m})\end{array}$ & $\begin{array}{c}\text { Integrated Hazard } \\
\text { (kW/m-year) }\end{array}$ \\
\hline Baseline & 0.003 & 1140 & 8.01 \\
\hline range & $0.0001-0.017$ & $0.749-52,593$ & $7.49 \times 10^{-5}-257$ \\
\hline SE & $\pm 6.88 \times 10^{-6}$ & \pm 4.38 & \pm 0.041 \\
\hline MIROC5 & 0.005 & 1109 & 13.43 \\
\hline range & $0.0001-0.028$ & $0.415-41,066$ & $4.15 \times 10^{-5}-472$ \\
\hline SE & $\pm 1.17 \times 10^{-5}$ & \pm 4.08 & \pm 0.068 \\
\hline MIROCCHEM & 0.007 & 1116 & 20.87 \\
\hline range & $0.0001-0.038$ & $0.818-97,725$ & $9.95 \times 10^{-5}-583$ \\
\hline SE & $\pm 1.71 \times 10^{-5}$ & \pm 3.99 & \pm 0.095 \\
\hline CNRM & 0.009 & 1125 & 24.29 \\
\hline range & $0.0001-0.057$ & $0.551-31,419$ & $5.51 \times 10^{-5}-968$ \\
\hline SE & $\pm 2.22 \times 10^{-5}$ & \pm 4.08 & \pm 0.126 \\
\hline HadGEM & 0.025 & 1158 & 71.57 \\
\hline range & $0.0001-0.140$ & $0.830-93,566$ & $1.57 \times 10^{-4}-2,895$ \\
\hline SE & $\pm 6.06 \times 10^{-5}$ & \pm 4.34 & \pm 0.358 \\
\hline
\end{tabular}



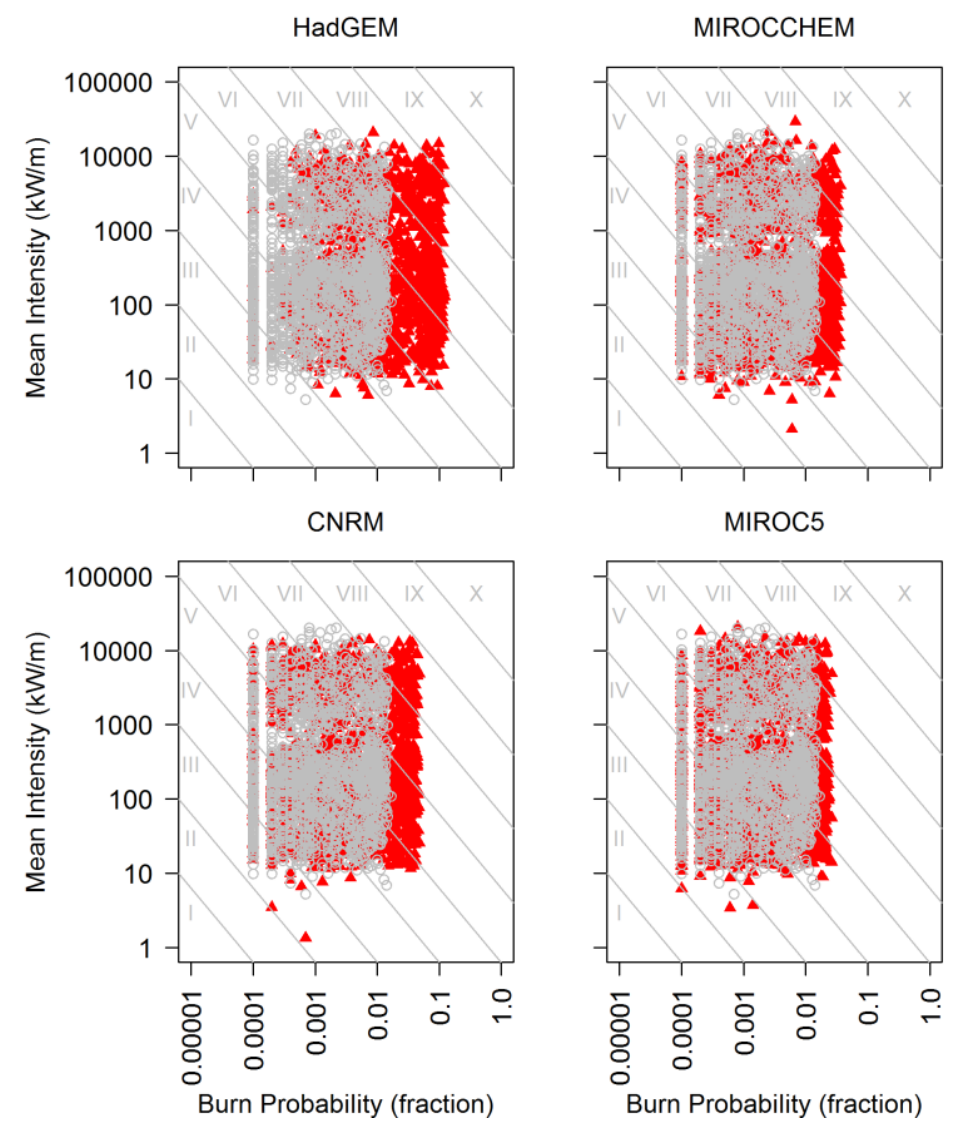

Figure 7. Burn probability and mean fireline intensity at each pixel in the study area under baseline (gray) and future scenarios (red). Diagonal lines demarcate integrated wildfire hazard classes

Mean fireline intensity did not change as a result of changes in temperature and relatively humidity (Table $4 \&$ Figure 7). Fireline intensity is a function of fuel characteristics and terrain, neither of which was manipulated among the climate scenarios. Mean fireline intensity in the watershed varies by approximately an order of magnitude from the lower watershed where the average value is about $300 \mathrm{~kW} / \mathrm{m}$ to the upper watershed where the average value is about $3000 \mathrm{~kW} / \mathrm{m}$. Fuels in the lower watershed are highly variable, ranging from grasslands and agriculture to small stands of 
managed timber. In contrast, the upper watershed includes generally continuous forest

fuels, including wilderness areas and unmanaged stands with dense canopies.
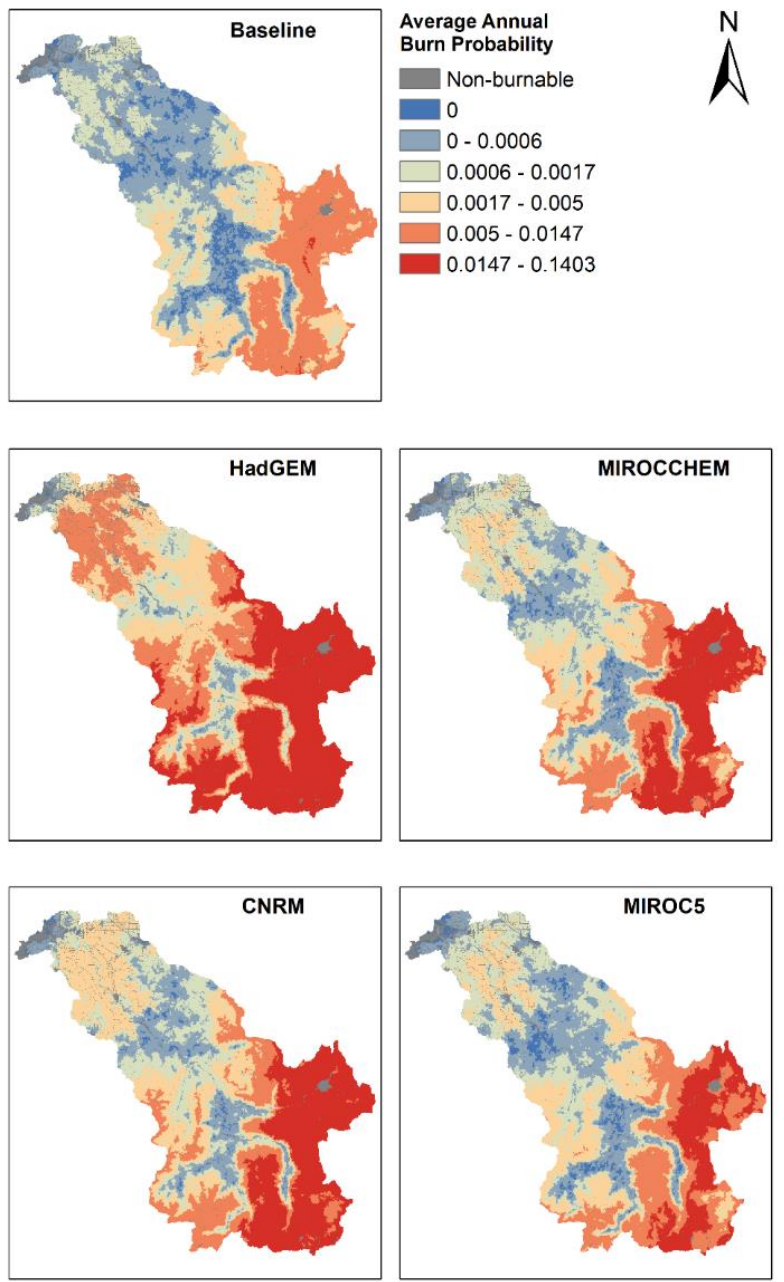

Figure 8. Average annual burn probability in the Clackamas under baseline (1992-2015) and four mid-century (2040-2069) scenarios. HadGEM is the warmest and driest future scenario, followed by CNRM. Both MIROCCHEM and MIROC5 project small increases in summer relative humidity and are less hot than HadGEM and CNRM, but are still warmer than baseline conditions. Non burnable pixels indicate water, rock/ice, high density urban areas, and agriculture. Results are classified using a quantile method. 

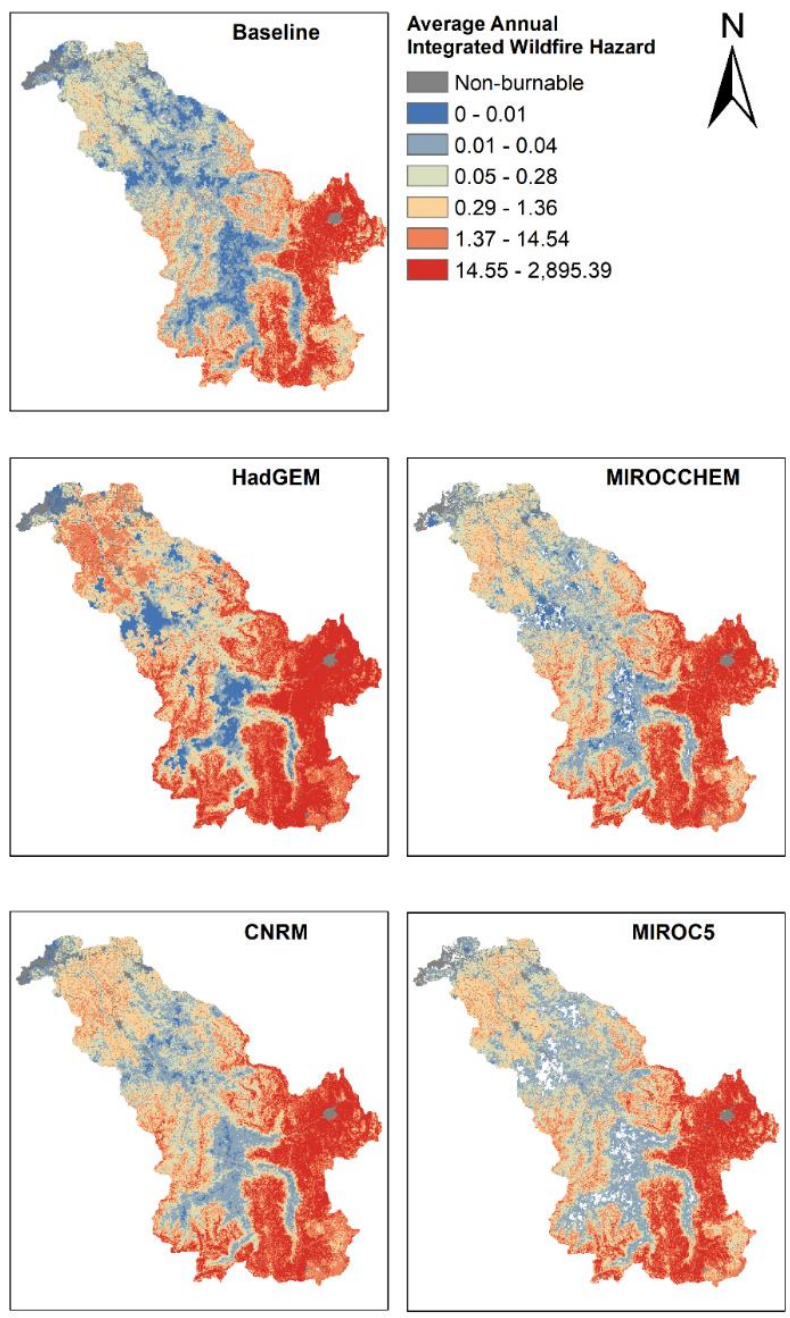

Figure 9. Integrated wildfire hazard is the product of annual burn probability and mean fireline intensity. Baseline wildfire hazard (upper left) under climate conditions based on empirical climate data 1992-2015. The four mid-century scenarios (right) are based on projected climate scenarios. HadGEM is the warmest and driest future scenario, followed by CNRM. Both MIROCCHEM and MIROC5 project small increases in summer relative humidity and are less hot than HadGEM and CNRM, but are still warmer than baseline conditions. Non-burnable pixels indicate water, rock/ice, high density urban areas, and agriculture. Results are classified using a quantile method.

Increases in future wildfire hazard roughly follow the same spatial pattern as under baseline conditions with increasing hazard under hotter and drier conditions (Figure 9). In baseline conditions, approximately 30,000 ha (12\%) are classified as very high hazard, but under mid-century conditions that percentage increased. Under 
MIROC5, 37,000 ha (15\%) of the watershed was classified as very high; Under MIROCCHEM, 42,000 ha (17\%) of the watershed was classified as very high; Under CNRM, 45,000 ha (18\%) of the watershed was classified as very high; and under HadGEM 62,000 ha (26\%) of the watershed was classified as very high. Under CNRM and HadGEM, the lower watershed adjacent to the Portland metro area is exposed to increasing wildfire hazard (Figure 9).

\section{DISCUSSION}

In fire prone ecosystems across the United States, there appears to be growing recognition of the unintended negative consequences of aggressive suppression policies and in response there are calls for increased application of managed and prescribed fire as a tool for risk reduction and climate adaptation (Calkin et al., 2015; North et al., 2015; Schoennagel et al., 2017). However, in comparatively lower-frequency fire regimes like the Clackamas, where the legacy of fire suppression is unclear (Parks et al., 2015) and where forest-based resources like drinking water are paramount, fire regime changes illustrated in this study would likely have overall net negative impacts (Gilbertson-Day et al., 2018). On one hand, in order to maintain the integrity of essential ecosystem services derived from westside forests as well as to prevent loss of life and property in the region's most populous communities, strategic active fire suppression may be the most effective strategy (Finney, 2020; J. S. Halofsky et al., 2018b). On the other hand, continued, let alone increased, suppression could inhibit climate adaptation by limiting opportunities for post-wildfire climate-adapted vegetation transitions (Halofsky et al., 2020). Our assessment of future wildfire hazard in the Clackamas illustrates the need for risk mitigation and climate adaptation and provides a foundation on which managers and 
planners can begin to develop strategies that will maintain the resiliency of ecosystem services and facilitate social and ecological adaptation to inevitable but uncertain changes in climate.

The range of mid-century wildfire regime changes illustrates the potential for social and ecological regime change. In our analysis we assumed that forest structure and composition would not change between baseline and mid-century scenarios. Of course, the landscape will change over the next 30 to 60 years as a result of land management and disturbances, but we assumed that mid-century forest structure and composition will be functionally equivalent to contemporary conditions. In westside forests, where landscape scale disturbances are uncommon and human land management is the largest driver of landscape change, our assumption may be reasonable (Halofsky et al., 2018a). Moreover, if climate change over the next several decades is akin to the scenario illustrated by MIROC5 and wildfire or other major disturbances remain uncommon, then forests may not change very quickly. However, if mid-century climate conditions are more similar to HadGEM, then significant changes in forest structure and composition may be facilitated by wildfire. Dramatic changes in the magnitude, frequency and location of disturbances can lead to ecological regime shifts wherein ecosystem structures, functions, and processes are fundamentally altered (Folke et al., 2004). In this study, wildfire regime characteristics projected under HadGEM conditions are similar to high-frequency, fire prone landscapes in central Oregon. We did not assess the effect of fire regime changes on vegetation, but Donato et al. (2020) found that fire rotation length is an important driver of forest structure and composition. Halofsky et al. (2020) 
projected that mid-century expansion of earl-seral forest and decline of late-seral forest structure was linked to wildfire frequency and only somewhat moderated by suppression efforts. Sheehan et al. (2015) projected that contemporary westside conifer forests will likely shift to hardwood-conifer mixed forests by the end of century as a result of increasingly common large fires. Similarly, Yospin et al. (2015) found, in a region similar to the Clackamas, that contemporary conifer forests are vulnerable to conversion to oak savannas under projected climate-mediated wildfire regime changes. However, Yospin et al. (2015) also found that broader conversion of conifer forests to hardwood species is likely overstated except in the most dramatic climate scenarios. Our analysis does not evaluate whether HadGEM conditions would actually be sufficient to initiate a regime shift, but it does lay the foundation and rationale for future work in that direction. Nonetheless, the range of mid-century changes in wildfire regime characteristics and hazard do indicate the likelihood of significant changes to major forest structure and composition.

The range of climate futures and wildfire outcomes modeled in this study illustrates the need for adaptive, near term approaches to risk mitigation and climate change. Climate projections for the future are inherently uncertain. Future precipitation magnitude and seasonality is particularly uncertain in the Pacific Northwest so we elected to not include projected precipitation changes in future scenarios (Mote and Salathé, 2010). Despite uncertainty, future changes in precipitation are generally projected to be minimal (Mote and Salathé, 2010; Rupp et al., 2013). However, Sheehan et al. (2015) demonstrated that even small increases in precipitation in early autumn could shorten 
future fire seasons despite warming temperatures. Three of the four mid-century scenarios we simulated projected fire seasons extending longer into the summer, but those projections could be moderated if in fact future autumn precipitation increases. Similarly, even though FSim accounts for variation in seasonal climate, it does not account for inter-seasonal climate patterns. Weisberg and Swanson (2003) found evidence for multidecadal, regionally synchronous fire regimes in western Oregon and Washington, indicating that inter-seasonal climate patterns like El Niño Southern Oscillation (ENSO) and the Pacific Decadal Oscillation play an important role in fire regime characteristics.

Other studies have selected specific GCMs or used ensemble averages in order to eliminate or diminish individual model biases (Rupp et al., 2013; Vano et al., 2015). Such approaches facilitate optimized planning to maximize net benefits or minimize net losses from future wildfire, but optimized risk reduction strategies are susceptible to unforeseen events or disruptions in anticipated trends (Hulse et al., 2016; Kunreuther et al., 2013; Lempert et al., 2002). In contrast, our results support the utility of an explore-than-test approach wherein managers and planners test possible risk mitigation strategies across several plausible futures and select the strategy that is most effective in all scenarios (Hulse et al., 2016; Lempert et al., 2006). In a landscape characterized by infrequent, but consequential wildfire events and where there is demonstrable uncertainty in future conditions, risk mitigation plans designed to meet average or optimized climate scenarios will likely not be sufficient under extreme conditions. Instead, managers and planners can use our findings to identify vulnerable resources and assets and test risk mitigation 
strategies that will be resilient in the face of climate change. Here again, resilience is measured by the ability of forests to adapt to novel fire regimes without sacrificing provision of or quality of ecosystem services like drinking water. By including both contemporary and near-future hazard assessments, our results can be used to design strategies that will likely be effective against contemporary conditions and which contribute to future resiliency as well.

Extreme event analysis was an important addition to this hazard assessment. Over the past century there have been a number of highly consequential westside fires that have become focusing events for managers, residents and policymakers in the region. Impactful as historical fires have been, simulated fire perimeters demonstrate that the Clackamas is vulnerable to fires that might challenge managers' conceptions of reality; there is sufficient fuel continuity such that under the right set of circumstances (ignition location and weather conditions) it is feasible for an extremely large fire to occur in close proximity to a major metro area, or to consume the majority of a municipal watershed in a single event. Increased resources will be needed in the future to keep ignitions from evolving into large, difficult-to-suppress fires. Fighting those fires is probably going to become more expensive; higher ERC values and larger fires like those modeled, generally means more expensive firefighting costs (Gebert et al., 2007). However, the generalized Pareto Distribution shape factor values indicated that fire size is more or less finite. This is probably a reflection of having clipped simulated perimeters to an artificially small study area. Future assessments of climate change impacts to westside 
extreme event probabilities should evaluate a larger landscape in order to avoid artificially clipping fire perimeters.

\section{CONCLUSION}

Projections of mid-century climate change illustrated a wide range of potential changes in wildfire regime characteristics and future wildfire hazard in the Clackamas River watershed. In all scenarios, wildfire hazard was highest in the upper watershed where historically significant fires have occurred, and where fuel conditions and ignition patterns facilitate large wildfires. However, all mid-century scenarios demonstrated the potential for large fires to occur in the lower watershed in close proximity to high density communities. Projected changes in temperature and relative humidity led to longer fire seasons and more severe fire weather in three of the four scenarios. Our analysis results are consistent with other studies which have also projected longer fire seasons and increased annual area affected by wildfire in westside forests. Improved projections of future precipitation and vegetation conditions could improve future wildfire hazard assessments. Our projected changes in wildfire occurrence and characteristics pose significant challenges for managers and planners. Our hazard analysis can be used to identify specific resources and assets that are exposed to future wildfire impact. Furthermore, our analysis describes the range of conditions for which managers and planners should develop and test risk mitigation strategies.

\section{REFERENCES}

Abatzoglou, J.T., Barbero, R., 2014. Observed and projected changes in absolute temperature records across the contiguous United States. Geophys. Res. Lett. 41, 6501-6508. https://doi.org/10.1002/2014GL061441 
Abatzoglou, J.T., Brown, T.J., 2012. A comparison of statistical downscaling methods suited for wildfire applications. International Journal of Climatology 32, 772-780. https://doi.org/10.1002/joc.2312

Abatzoglou, J.T., Kolden, C.A., 2013. Relationships between climate and macroscale area burned in the western United States. Int. J. Wildland Fire 22, 1003. https://doi.org/10.1071/WF13019

Agee, J.K., 1993. Fire Ecology of Pacific Northwest Forests. Island Press, Washington, D.C.

Ager, A.A., Day, M.A., Vogler, K., 2016. Production possibility frontiers and socioecological tradeoffs for restoration of fire adapted forests. Journal of Environmental Management 176, 157-168. https://doi.org/10.1016/j.jenvman.2016.01.033

Ager, A.A., Kline, J.D., Fischer, A.P., 2015. Coupling the Biophysical and Social Dimensions of Wildfire Risk to Improve Wildfire Mitigation Planning: Coupling the Biophysical and Social Dimensions of Wildfire Risk. Risk Analysis 35, 1393 1406. https://doi.org/10.1111/risa.12373

Ager, A.A., Vaillant, N.M., Finney, M.A., 2010. A comparison of landscape fuel treatment strategies to mitigate wildland fire risk in the urban interface and preserve old forest structure. Forest Ecology and Management 259, 1556-1570. https://doi.org/10.1016/j.foreco.2010.01.032

Andrews, P.L., Loftsgaarden, D.O., Bradshaw, L.S., 2003. Evaluation of fire danger rating indexes using logistic regression and percentile analysis. Int. J. Wildland Fire 12, 213. https://doi.org/10.1071/WF02059

Bakker, J.D., Jones, E., Sprenger, C.B., 2019. Evidence of a historical frequent, lowseverity fire regime in western Washington, USA. Can. J. For. Res. 49, 575-585. https://doi.org/10.1139/cjfr-2018-0354

Bradshaw, L.S., McCormick, E., 2009. FireFamily Plus users guide, version 4.0.

Brown, T.C., Hobbins, M.T., Ramirex, J.A., 2008. Spatial Distribution of Water Supply in the Coterminous United States. Journal of the American Water Resources Association 44, 1474-1487.

Buma, B., 2015. Disturbance interactions: characterization, prediction, and the potential for cascading effects. Ecosphere 6, 1-15. https://doi.org/10.1890/ES15-00058.1

Calkin, D.E., Ager, A.A., Gilbertson-Day, J., 2010. Wildfire Risk and Hazard: Prodcedures for the First Approximation (General Technical Report No. RMRSGTR-235). U.S. Departmnet of Agriculture, Rocky Mountain Research Station, Fort Collins, CO.

Calkin, D.E., Cohen, J.D., Finney, M.A., Thompson, M.P., 2014. How risk management can prevent future wildfire disasters in the wildland-urban interface. Proceedings of the National Academy of Sciences 111, 746-751. https://doi.org/10.1073/pnas.1315088111

Calkin, D.E., Thompson, M.P., Finney, M.A., 2015. Negative consequences of positive feedbacks in US wildfire management. For. Ecosyst. 2, 9. https://doi.org/10.1186/s40663-015-0033-8 
Cansler, C.A., McKenzie, D., 2014. Climate, fire size, and biophysical setting control fire severity and spatial pattern in the northern Cascade Range, USA. Ecological Applications 24, 1037-1056. https://doi.org/10.1890/13-1077.1

Cohen, J.D., Deeming, J.E., 1985. The national fire-danger rating system: basic equations (No. PSW-GTR-82). U.S. Department of Agriculture, Forest Service, Pacific Southwest Forest and Range Experiment Station, Berkeley, CA. https://doi.org/10.2737/PSW-GTR-82

Cooper, M.G., Nolin, A.W., Safeeq, M., 2016. Testing the recent snow drought as an analog for climate warming sensitivity of Cascades snowpacks. Environ. Res. Lett. 11, 084009. https://doi.org/10.1088/1748-9326/11/8/084009

Cumming, S. g., 2001. A parametric model of the fire-size distribution. Canadian Journal of Forest Research 31, 1297. https://doi.org/10.1139/x01-032

Dalton, M.M., Shell, K.M., 2013. Comparison of Short-Term and Long-Term Radiative Feedbacks and Variability in Twentieth-Century Global Climate Model Simulations. Journal of Climate 26, 10051-10070. https://doi.org/10.1175/JCLID-12-00564.1

de la Barrera, F., Barraza, F., Favier, P., Ruiz, V., Quense, J., 2018. Megafires in Chile 2017: Monitoring multiscale environmental impacts of burned ecosystems.

Science of The Total Environment 637-638, 1526-1536. https://doi.org/10.1016/j.scitotenv.2018.05.119

Dennison, P.E., Brewer, S.C., Arnold, J.D., Moritz, M.A., 2014. Large wildfire trends in the western United States, 1984-2011: Geophys. Res. Lett. 41, 2928-2933. https://doi.org/10.1002/2014GL059576

Donato, D.C., Halofsky, J.S., Reilly, M.J., 2020. Corralling a black swan: natural range of variation in a forest landscape driven by rare, extreme events. Ecol Appl 30. https://doi.org/10.1002/eap.2013

Emelko, M.B., Silins, U., Bladon, K.D., Stone, M., 2011. Implications of land disturbance on drinking water treatability in a changing climate: Demonstrating the need for "source water supply and protection" strategies. Water Research 45, 461-472. https://doi.org/10.1016/j.watres.2010.08.051

Emelko, M.B., Stone, M., Silins, U., Allin, D., Collins, A.L., Williams, C.H.S., Martens, A.M., Bladon, K.D., 2016. Sediment-phosphorus dynamics can shift aquatic ecology and cause downstream legacy effects after wildfire in large river systems. Glob Change Biol 22, 1168-1184. https://doi.org/10.1111/gcb.13073

Finney, M.A., 2020. The wildland fire system and challenges for engineering. Fire Safety Journal 103085. https://doi.org/10.1016/j.firesaf.2020.103085

Finney, M.A., McHugh, C.W., Grenfell, I.C., Riley, K.L., Short, K.C., 2011. A simulation of probabilistic wildfire risk components for the continental United States. Stoch Environ Res Risk Assess 25, 973-1000. https://doi.org/10.1007/s00477-011-0462-z

Flannigan, M.D., Krawchuk, M.A., de Groot, W.J., Wotton, B.M., Gowman, L.M., 2009. Implications of changing climate for global wildland fire. International Journal of Wildland Fire 18, 483. https://doi.org/10.1071/WF08187 
Folke, C., Carpenter, S., Walker, B., Scheffer, M., Elmqvist, T., Gunderson, L., Holling, C.S., 2004. Regime Shifts, Resilience, and Biodiversity in Ecosystem Management. Annu. Rev. Ecol. Evol. Syst. 35, 557-581. https://doi.org/10.1146/annurev.ecolsys.35.021103.105711

Gebert, K.M., Calkin, D.E., Yoder, J., 2007. Estimating Suppression Expenditures for Individual Large Wildland Fires. Western Journal of Applied Forestry 22, 188 196. https://doi.org/10.1093/wjaf/22.3.188

Gedalof, Z., Peterson, D.L., Mantua, N.J., 2005. Atmospheric, Climatic, And Ecological Controls on Extreme Wildfire Years in the Northwestern United States. Ecological Applications 15, 154-174. https://doi.org/10.1890/03-5116

Gilbertson-Day, J., Stratton, R.D., Scott, J.H., Vogler, K.C., Brough, A., 2018. Pacific Northwest Quantitative Wildfire Risk Assessment: Methods and Results.

Gilleland, E., 2020. extRemes, Extreme Value Analysis.

Gleason, K.E., Nolin, A.W., 2016. Charred forests accelerate snow albedo decay: parameterizing the post-fire radiative forcing on snow for three years following fire: Charred Forests Accelerate Snow Albedo Decay. Hydrol. Process. 30, 38553870. https://doi.org/10.1002/hyp.10897

Graves, D., Chang, H., 2007. Hydrologic impacts of climate change in the Upper Clackamas River Basin, Oregon, USA. Clim. Res. 33, 143-157. https://doi.org/10.3354/cr033143

Hallema, D.W., Robinne, F.-N., Bladon, K.D., 2018. Reframing the Challenge of Global Wildfire Threats to Water Supplies. Earth's Future 6, 772-776. https://doi.org/10.1029/2018EF000867

Hallema, D.W., Sun, G., Bladon, K.D., Norman, S.P., Caldwell, P.V., Liu, Y., McNulty, S.G., 2017. Regional patterns of postwildfire streamflow response in the Western United States: The importance of scale-specific connectivity. Hydrological Processes 31, 2582-2598. https://doi.org/10.1002/hyp.11208

Haller, G., Moryc, D., 2018. Forests to Faucets. Pacific Rivers.

Halofsky, J.E., Peterson, D.L., Harvey, B.J., 2020. Changing wildfire, changing forests: the effects of climate change on fire regimes and vegetation in the Pacific Northwest, USA. fire ecol 16, 4. https://doi.org/10.1186/s42408-019-0062-8

Halofsky, J.S., Conklin, D.R., Donato, D.C., Halofsky, J.E., Kim, J.B., 2018a. Climate change, wildfire, and vegetation shifts in a high-inertia forest landscape: Western Washington, U.S.A. PLoS ONE 13, e0209490. https://doi.org/10.1371/journal.pone.0209490

Halofsky, J.S., Donato, D.C., Franklin, J.F., Halofsky, J.E., Peterson, D.L., Harvey, B.J., 2018b. The nature of the beast: examining climate adaptation options in forests with stand-replacing fire regimes. Ecosphere 9, e02140. https://doi.org/10.1002/ecs2.2140

Haugo, R., Zanger, C., DeMeo, T., Ringo, C., Shlisky, A., Blankenship, K., Simpson, M., Mellen-McLean, K., Kertis, J., Stern, M., 2015. A new approach to evaluate forest structure restoration needs across Oregon and Washington, USA. Forest Ecology and Management 335, 37-50. https://doi.org/10.1016/j.foreco.2014.09.014 
Haugo, R.D., Kellogg, B.S., Cansler, C.A., Kolden, C.A., Kemp, K.B., Robertson, J.C., Metlen, K.L., Vaillant, N.M., Restaino, C.M., 2019. The missing fire: quantifying human exclusion of wildfire in Pacific Northwest forests, USA. Ecosphere 10, e02702. https://doi.org/10.1002/ecs2.2702

Hessburg, P.F., Spies, T.A., Perry, D.A., Skinner, C.N., Taylor, A.H., Brown, P.M., Stephens, S.L., Larson, A.J., Churchill, D.J., Povak, N.A., Singleton, P.H., McComb, B., Zielinski, W.J., Collins, B.M., Salter, R.B., Keane, J.J., Franklin, J.F., Riegel, G., 2016. Tamm Review: Management of mixed-severity fire regime forests in Oregon, Washington, and Northern California. Forest Ecology and Management 366, 221-250. https://doi.org/10.1016/j.foreco.2016.01.034

Heyerdahl, E.K., McKenzie, D., Daniels, L.D., Hessl, A.E., Littell, J.S., Mantua, N.J., 2008. Climate drivers of regionally synchronous fires in the inland Northwest (1651 - 1900). Int. J. Wildland Fire 17, 40. https://doi.org/10.1071/WF07024

Hohner, A.K., Rhoades, C.C., Wilkerson, P., Rosario-Ortiz, F.L., 2019. Wildfires Alter Forest Watersheds and Threaten Drinking Water Quality. Acc. Chem. Res. acs.accounts.8b00670. https://doi.org/10.1021/acs.accounts.8b00670

Holden, Z.A., Swanson, A., Luce, C.H., Jolly, W.M., Maneta, M., Oyler, J.W., Warren, D.A., Parsons, R., Affleck, D., 2018. Decreasing fire season precipitation increased recent western US forest wildfire activity. Proc Natl Acad Sci USA 115, E8349-E8357. https://doi.org/10.1073/pnas.1802316115

Hulse, D., Branscomb, A., Enright, C., Johnson, B., Evers, C., Bolte, J., Ager, A., 2016. Anticipating surprise: Using agent-based alternative futures simulation modeling to identify and map surprising fires in the Willamette Valley, Oregon USA. Landscape and Urban Planning 156, 26-43. https://doi.org/10.1016/j.landurbplan.2016.05.012

Jennings, K., Jones, J.A., 2015. Precipitation-snowmelt timing and snowmelt augmentation of large peak flow events, western Cascades, Oregon: PrecipitationSnowmelt Timing and Peak Flows, Oregon. Water Resour. Res. 51, 7649-7661. https://doi.org/10.1002/2014WR016877

Jiang, Y., Zhuang, Q., 2011. Extreme value analysis of wildfires in Canadian boreal forest ecosystems. Canadian Journal of Forest Research 41, 1836-1851. https://doi.org/10.1139/x11-102

Jung, I.-W., Chang, H., 2011. Assessment of future runoff trends under multiple climate change scenarios in the Willamette River Basin, Oregon, USA. Hydrol. Process. 25, 258-277. https://doi.org/10.1002/hyp.7842

Jurjevich, J., Proehl, R., Chun, N., Rancik, K., Harada, M., Loftus, D., Morris, R., Rynerson, C., 2017. Coordinated Population Forecast for Clackamas County, its Urban Growth Boundaries (UGB) and Area Outside UGB. Population Research Center, Portland State University, Portland, OR.

Keane, R.E., Agee, J.K., Fulé, P., Keeley, J.E., Key, C., Kitchen, S.G., Miller, R., Schulte, L.A., 2008. Ecological effects of large fires on US landscapes: benefit or catastrophe? Int. J. Wildland Fire 17, 696. https://doi.org/10.1071/WF07148 
Krawchuk, M.A., Moritz, M.A., Parisien, M.-A., Van Dorn, J., Hayhoe, K., 2009. Global Pyrogeography: the Current and Future Distribution of Wildfire. PLoS ONE 4, e5102. https://doi.org/10.1371/journal.pone.0005102

Kunreuther, H., Heal, G., Allen, M., Edenhofer, O., Field, C.B., Yohe, G., 2013. Risk management and climate change. Nature Clim Change 3, 447-450. https://doi.org/10.1038/nclimate 1740

LANDFIRE, U.S. Department of Agriculture, Forest Service, U.S. Department of Interior, 2014. 40 Scott and Burgan Fire Behavior Fuel Models, 1.4.0 https://landfire.gov/fbfm40.php

Lempert, R., Popper, S., Bankes, S., 2002. Confronting Surprise. Social Science Computer Review 20, 420-440. https://doi.org/10.1177/089443902237320

Lempert, R.J., Groves, D.G., Popper, S.W., Bankes, S.C., 2006. A General, Analytic Method for Generating Robust Strategies and Narrative Scenarios. Management Science 52, 514-528. https://doi.org/10.1287/mnsc. 1050.0472

Littell, J.S., McKenzie, D., Peterson, D.L., Westerling, A.L., 2009. Climate and wildfire area burned in western U.S. ecoprovinces, 1916-2003. Ecological Applications 19, 1003-1021. https://doi.org/10.1890/07-1183.1

McKenzie, D., Gedalof, Z., Peterson, D.L., Mote, P., 2004. Climatic Change, Wildfire, and Conservation. Conservation Biology 18, 890-902. https://doi.org/10.1111/j.1523-1739.2004.00492.x

McKenzie, D., Littell, J.S., 2017. Climate change and the eco-hydrology of fire: Will area burned increase in a warming western USA? Ecological Applications 27, 26-36. https://doi.org/10.1002/eap.1420

Moody, J.A., Martin, D.A., Haire, S.L., Kinner, D.A., 2008. Linking runoff response to burn severity after a wildfire. Hydrol. Process. 22, 2063-2074. https://doi.org/10.1002/hyp.6806

Moody, J.A., Shakesby, R.A., Robichaud, P.R., Cannon, S.H., Martin, D.A., 2013. Current research issues related to post-wildfire runoff and erosion processes. Earth-Science Reviews 122, 10-37. https://doi.org/10.1016/j.earscirev.2013.03.004

Moritz, M.A., 1997. Analyzing Extreme Disturbance Events: Fire in Los Padres National Forest. Ecological Applications 7, 1252-1262. https://doi.org/10.1890/10510761(1997)007[1252:AEDEFI]2.0.CO;2

Mote, P.W., Parson, E.A., Hamlet, A.F., Keeton, W.S., Lettenmaier, D., Mantua, N., Miles, E.L., Peterson, D.W., Peterson, D.L., Slaughter, R., Snover, A.K., 2003. Preparing for Climatic Change: The water, salmon, and forests of the Pacific Northwest. Climatic Change 61, 45-88. https://doi.org/10.1023/A:1026302914358

Mote, P.W., Salathé, E.P., 2010. Future climate in the Pacific Northwest. Climatic Change 102, 29-50. https://doi.org/10.1007/s10584-010-9848-z

Nolin, A.W., 2012. Perspectives on Climate Change, Mountain Hydrology, and Water Resources in the Oregon Cascades, USA. Mountain Research and Development 32, S35-S46. https://doi.org/10.1659/MRD-JOURNAL-D-11-00038.S1 
North, M.P., Stephens, S.L., Collins, B.M., Agee, J.K., Aplet, G., Franklin, J.F., Fule, P.Z., 2015. Reform forest fire management. Science 349, 1280-1281. https://doi.org/10.1126/science.aab2356

Parisien, M.-A., Dawe, D.A., Miller, C., Stockdale, C.A., Armitage, O.B., 2019. Applications of simulation-based burn probability modelling: a review. Int. J. Wildland Fire 28, 913. https://doi.org/10.1071/WF19069

Parks, S.A., Miller, C., Parisien, M.-A., Holsinger, L.M., Dobrowski, S.Z., Abatzoglou, J., 2015. Wildland fire deficit and surplus in the western United States, 19842012. Ecosphere 6, art275. https://doi.org/10.1890/ES15-00294.1

Pausas, J.G., Keeley, J.E., 2019. Wildfires as an ecosystem service. Front Ecol Environ 17, 289-295. https://doi.org/10.1002/fee.2044

Portland Water Bureau, 2020. Bull Run Watershed [WWW Document]. URL https://www.portlandoregon.gov/water/29784

R Core Team, 2018. R: A Language and Environment for Statistical Computing. R Foundation for Statistical Computing, Vienna, Austria.

Reilly, M.J., Dunn, C.J., Meigs, G.W., Spies, T.A., Kennedy, R.E., Bailey, J.D., Briggs, K., 2017. Contemporary patterns of fire extent and severity in forests of the Pacific Northwest, USA (1985-2010). Ecosphere 8, e01695. https://doi.org/10.1002/ecs2.1695

Rhoades, C.C., Chow, A.T., Covino, T.P., Fegel, T.S., Pierson, D.N., Rhea, A.E., 2019. The Legacy of a Severe Wildfire on Stream Nitrogen and Carbon in Headwater Catchments. Ecosystems 22, 643-657. https://doi.org/10.1007/s10021-018-02936

Riley, K., Thompson, M., Scott, J., Gilbertson-Day, J., 2018. A Model-Based Framework to Evaluate Alternative Wildfire Suppression Strategies. Resources 7, 4. https://doi.org/10.3390/resources7010004

Riley, K.L., Abatzoglou, J.T., Grenfell, I.C., Klene, A.E., Heinsch, F.A., 2013. The relationship of large fire occurrence with drought and fire danger indices in the western USA, 1984-2008: the role of temporal scale. Int. J. Wildland Fire 22, 894. https://doi.org/10.1071/WF12149

Riley, K.L., Loehman, R.A., 2016. Mid-21st-century climate changes increase predicted fire occurrence and fire season length, Northern Rocky Mountains, United States. Ecosphere 7, e01543. https://doi.org/10.1002/ecs2.1543

Rupp, D.E., Abatzoglou, J.T., Hegewisch, K.C., Mote, P.W., 2013. Evaluation of CMIP5 $20^{\text {th }}$ century climate simulations for the Pacific Northwest USA: CMIP5 20th century climate of the PNW. J. Geophys. Res. Atmos. 118, 10,884-10,906. https://doi.org/10.1002/jgrd.50843

Schoennagel, T., Balch, J.K., Brenkert-Smith, H., Dennison, P.E., Harvey, B.J., Krawchuk, M.A., Mietkiewicz, N., Morgan, P., Moritz, M.A., Rasker, R., Turner, M.G., Whitlock, C., 2017. Adapt to more wildfire in western North American forests as climate changes. Proceedings of the National Academy of Sciences 114, 4582-4590. https://doi.org/10.1073/pnas.1617464114 
Schoennagel, T., Veblen, T.T., Romme, W.H., 2004. The Interaction of Fire, Fuels, and Climate across Rocky Mountain Forests. BioScience 54, 661. https://doi.org/10.1641/0006-3568(2004)054[0661:TIOFFA]2.0.CO;2

Schoof, J.T., 2015. High-resolution projections of 21 st century daily precipitation for the contiguous U.S. J. Geophys. Res. Atmos. 120, 3029-3042. https://doi.org/10.1002/2014JD022376

Scott, J., Helmbrecht, D., Thompson, M.P., Calkin, D.E., Marcille, K., 2012. Probabilistic assessment of wildfire hazard and municipal watershed exposure. Nat Hazards 64, 707-728. https://doi.org/10.1007/s11069-012-0265-7

Scott, J.H., Thompson, M.P., Calkin, D.E., 2013. A wildfire risk assessment framework for land and resource management (No. RMRS-GTR-315). U.S. Department of Agriculture, Forest Service, Rocky Mountain Research Station, Ft. Collins, CO. https://doi.org/10.2737/RMRS-GTR-315

Sheehan, T., Bachelet, D., Ferschweiler, K., 2015. Projected major fire and vegetation changes in the Pacific Northwest of the conterminous United States under selected CMIP5 climate futures. Ecological Modelling 317, 16-29. https://doi.org/10.1016/j.ecolmodel.2015.08.023

Short, K.C., 2017. Spatial wildfire occurrence data for the United States, 1992-2015 [FPA_FOD_20170508] (4th Edition). https://doi.org/10.2737/RDS-2013-0009.4

Simpson, M., 2013. Forest Vegetation Zone Map.

Spies, T.A., Stine, P.A., Gravenmier, R., Long, J.W., Reilly, M.J., Technical Coordinators, 2018. Synthesis of Science to Inform Land Management Within the Northwest Forest Plan Area (General Technical Report No. PNW-GTR-966 Vol. 1). U.S. Department of Agriculture, Forest Service, Pacific Northwest Research Station.

Stavros, E.N., Abatzoglou, J.T., McKenzie, D., Larkin, N.K., 2014. Regional projections of the likelihood of very large wildland fires under a changing climate in the contiguous Western United States. Climatic Change 126, 455-468. https://doi.org/10.1007/s10584-014-1229-6

Tague, C., Grant, G.E., 2009. Groundwater dynamics mediate low-flow response to global warming in snow-dominated alpine regions: Groundwater Dynamics and Low-Flow Response. Water Resour. Res. 45. https://doi.org/10.1029/2008WR007179

Taleb, N.N., 2010. Black Swan: The Impact of the Highly Improbable, Second. ed. Random House Trade Paperbacks, New York.

Tepley, A.J., Swanson, F.J., Spies, T.A., 2013. Fire-mediated pathways of stand development in Douglas-fir/western hemlock forests of the Pacific Northwest, USA. Ecology 94, 1729-1743. https://doi.org/10.1890/12-1506.1

Thompson, M., Bowden, P., Brough, A., Scott, J., Gilbertson-Day, J., Taylor, A., Anderson, J., Haas, J., 2016. Application of Wildfire Risk Assessment Results to Wildfire Response Planning in the Southern Sierra Nevada, California, USA. Forests 7, 64. https://doi.org/10.3390/f7030064 
Vano, J.A., Kim, J.B., Rupp, D.E., Mote, P.W., 2015. Selecting climate change scenarios using impact-relevant sensitivities: Selecting Scenarios by Impact Sensitivity. Geophys. Res. Lett. 42, 5516-5525. https://doi.org/10.1002/2015GL063208

Vogler, K., Ager, A., Day, M., Jennings, M., Bailey, J., 2015. Prioritization of Forest Restoration Projects: Tradeoffs between Wildfire Protection, Ecological Restoration and Economic Objectives. Forests 6, 4403-4420. https://doi.org/10.3390/f6124375

Walsh, M.K., Marlon, J.R., Goring, S.J., Brown, K.J., Gavin, D.G., 2015. A Regional Perspective on Holocene Fire-Climate-Human Interactions in the Pacific Northwest of North America. Annals of the Association of American Geographers 105, 1135-1157. https://doi.org/10.1080/00045608.2015.1064457

Weisberg, P.J., Swanson, F.J., 2003. Regional synchroneity in fire regimes of western Oregon and Washington, USA. Forest Ecology and Management 172, 17-28. https://doi.org/10.1016/S0378-1127(01)00805-2

Westerling, A.L., 2006. Warming and Earlier Spring Increase Western U.S. Forest Wildfire Activity. Science 313, 940-943. https://doi.org/10.1126/science.1128834

Wondzell, S.M., King, J.G., 2003. Postfire erosional processes in the Pacific Northwest and Rocky Mountain regions. Forest Ecology and Management 178, 75-87. https://doi.org/10.1016/S0378-1127(03)00054-9

Yospin, G.I., Bridgham, S.D., Neilson, R.P., Bolte, J.P., Bachelet, D.M., Gould, P.J., Harrington, C.A., Kertis, J.A., Evers, C., Johnson, B.R., 2015. A new model to simulate climate-change impacts on forest succession for local land management. Ecological Applications 25, 226-242. https://doi.org/10.1890/13-0906.1 


\section{APPENDIX A}

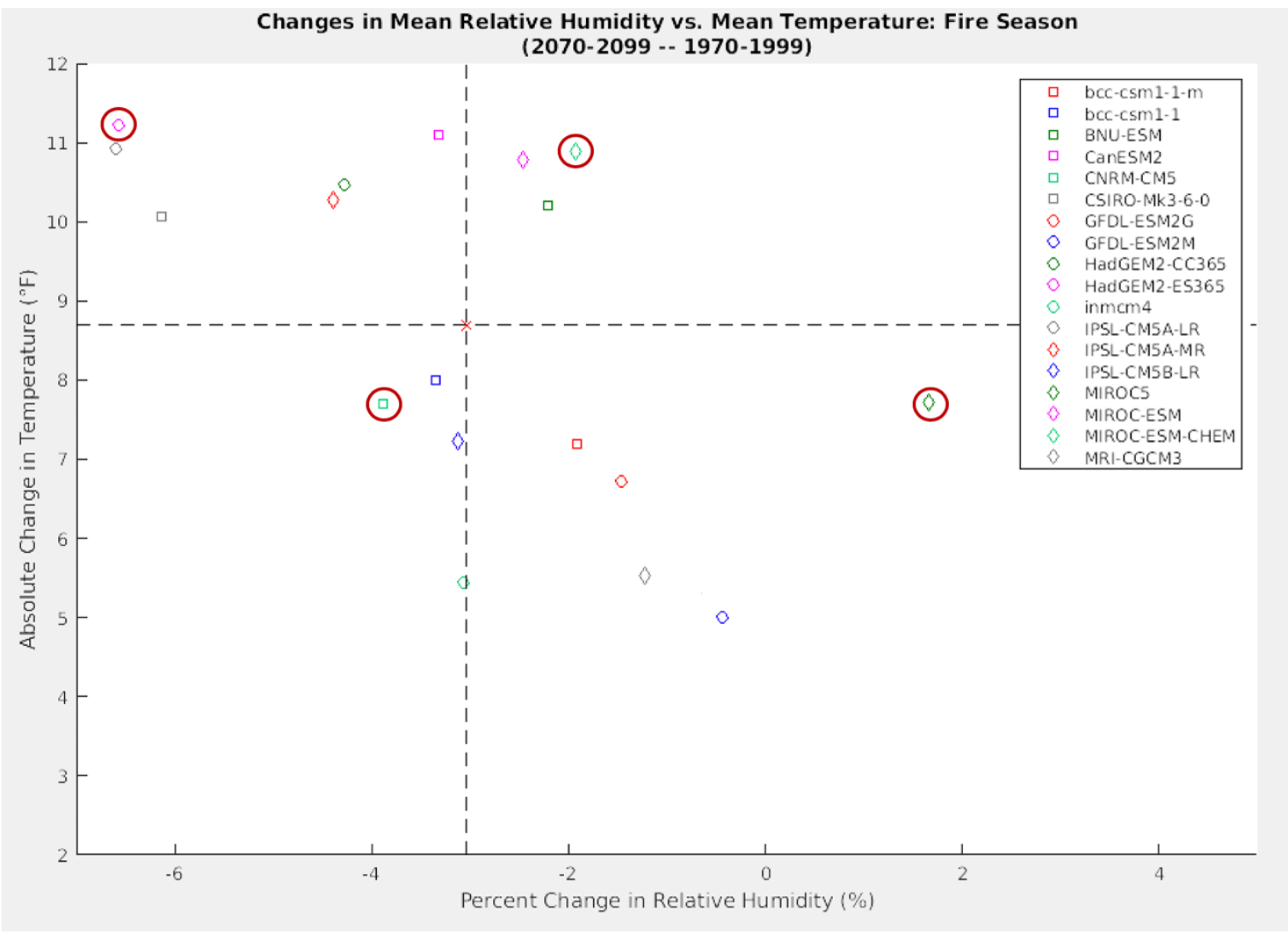

Figure 10. Projected average annual change in temperature and relative humidity between the end of the $21^{\text {st }}$ century (2070-2099) and the historical reference period (1970-1999) under RCP 8.5 from eighteen GCMs from CMIP5. Circled models were used to model mid-century (20402069) wildfire characteristics: HadGEM (upper left), MIROCCCHEM (upper right), CNRM (lower left), MIROC5 (lower right). 


\title{
CHAPTER 2: New Perspectives on Wildfire Risk Assessments in Low Frequency Fire Regimes
}

\author{
ABSTRACT \\ One the most pressing challenges for wildfire science is to characterize how \\ contemporary wildfire risk is changing and will continue to change as a result of novel \\ climate conditions. Over the past decade wildfire risk sciences developed sophisticated \\ tools to identify and reduce uncertainty inherent in wildfire management. However, \\ contemporary wildfire risk assessment methods are largely based on probabilistic \\ characterizations of risk which present unique challenges in moist, mixed conifer forests \\ with low annual burn probabilities. In this study we present a method for combining \\ analysis of rare, consequential events with probabilistic analysis to more fully \\ characterize wildfire exposure in a municipal watershed outside Portland, Oregon, USA. \\ Specifically, we evaluate the characteristics of surprise fires, fires which are considered \\ implausible but which, if they did occur, would have profound social and ecological \\ impacts. Using the large fire simulator, FSim, we modeled fire occurrence under \\ observed contemporary (199-2015) and projected mid-century (2040-2069) climate \\ scenarios. We defined three classes of surprising fires based on expert input and assessed \\ the impact of climate change on surprise fire occurrence. Results indicated as much as a \\ $400 \%$ increase in extremely large fires under future scenarios and increasing wildfire \\ exposure in densely populated parts of the watershed. The wide range of scenario \\ outcomes demonstrates the plausibility of novel fire regimes and consequently the need \\ for robust strategies for risk mitigation and climate adaptation.
}




\section{INTRODUCTION}

One the most pressing challenges for wildfire science is to characterize how contemporary fire regimes are changing and will continue to change as a result of novel climate conditions (Archibald et al., 2013). Despite strong relationships between climate change and increased wildfire activity (i.e. Abatzoglou and Williams, 2016), future wildfire regimes will be strongly modulated by regional conditions and human decisions (Krawchuk et al., 2009). In the western U.S., the annual footprint of wildfire is expected to increase due largely to warmer temperatures, but precise changes in fire frequency and extent will be regionally specific (McKenzie and Littell, 2017; Westerling, 2006).

Climate change only exacerbates uncertainty in wildfire management which is otherwise due to the complexity of fire ecology, as well as incomplete knowledge and scientific understanding of physical and social processes driving fire occurrence and impact. Thompson and Calkin (2011) reviewed definitions and sources of uncertainty in wildfire management based on the uncertainty typology described in Ascough et al. (2008), focusing primarily on knowledge and decision uncertainty. Based on the risk assessment framework from Fairbrother and Turnley (2005), wildfire risk sciences have advanced dramatically over the past decade in an effort to identify and overcome reducible uncertainty. In particular, wildfire risk managers have largely adopted an actuarial view of "risk", where risk is the product of probability of an event occurring and a response function that quantifies the impact of the event (Finney, 2005; Scott et al., 2013a). As a result of rapid advancements in computational power, probabilistic risk assessments, based largely on Monte Carlo simulation models, have become one of most 
common tools for characterizing and communicating contemporary wildfire risk and projecting changes in future risk (Parisien et al., 2019).

Probabilistic assessments can be valuable tools for reducing uncertainty around otherwise stochastic events (Thompson and Calkin, 2011; i.e. G. Barros et al., 2019; Riley et al., 2018), but may not always be the most effective method. In particular, low probability, high consequence events present a challenge for interpretation and application of probabilistic risk assessments. Low probability, high consequence events are sometimes called surprises, extreme events, black swans, and dragon kings (Markley, 2011; Bowman et al., 2017; Taleb, 2010; Sachs et al., 2012). As the name indicates, a common feature of all these events is that they are characterized by exceedingly low probabilities of occurrence. Problematically, individuals struggle to incorporate low probabilities into decisions of risk (Kahneman and Tversky, 1979; Kunreuther et al., 2001). On one hand, in the absence of sufficient supporting information or in instances where the decision-maker is not knowledgeable, low probabilities can be evaluated as essentially zero and are not considered in subsequent decisions (Kunreuther et al., 2001). On the other hand, when the consequences of low probability events are extremely high, it has been demonstrated that individuals actually overpredict the probability of the event (Hertwig et al., 2004; Slovic, 1987). Whether or not an individual over- or underestimates the associated risk of wildfires is often related to demographics, personal experience, and whether or not they are a wildfire professional (Meldrum et al., 2015). Knoblauch et al. (2018) reviewed the literature on communicating risk from lowprobability-high-consequence events from many industries and fields and identified many 
diverse strategies. There appears to be value in presenting risk in multiple formats and with detailed contextual information, supporting constructivist theories on risk perception (Slovic, 1987; Slovic et al., 1974).

Aven and Krohn (2014) describe a broader perspective on risk assessments that builds on probabilistic characterizations of risk but does not rely on probabilities alone. According to Aven and Krohn (2014), probabilistic risk assessments are improved by including (1) explicit characterizations of the strength of knowledge that underpins the probabilistic assessment, and (2) evaluation of surprises. The purpose of characterizing knowledge limitations is to clarify that probabilistic assessments reflect the assessor's uncertainty and not just the probability of occurrence. The concept of surprise is closely related to low probability, high consequence event analysis and has been applied to characterization of risk from climate change, natural hazards, and industrial disasters (Kates and Clark, 1996). Surprising events are unanticipated and do not meet an individual's expectation of reality (Lindenmayer et al., 2010). While many surprises are low probability, high consequence events, surprise can also characterize events with demonstrably high probability - as determined by subject experts - but low credibility amongst non-experts (Markley, 2011). For example, scientists have been confident that the likelihood of climate driven natural disasters will increase as a result of climate change, but in many public arenas skepticism towards scientists has led to inaction rather than climate adaption. Surprise analysis acknowledges that much risk is the result of either reducible or irreducible ignorance which prevents us from foreseeing and planning for sources of risk (Faber et al., 1992). 
The challenge of relying on probabilistic risk assessments to characterize risk is particularly relevant to forests west of the Cascade crest in Oregon and Washington, USA (westside). In the context of this paper, westside forests are notable primarily because they are characterized by long fire return intervals (Agee, 1993) and low annual burn probability (Finney et al., 2011). However, westside fire regimes are not spatially homogenous. While much of the region is characterized by large patches of high severity fire and fire return intervals exceeding 200 years, there is also strong evidence of frequent, low severity fire in the western Washington (Bakker et al., 2019) as well as in the Willamette Valley of Oregon (Tepley et al., 2013). Spies et al. (2018) argue that fire regime characterizations in the national LANDFIRE dataset are too coarse for local analysis, noting especially that the drier and warmer portions of the region should be characterized as moderate frequency-mixed severity regimes. Spies et al. (2018) also summarizes research from the past 40 years in Oregon, Washington and California and illustrates that fire regime characteristics, including frequency and severity, are strongly mediated by local topography, vegetation feedbacks, and climate. Nonetheless, Uncertainty and variation in fire return intervals aside, average annual burn probability in westside forests is less than one hundredth of a percent (Figure 1; "Probabilistic Wildfire Risk,” 2020), and regional probabilistic risk assessments characterize westside risk as low, especially when compared to high-frequency fire regimes east of the Cascades (Figure 1).

However, the westside contains the overwhelming majority of Oregon and Washington's population, significant timber and agricultural resources, and is dependent 
on forests to provide many ecosystem services, all of which would be negatively impacted by a large or severe wildfire. Moreover, westside wildfire history demonstrates the potential for large, highly consequential events. The Yacolt fire is suspected to have been caused by humans and burned over 200,000 hectares in the Columbia River Gorge in 1902 and killed at least sixty-five people. The Tillamook Burn, a series of fires over the course of 1933-1951 each of which was human-caused, burned over 121,000 hectares in the northern Coast Range of Oregon. Most recently, the Eagle Creek fire ignited in late summer 2017 when firecrackers were thrown from an overlook into forests below. Approximately 20,000 hectares burned on the Oregon side of the Columbia River Gorge. To our knowledge, westside wildfire risk has only been characterized as part of national and regional efforts like the Pacific Northwest Quantitative Risk Assessment or the West Wide Wildfire Risk Assessment, both multi-state wildfire risk assessments (Gilbertson-Day et al., 2018; Sanborn Map Company, 2016). No probabilistic assessments have been conducted specifically for westside forests. Relying on regional risk assessments in Oregon and Washington is uniquely challenging because of the stark contrast between fire frequency on either side of the Cascade crest (Figure 1). Including both sides of the Cascade crest is essential for regional planning, but may unintentionally propagate the challenges of communicating low probability risk and as result contribute to undervaluing of westside risk at a local scale. In Oregon's Coast Range, for instance, homeowners' willingness to implement defensible space was largely correlated with their perception of risk (Hall and Slothower, 2009). 
We argue that probabilistic assessments alone are inadequate for effectively characterizing and communicating wildfire risk in low frequency fire regimes. Probabilistic assessments are often presented and interpreted as frequentist measures of risk representing an objective result that is the consequence of infinite sampling, and not as subjective descriptions of uncertainty about the state of knowledge on the subject (Morgan and Henrion, 1990). The distinction is valuable because the former can lead to misinterpretations and misapplications of risk probabilities. The simulation models used to create probabilistic risk assessments are built on assumptions, data limitations, and communication biases, which may all be accounted for by the researchers running the models, but are not always known by end users interpreting the probabilities and spatial data.

Our aim is to apply Aven and Krohn's (2014) perspective on risk assessments and specifically to demonstrate a method for including surprise analysis alongside probabilistic risk assessments. To do so, we evaluated contemporary and future wildfire occurrence and characteristics in the Clackamas River watershed outside of Portland, OR. In order to develop a method that highlights the value of both surprise and probabilistic assessments, we applied our method using the large fire simulator FSim which has been the foundation of regional and national probabilistic risk assessments (Finney et al., 2011). FSim uses a Monte Carlo approach by simulating thousands of iterations, each a statistically plausible fire season. Evaluating surprising events in low-frequency fire regimes produces large numbers of simulated fire perimeters, which helps to compensate for the lack of empirical fire histories. We present a relatively simple analysis method for 
using FSim outputs to evaluate surprising fires that could be the basis for additional risk characterizations to improve communication around low probability, high consequence events. To assess the impact of climate change we ran FSim under contemporary climate conditions, or baseline scenario, as well as under two distinct climate scenarios for 20402069 referred to as low climate and high climate. The two scenarios capture the range of projected changes in temperature and relative humidity from the Coupled Model Intercomparison Project phase 5 (CMIP 5), where high climate projects the hottest and driest conditions and low climate the least warm and wettest conditions. We defined thresholds of surprise based on unstructured interviews with resource managers in region. We defined surprising events based on their size, location, and the seasonality of the event. For each of the three scenarios we determined how often, where, and when surprising wildfires were projected.

\section{METHODS}

\section{Study Area}

Our study area is the Clackamas River watershed (Clackamas), in Clackamas County, Oregon just east of Portland. The Clackamas is 244,002 ha and runs from the Cascade crest down to the Willamette Valley (Figure 2). The Clackamas provides drinking water to over 300,000 residents and is the second largest surface drinking water source for the Portland region. However, Clackamas County's population is expected to grow by nearly 270,000 individuals in the next fifty years, placing increasing demand on land and water resources (Jurjevich et al., 2017). In addition to being an important source of drinking water, the Clackamas includes important agricultural and timber resources 
and provides popular opportunities for motorized and non-motorized recreation region. The Clackamas is also the site of numerous long-term conservation efforts, including portions of three wilderness areas as well as spotted owl and salmon recovery plans.

Land ownership and management in the Clackamas is heavily segmented (Figure 11). Approximately two-thirds of the watershed is managed for multiple uses by the U.S. Forest Service in the Mt. Hood National Forest (MHNF). Along the western edge of MHNF, the U.S. Bureau of Land Management (BLM) and private industrial timber companies manage mid-elevation forests for commercial value. In the lower watershed tree farms, nurseries, and other agricultural land transitions into rural residential housing, and eventually into urban housing in the Portland metro area.

The Clackamas is dominated by moist, mixed conifer forest types including Douglas-fir (Pseudotsuga menziesii), western hemlock (Tsuga heterophylla) and Pacific silver fir (Abies amibilis) as well as other conifers in smaller extents. Although potential vegetation maps indicate that forests in the region are adapted to infrequent, mixed severity wildfires (Simpson, 2013; Spies et al., 2018), timber management has been the most significant driver of westside forest structure and composition (Haugo et al., 2015). The watershed receives $195 \mathrm{~cm}$ of precipitation a year, but is characterized by dry summers (Graves and Chang, 2007). Still, fuel moisture remains relatively high, even throughout the summer, as a result of snowmelt and periodic storms (Agee, 1993). Historically, westside wildfires have occurred during anomalously dry summers, and have been driven by intraseasonal drought patterns rather than interannual drought (Littell et al., 2016; Stavros et al., 2014a). However, there is some evidence that westside 
wildfire has been regionally synchronous, indicating a role for inter-seasonal and long term drought in governing fire regime characteristics (Weisberg and Swanson, 2003).

Characterizing fire regimes in the Clackamas is complicated, in part because the regional climate patterns previously described are rarely conducive to wildfires and even when they are, lightning ignitions are not common (Gedalof et al., 2005). However, wildfires can be both facilitated and suppressed by humans and so we have to consider the impact of human actions on fire frequency when describing the fire regime. For instance, Spies et al. (2018) uses a map adapted from Thompson and Johnson (1902) showing that at the turn of the $20^{\text {th }}$ century large extents of the Clackamas had been recently burned. Morris $\underline{\text { S }}(1934)$ recounts numerous fires from the early $20^{\text {th }}$ century from the Willamette Valley, west Cascades, and Coast Range, most of which seem to have been caused by human activities. In the Clackamas, there are about 50 recorded wildfire ignitions each year, 75\% of which are human-caused. From 1992 - present there have only been nine wildfires larger than 100 ha. The most recent large wildfire was the 36 Pit fire in 2014 which burned approximately 2,200 ha on MHNF adjacent to BLM and private industrial timber land. In 2011, the Motherlode fire burned approximately 1,100 ha, and in 2010 the Bull of the Woods fire burned about 1,200 ha. 

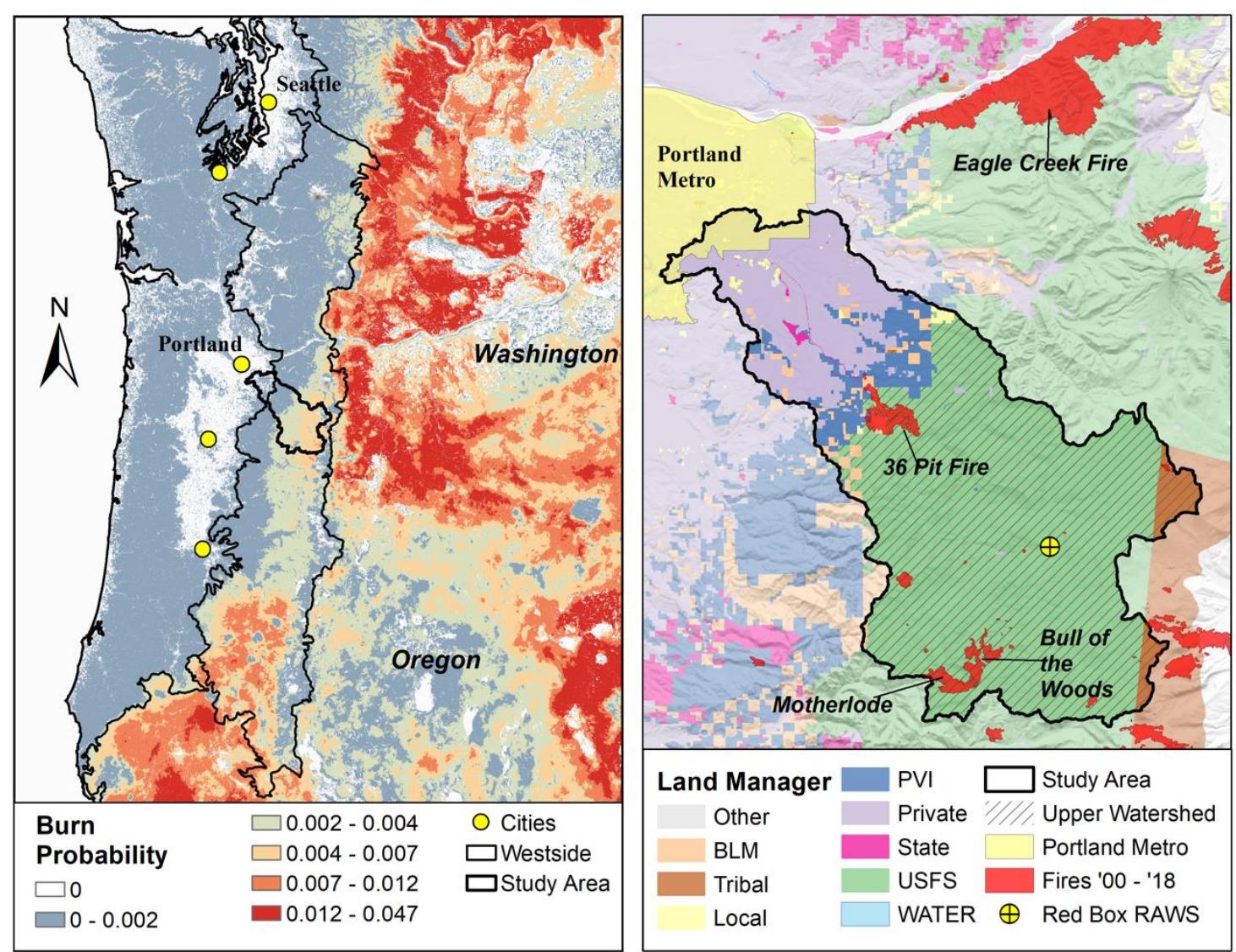

Figure 11. Annual burn probability for Oregon and Washington (left) adapted from the 2018 Pacific Northwest Quantitative Risk Assessment. The Clackamas River watershed (right) land management and notable fires from the 200-2018 National Interagency Fire Center. The largest wildfire in recent history in the Clackamas River watershed (right) was the 36 Pit fire in 2014 which burned just over 2,200 ha on the Mt. Hood National Forest, but adjacent to private land. Also shown is the Eagle Creek fire from 2017 which burned about 20,000 ha in the Columbia River Gorge.

\section{Wildfire Modeling}

We used the large fire simulator, FSim (Finney et al., 2011), to model the effect of climate change on wildfire characteristics and hazard in the Clackamas during 2040 2069 (mid-century) and to compare it to simulated contemporary (baseline) wildfire characteristics and hazard. See Chapter 1 Methods for details. However, rather than model four future scenarios in this chapter, similar to Hulse et al. (2016) we used 
projections from HadGEM-ES365 (high climate) which projected hottest and driest projections of all CMIP5 GCMs, and MIROC5 (low climate) which projected the least warm and wettest (See Chapter 1, Appendix A, Figure 10 for description of CMIP5 GCM selection).
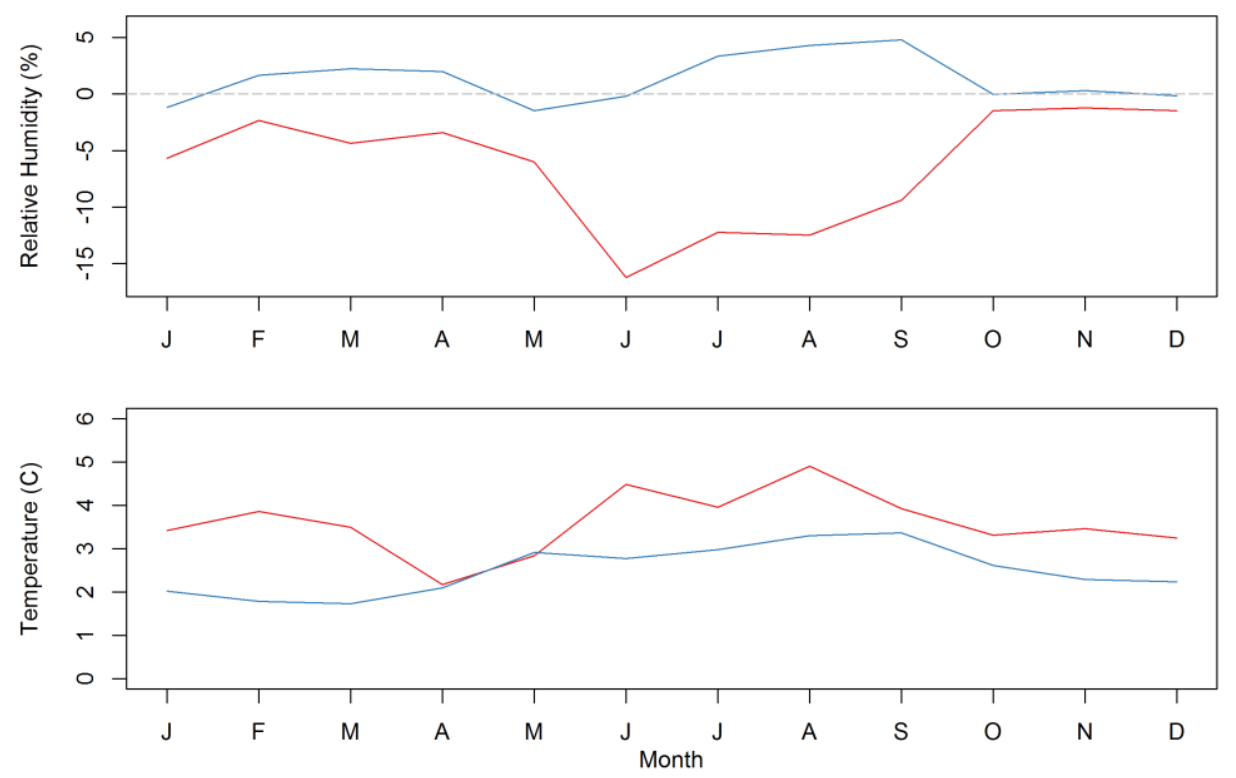

- High Climate - HadGEM | Low Climate - MIROC5

Figure 12. Average monthly temperature and relative humidity departure from historical (1970 - 1999) projected by the two GCMs selected to model future fire weather conditions. These two GCMs represent a full range of projected climate futures and were downscaled over the study area.

\section{Probabilistic Assessment}

For this paper we used annual burn probability rasters to communicate the probabilistic impact of climate change on wildfire occurrence. The burn probability values reflect the number of instances that a pixel was impacted by wildfire during the 10,000 simulated iterations. Within each model scenario, FSim incorporates climate and 
spatial ignition variability so that each simulation iteration is a unique, but statistically plausible fire season. All together, 10,000 iterations should describe a wide range of plausible fire season outcomes, however, average annual burn probability is a very common way to report the most likely or expected annual likelihood of fire occurrence (Parisien et al., 2019).

\section{Surprise Thresholds}

Based on informal, unstructured conversations with resource managers as well as known fire histories, we developed thresholds for surprise based on size, seasonality, or location of wildfire. The first kind surprise identified was an "extremely large" wildfire that occurred anywhere in the watershed. The Eagle Creek fire in 2017 in the Columbia River Gorge just north of the Clackamas River watershed burned a little over 20,000 ha and was by all accounts a surprising event. No event of that magnitude is recorded in the watershed in recent history so we determined that a fire 20,000 ha or greater anywhere in the watershed would be surprising. Second, there was a common conception amongst the managers with whom we interacted that large wildfires are mainly a concern in the upper watershed of the Mt. Hood National Forest, as well as along the Cascade crest on the Confederated Tribes of the Warm Springs Reservation. The most recent event that challenged this conception was the 36 Pit fire in 2014, which burned approximately 2,200 ha near the western edge of the Mt. Hood National Forest adjacent to Bureau of Land Management and private industrial forest land. We determined that a "location surprise" would be any fire greater than 2,200 ha occurring anywhere in the watershed other than on Mt. Hood National Forest or the Warm Springs Reservation. Third, we heard from 
managers a strong belief that large fires are only probable from mid-August to midSeptember because fuels are rarely sufficiently dry before then and fall weather patterns bring rain and higher humidity after that time. In order to define "out-of-season" surprises, we referred to the Fire Program Analysis Fire Occurrence Data which is the most comprehensive dataset of wildfire ignitions from 1992-2015 (Short, 2017). Using that data set we defined the contemporary fire season as the time of year during which fires greater than 100 ha accounted for $90 \%$ of the annual area burned. Based on this definition, the contemporary large fire season is June $23^{\text {rd }}$ to September $22^{\text {nd }}$, and in order to be conservative we defined out-of-season surprise fires as any fire greater than 2,200 ha and which ignited before June $23^{\text {rd }}$ or after September $22^{\text {nd }}$. Surprise fires can fit into more than one category as would be the case for an extremely large fire on private land in the lower watershed.

\section{RESULTS}

\section{Probabilistic Assessment}

The average watershed-wide baseline burn probability is 0.003 , confirming that the likelihood of any location being affected by a wildfire in any given year is exceedingly low (Table 2). However, burn probability is not evenly distributed across the watershed (Figure 12); it is greatest in the higher elevations of the upper watershed and notably lower along river valleys and in the middle watershed. Also, burn probabilities are notably higher in the lower watershed, likely reflecting the concentration of humancaused ignitions around communities.

Under low and high climate scenarios, the watershed-wide average burn probability remained relatively low, but increased substantially compared to baseline, 
0.005 (226\% increase ) and 0.025 (1,663\% increase), respectively. Mid-century increases in burn probability were the result of larger and more frequent fires (Table 2). In the low climate scenario, the spatial distribution of burn probabilities appears approximately similar to baseline distributions, but the probabilities are higher although still less than $1 \%$ in most of the watershed (Figure 13). In contrast, the high climate scenario illustrates a shift to a very different fire environment. In the high climate scenario, the upper watershed is characterized by burn probabilities that are equivalent to contemporary burn probabilities in much higher-frequency fire regimes like central or far southwestern Oregon. Hot and dry conditions in the high climate scenario simulated expansion of high burn probabilities into lower elevations, through the middle of the watershed, and in the lower watershed.

The impact of mid-century fire regime changes is projected to significantly increase the area burned during the thirty-year climate period. Under contemporary climate conditions wildfire is expected to affect the equivalent of less than $10 \%$ of the watershed over the course of thirty years and under low climate conditions the projection increased moderately to $13 \%$ of the watershed. However, under high climate conditions the equivalent of $56 \%$ of the watershed is projected to burn between 2040-2069. This does not mean that more than half of the actual watershed will be burned; rather, because of the stochastic nature of fire, some fires will occur in the same location during the thirtyyear period. Still, given the change in spatial extents of high burn probabilities under high climate scenarios we believe it is reasonable to assume that a larger portion of the watershed will be burned as the climate gets hotter and drier. 


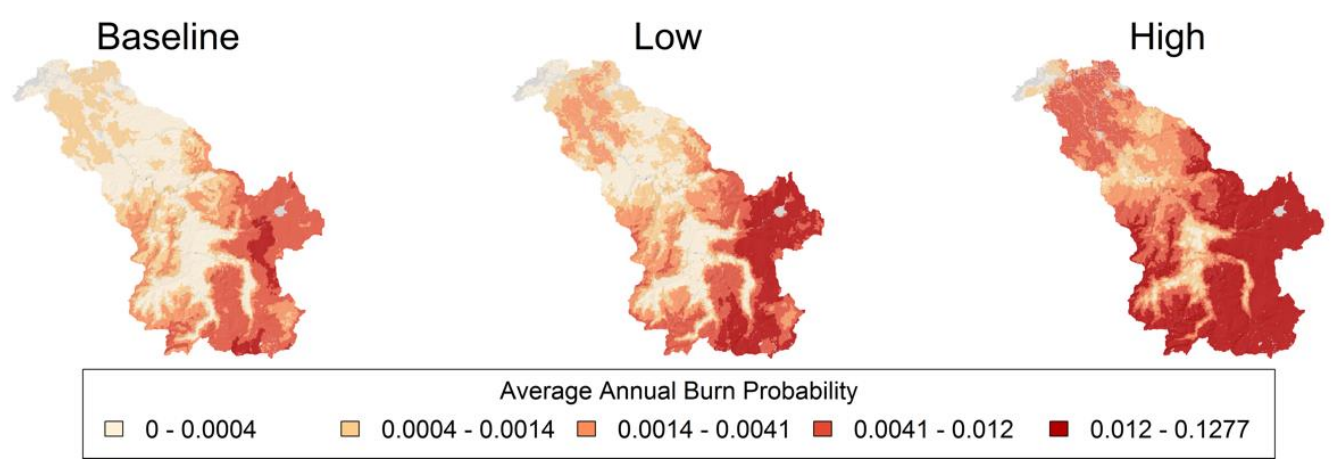

Figure 13. Burn probabilities in the Clackamas River watershed under baseline (left) and two mid-century climate scenarios. Burn probability values are mapped using a quantile method with the percentiles based on the range of burn probabilities from all three scenarios.

\section{Surprising Fires}

Surprising fires became increasingly plausible under mid-century climate

conditions, but the results illustrate a wide range of possible surprise scenarios. Results confirm that under baseline climate conditions all three types of surprise are possible, although they are rare. Surprises in the baseline scenario affected much of the watershed over the 10,000 simulated iterations, but were concentrated in the eastern side of the watershed at relatively high elevations near the Cascade crest (Figure 14). The impact of surprise fires under baseline conditions was disproportionately large compared to their frequency; in total, baseline surprising fires accounted for $33 \%$ of the total area burned by all fires in all iterations. Under low climate conditions there were approximately twice as many simulated surprises (Table 5), but the distribution of surprising fires across the watershed was similar to baseline (Figure 14). In the low climate scenario, surprise fires accounted for $42 \%$ of the total area burned by all fires in all iterations. Results from the high climate scenario illustrate a very different future. Surprise fires are far more plausible on an annual basis and are more plausible across the entire watershed. Despite 
accounting for less than $10 \%$ of all simulated fires, surprising fires in high climate

conditions accounted for $43 \%$ of the area burned by all fires in all iterations.

Table 5. Count of the total number of surprise fires under each scenario and broken down by surprise type. Percentages in parentheses indicate the percent of all simulated fires in each scenario that were characterized as surprises. The total is not the sum of the categories because some fires satisfied multiple definitions of surprise.

\begin{tabular}{|c|c|c|c|c|c|}
\hline & \multicolumn{5}{|c|}{ Seasonality } \\
\hline & $\begin{array}{c}\text { Total } \\
\text { Number of } \\
\text { Surprises }\end{array}$ & $\begin{array}{l}\text { Extremely } \\
\text { Large }\end{array}$ & Location & Early & Late \\
\hline Baseline & $288(2.5 \%)$ & 22 & 19 & 32 & 228 \\
\hline Low & 583 (4.0\%) & 55 & 57 & 123 & 396 \\
\hline High & 2231 (6.4\%) & 493 & 214 & 843 & 826 \\
\hline
\end{tabular}
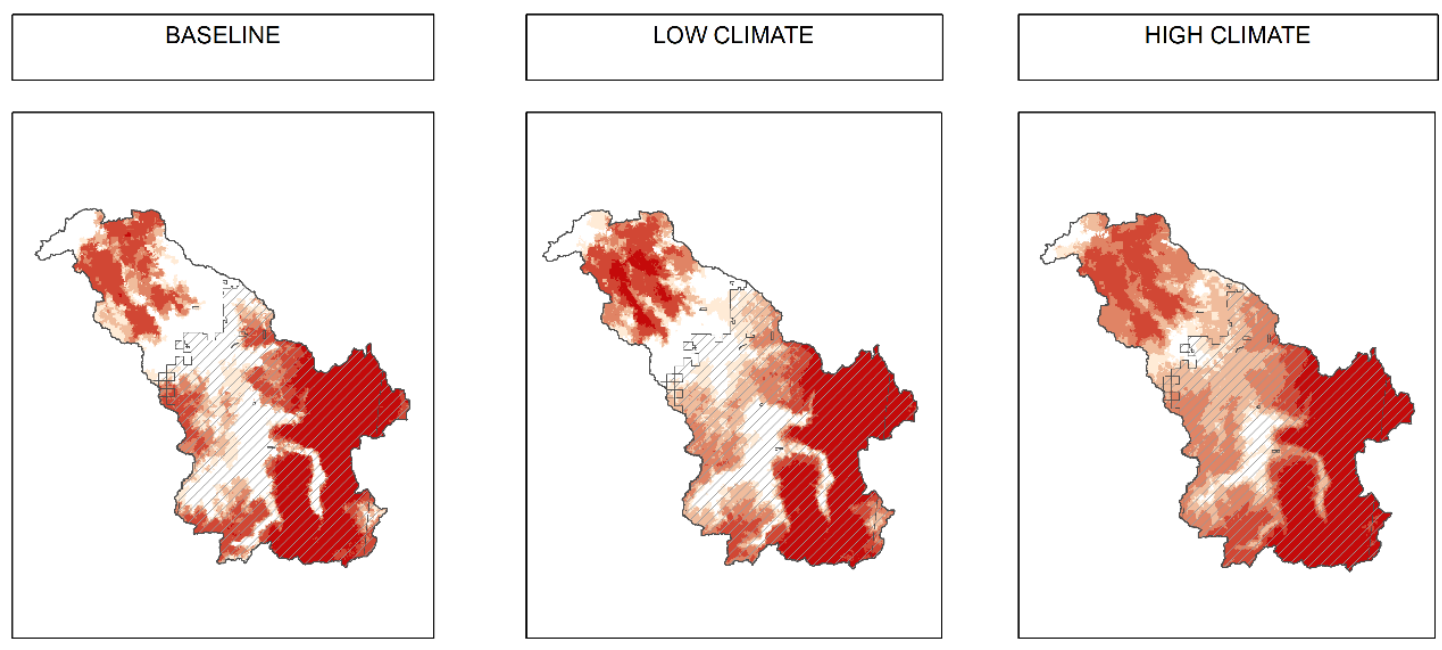

Number of Simulated Surprise Fires

Number of Simulated Surprise Fires

Number of Simulated

$\square 1 \quad 6-10$

$\begin{array}{r}\square-3 \\ \square\end{array} 11-15$

4- 5 Upper Watershed

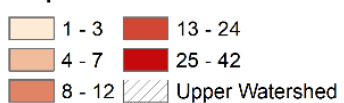

Surprise Fires

$\square 1-2 \square 48-124$

$\square-14$
$\square$

8- 12 U Upper Watershed

$15-47$ Upper Watershed

Figure 14. Count of all simulated surprise fires from 10,000 iterations in each climate scenario.

\section{Out-Of-Season Surprises}

Out-of-season surprises were the most common surprise fires in all three scenarios.

They comprised $85 \%$ of baseline surprises, $81 \%$ of low climate and $68 \%$ of high climate. 
Changes in seasonal climate patterns under the mid-century scenarios resulted in more out-of-season surprises compared to baseline (Table 5). While there were more out-ofseason ignitions under low climate compared to baseline, in both cases out-of-season ignitions were far more common late in the season; $87 \%$ of baseline out-of-season fires and $75 \%$ of low climate ignited after September $22^{\text {nd }}$. This finding is consistent with the contemporary notion that westside fuels require extended periods of drought before they are sufficiently dry to facilitate a large fire, and that the region is most susceptible after a summer of drying. However, high climate simulations project a new paradigm where significantly warmer and drier spring conditions make early out-of-season surprises equally as likely as late out-of-season surprises.

The spatial distribution of out-of-season ignitions is similar across all climate scenarios even though the number of ignitions increases dramatically under high climate (Figure 15). In all scenarios, the upper watershed is more likely to experience an out-ofseason surprise. Under all scenarios some of the out-of-season surprises are a result of ignitions outside the watershed, but under high climate early out-of-season surprises are more frequently the result of ignitions from outside the watershed (Figure 15). Specifically, many of these early out-of-season ignitions occur on the east side of the Cascade crest. A hotter, drier spring, as projected by high climate, apparently leads to more fires ignited on more fire prone eastern slope of the Cascades but spreading west into the Clackamas watershed. 

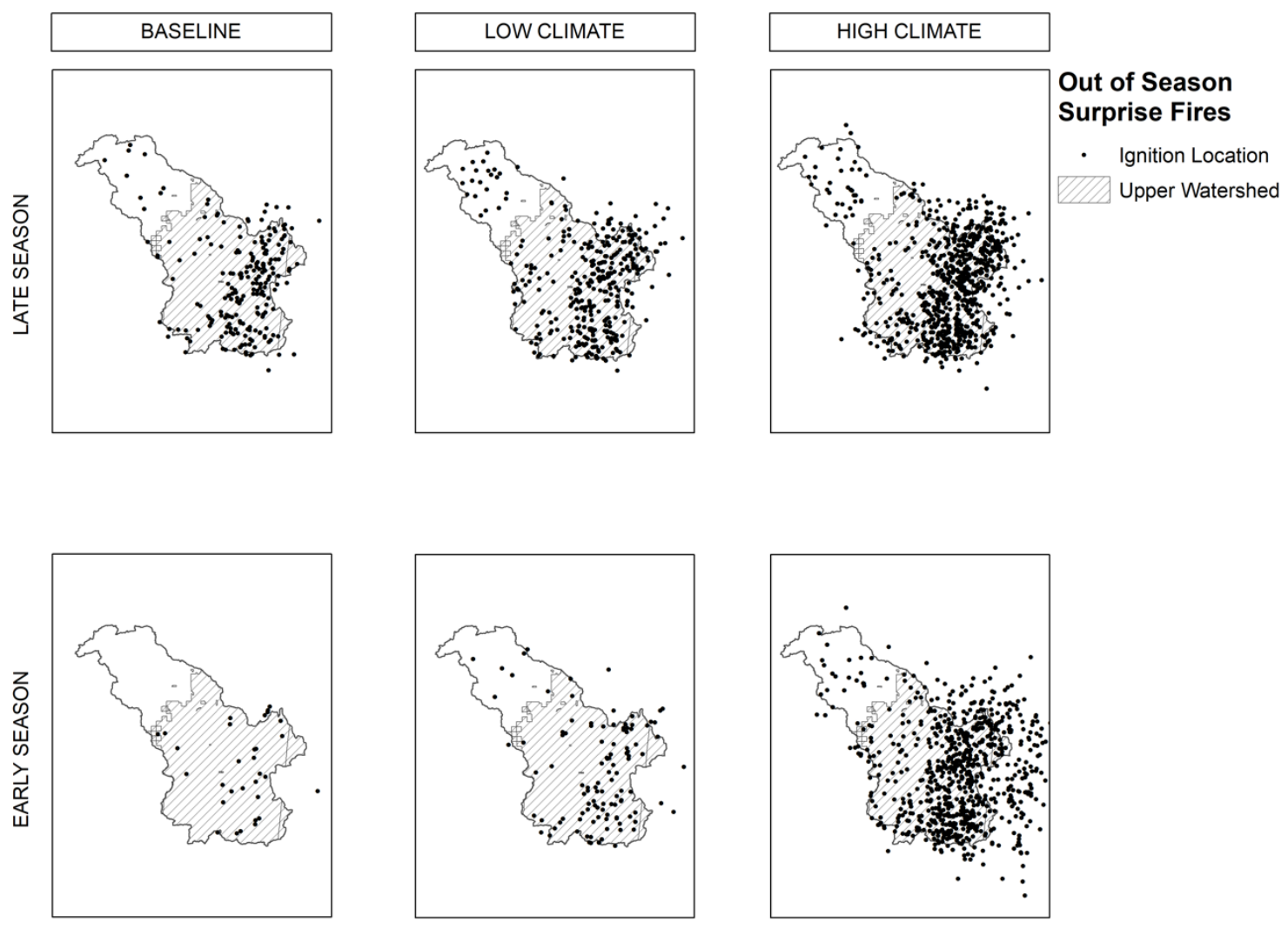

Figure 15. Ignition location of out-of-season surprise fires in each climate scenario with fires igniting after September $22^{\text {nd }}$ on the top row and fires igniting before June $23^{\text {rd }}$ on the bottom row.

Under baseline conditions the average out-of-season surprise fire was 6,328 ha, and although the increase under low climate was not significant (mean =6,710 ha; Wilcox, $\mathrm{p}$-value $=0.21)$, under high climate out-of-season surprises were larger (mean $=$ 7,599 ha; Wilcox, p-value $=0.0008$ ). Under baseline and low climate simulations there were no significant differences between fire size distributions of early- and late out-ofseason surprises (Wilcox, $p$-value $=0.326$ and $p$-value $=0.065$, respectively). Under high climate, late out-of-season fires were significantly larger than early out-of-season 
surprises (Wilcox, p-value $<0.00001$ ).
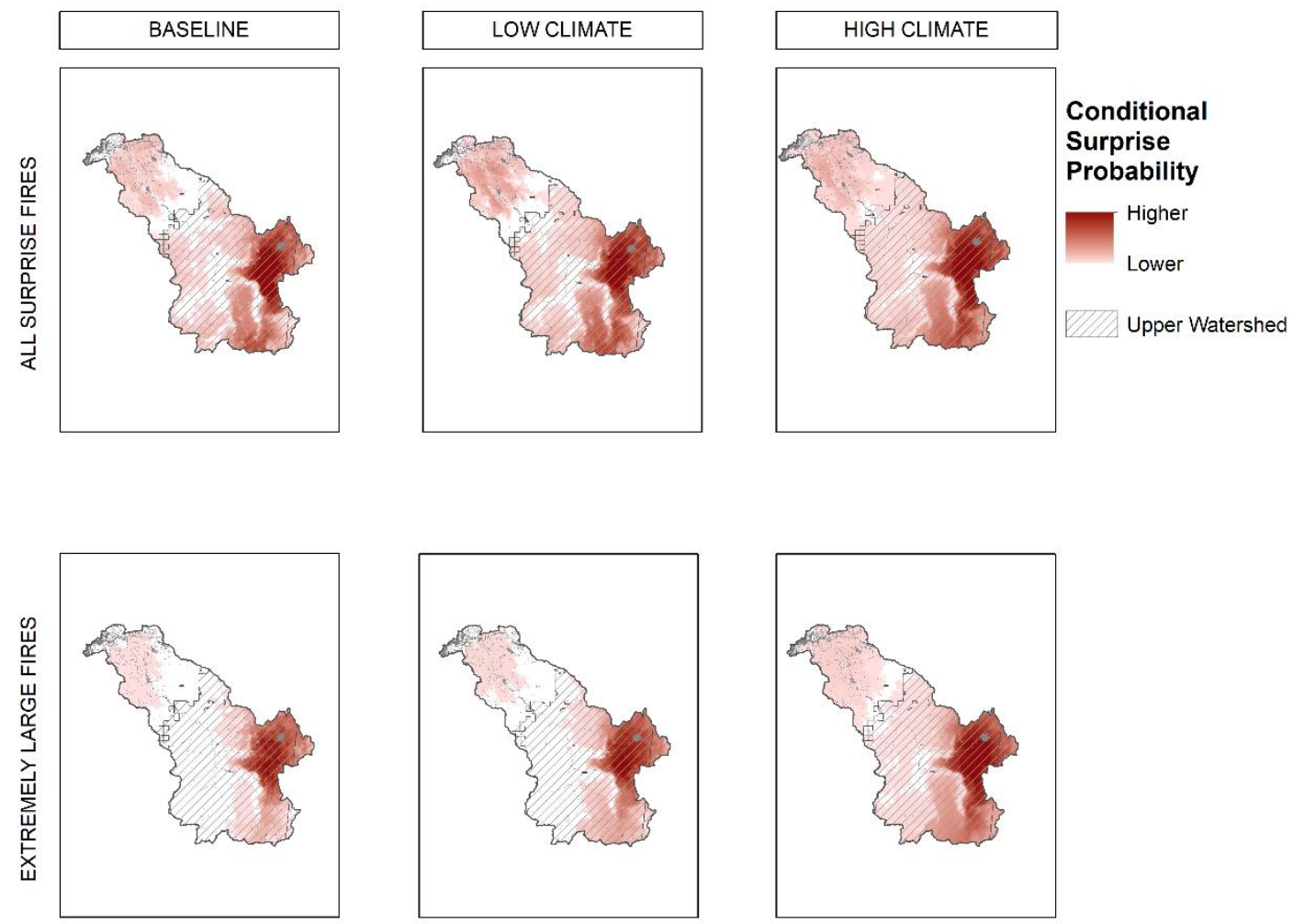

Figure 16. Surprise fire occurrence under all three climate scenarios. Conditional surprise probability is the probability of a surprising fire of any kind (top) or an extremely large fire (bottom) given that a fire does occur. Non-burnable pixels are shown in gray.

Under all scenarios, there were out-of-season surprises that were also extremely large fires. Under baseline there was one extremely large fire simulated before June $23^{\text {rd }}$ and five after September $22^{\text {nd }}$. Under low climate, there were six early out-of-season extremely large fires and sixteen late out-of-season extremely large fires. Under high climate, there were 62 early out-of-season extremely large fires and thirty-seven late outof-season extremely large fires. 


\section{Location Surprises}

Fires greater than 2,200 ha in the lower watershed are increasingly plausible under mid-century climate scenarios (Table 6). Under baseline conditions 93\% of all surprise events were in the upper watershed. Under low and high climate scenarios the percentage of non-upper watershed surprise fires increased to $10 \%$. In all scenarios, location surprises were most common on private non-industrial land which makes up the majority of the lower watershed, but ignitions did occur on state, BLM and private industrial land (Table 6). Land managed by BLM and private industrial timber companies in the middle watershed appears particularly resistant to surprising events in baseline and low climate conditions. This likely reflects both a relative lack of ignitions and reduced fuels. Ignitions are limited because there is little to public access on private industrial timber land, and BLM land receives far less visitation then the adjacent MHNF. Likewise both land managers prioritize commercial timber value which is generally associated with lower fuel levels and wide spacing between trees (Scott and Burgan, 2005).

Table 6. Number of ignitions resulting in a surprise fire under each climate scenario by land manager where ignition occurred.

\begin{tabular}{lccccccc}
\hline \multicolumn{7}{c}{ Land Manager } \\
\hline & USFS & Private & Private Ind. & BLM & State & Federal & Local \\
\hline \hline Baseline & 15 & 16 & 1 & -- & -- & -- & -- \\
Low & 41 & 47 & 3 & 2 & 1 & -- & -- \\
High & 347 & 174 & 15 & 6 & 2 & 6 & 3 \\
\hline
\end{tabular}

The average size of surprise location fires was 4,409 ha under baseline. Under low climate the average size was 5,032 ha but location surprises were not significantly larger compared to baseline (Wilcox test, $\mathrm{p}$-value $=0.15$ ). The average surprise location fire 
under high climate was 5,483 ha, which is borders on significance for a larger average compared to baseline (Wilcox test, $\mathrm{p}$-value $=0.06$ ).

Results demonstrated that extremely large fires are possible in the lower watershed. All scenarios included at least one surprising location that was also greater than 20,000 ha (Figures 16 \& 17). Under baseline, only one extremely large fire occurred in a surprising location $(28,089 \mathrm{ha})$ and under low climate two were simulated (the largest was 27,325 ha). Under high climate, however, twenty extremely large fires were simulated outside the upper watershed, the largest of which was 41,659 ha.

Location surprises under all scenarios were caused primarily by ignitions inside the watershed, but in all scenarios at least three surprising location fires started outside the watershed and spread into the watershed (Figure 17). Mid-century climate conditions are projected to increase the number of ignitions that result in location surprises and to affect an increasing number of non-U.S. Forest Service landowners (Table 6). Under baseline conditions there was no instance of a location surprise that resulted from an ignition in the upper watershed. However, under low and high climate there were increasing instances of ignitions in the upper watershed spreading onto BLM, private industrial, and private land resulting in location surprises. Most often, cross boundary location surprises were not extremely large fires. 

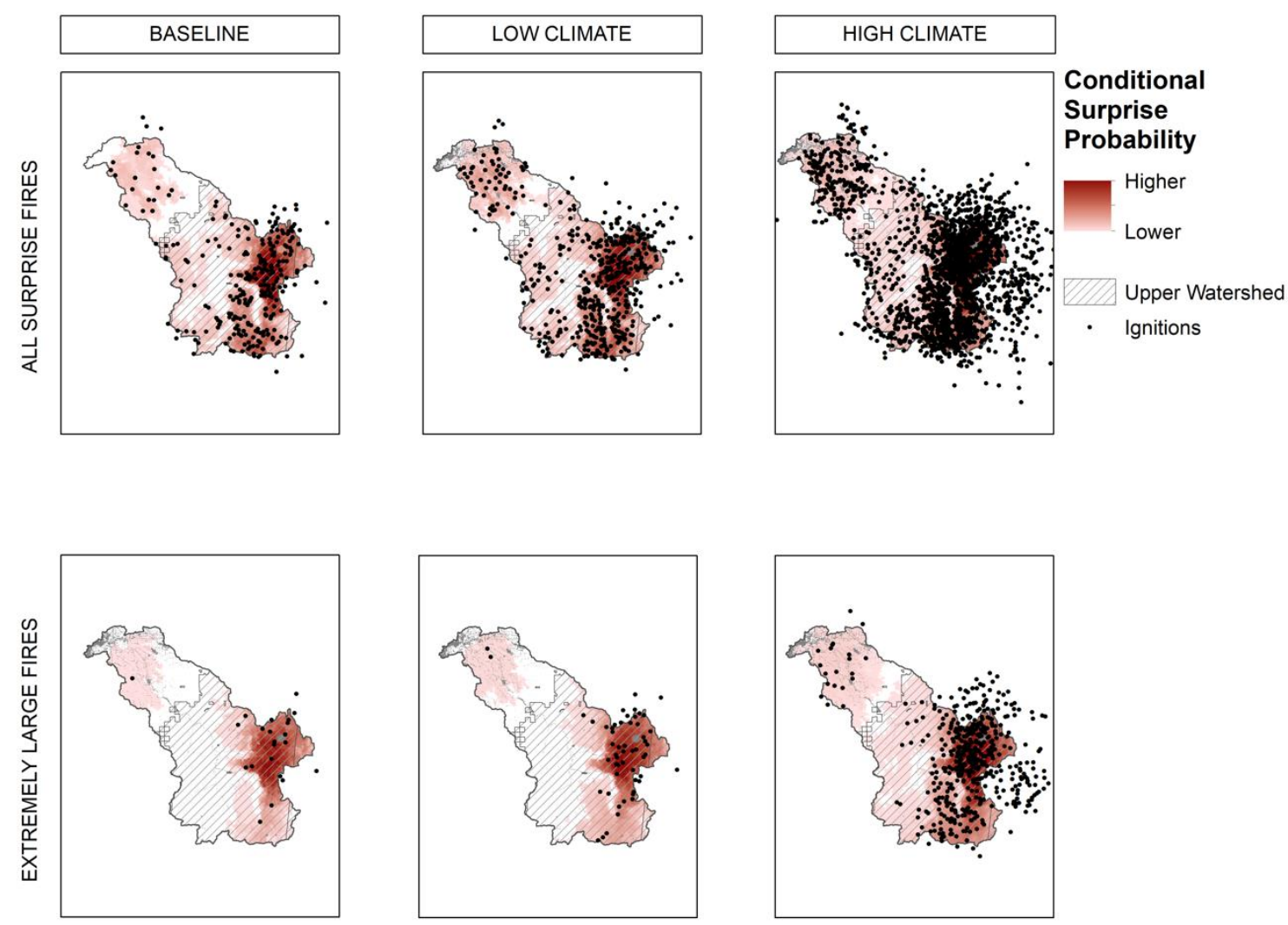

Figure 17. Ignition location of all surprise fires (top) and only fires greater than 20,000 ha (bottom).

Mid-century scenarios indicate a much longer season during which location surprises are plausible (Figure 18). Baseline location surprises occurred later in the fire season, the majority occurring from late August to late September. There was one early season event that occurred on July 2. Figure 15 shows low and high climate location surprises occurring as early as May and as late as November.

\section{Extremely Large Fires}

Extremely large fires were rare events in all scenarios but do appear to become more plausible under mid-century climate conditions (Table 5). Under baseline and low conditions, the annual likelihood of an extremely large wildfire occurring is under $1 \%$, 
but under high climate conditions the annual probability increases by $400 \%$. Extremely large wildfires did not appear temporally clustered. In both baseline and low climate scenarios there was only one iteration in which multiple extremely large fires were simulated. In other words, it is possible for more than one extremely large fire to occur in the watershed in a single fire season, but exceedingly unlikely. Fire seasons with multiple extremely large fires were more common under high climate conditions but there were only twenty-nine (out of 10,000) iterations with more than one extremely large fire.

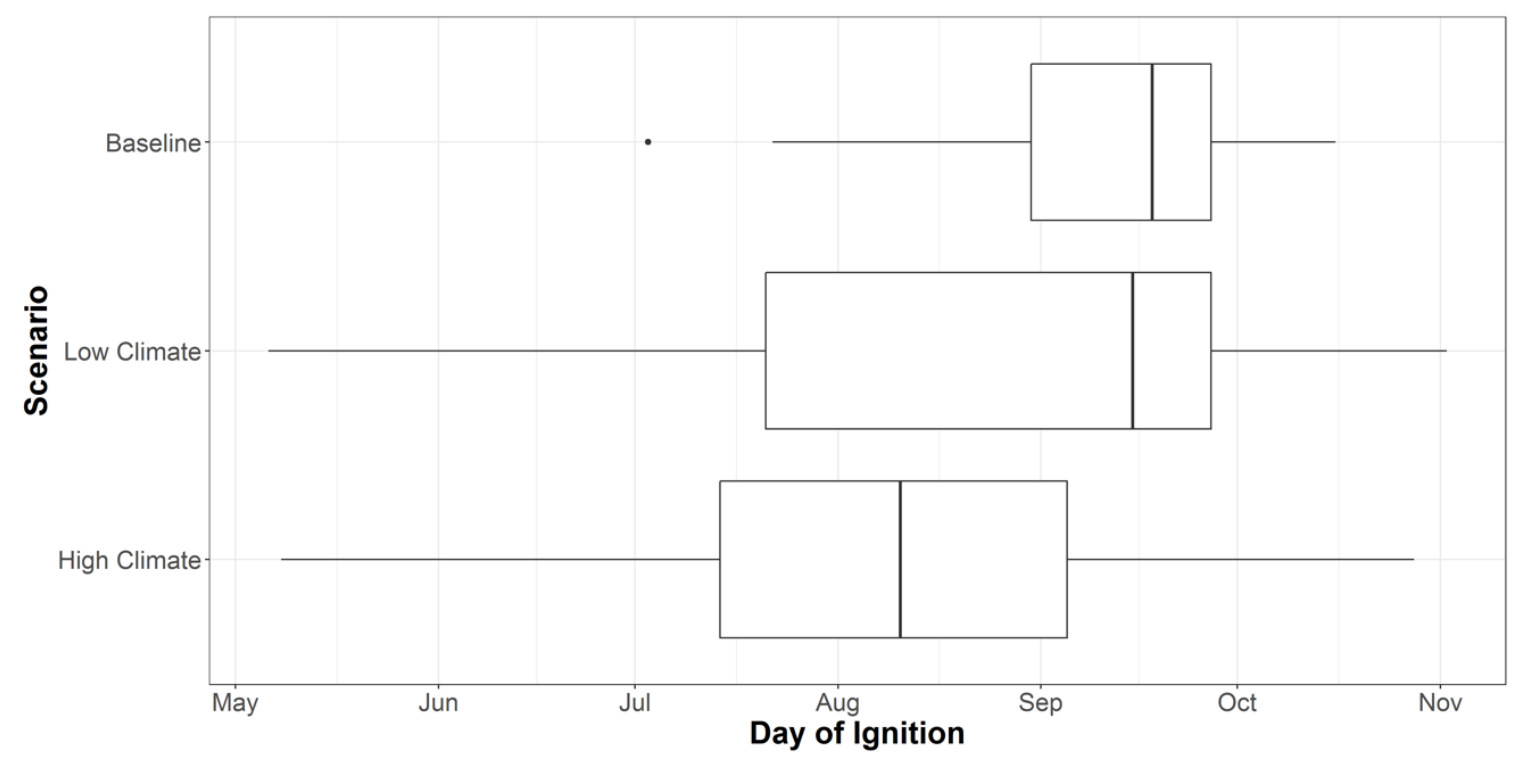

Figure 18. Boxplot of location surprise ignition by day of year.

The occurrence of extremely large fires was similar under baseline and low climate conditions. In those two scenarios extremely large fires accounted for $8 \%-9 \%$ of all surprising fires. The largest simulated fire under baseline conditions was 37,563 ha and, in total, extremely large fires accounted for just $8 \%$ of the total simulated area burned. Under low climate the largest fire was 42,899 ha and extremely large fires 
accounted for $12 \%$ of total simulated area burned. Despite a slightly larger average extreme fire size, the low climate extreme fire size distribution was not significantly different from the baseline scenario (Wilcox, $\mathrm{p}$-value $=0.1667$ ). In both scenarios, the majority of extremely large fire ignitions occurred in the upper watershed in popular recreation areas of the MHNF, but at least one ignition and subsequent extremely large fire was simulated in the lower watershed (Figure 17). Baseline extremely large fires were simulated between late August and mid-September which is in line with observed large fire occurrence in recent history. Low climate extremely large fires were also most common at the end of summer but were simulated as early as July $2^{\text {nd }}$.

Under high climate conditions extremely large fires were more plausible and more widely distributed across the watershed. Extremely large fires accounted for $22 \%$ of all surprising fires. Extremely large fires in high climate conditions appear to be larger than under baseline conditions (Wilcox, $p$-value $=0.06$ ); the largest simulated fire was 68,152 ha. In total, extremely large fires accounted for $22 \%$ of the area burned by all fires in all iterations under high climate conditions. Extremely large fires were more widespread under high climate conditions and impacted nearly all parts of the watershed in contrast to baseline and low climate scenarios (Figure 17). Larger numbers of extremely large fires under high climate appear to be the result of a longer season during which fuels are likely to be combustible. Extremely large fires under high climate were simulated from late April through late October with most fires simulated between early July and mid-August. 


\section{DISCUSSION}

In this study we have demonstrated a novel, replicable method for evaluating surprising wildfires as a complement to traditional probabilistic risk assessments. The inclusion of surprise evaluation is aligned with perspectives on risk assessments that aim to characterize uncertainty in multiple ways so as to facilitate robust decision making (Aven, 2013; Lempert et al., 2006). Our method is unique in two ways. First, it draws on data which is generated from the large fire simulator FSim. We believe that this approach is uniquely reproducible for a wide audience because, while we conducted our own modelling, FSim outputs are frequently available as part of regional and national risk assessments and are used commonly for planning among by a diverse set of agencies and organizations. Second, we relied on expert opinions to define surprising fires. Surprising events are generally defined by two traits: low probability of occurrence, and high consequence. Other studies of surprise wildfire have used only size thresholds to define surprising events because very large fires are unlikely, but also because large fires are assumed to be highly consequential (i.e. Hulse et al., 2016). However, Markley (2011) outlines a typology of surprise that includes probability and consequence, but which also accounts for credibility. For instance, relatively high probability events can still be surprising if the public simply does not trust the information or the agency/entity communicating the risk has low credibility. Our conversations with county officials and resource managers in the Clackamas indicated that large wildfires in the lower watershed have low credibility, and thus their occurrence would be a surprise. By including definitions of surprise based on attributes other than just size we illustrated that surprising fires are plausible under contemporary climate conditions and are increasingly likely 
under mid-century climate scenarios. Furthermore, our results illustrate that meaningfully expanding the definition of surprise helped to counterbalance the notion that only the upper watershed is affected by significant wildfire. Evaluating surprise fire potential provides managers with communication tools to complement probabilistic assessments. Evaluating surprising fires provided a spatially explicit illustration of plausible events that would be disruptive and would likely change existing conceptions about when and where wildfire risk exists and what resources are exposed to the consequences. Similar to recent events like the Eagle Creek fire, each one of the simulated fires represents a potential focusing event and an opportunity for social and ecological adaptation. Ecological surprises frequently lead to discoveries and rapid increases in knowledge about the system (Lindenmayer et al., 2010). Characterizing surprise fires addresses what Faber et al. (1992) called "reducible ignorance." In the case of the Clackamas, reducible ignorance is largely the result of scant experience with significant events from which to extrapolate the nature and plausibility of future disruptive events. Indeed, even in higher frequency fire regimes the past is not always the best indication of what is plausible in the future. For instance, Riley and Loehman (2016a) demonstrated that fire frequency is projected to increase significantly in the northern Rockies as a result of interactions between climate change and forest structure and composition. The Monte Carlo approach we used helps to address both a lack of precedent and a failure to conceive of plausible alternative surprises by generating a large dataset of equally plausible fire season scenarios. Furthermore, surprise analysis facilitates a 
communication of risk that avoids the challenges associated with communicating low probabilities.

It is not clear how homeowners, community leaders, or natural resource managers might react to our characterization of low probability, high consequence surprises. The threat of hard-to-predict, involuntary, catastrophic hazards can result in dread risk which, in the case of wildfire, could lead to public support for additional regulation of risky activities and support for changes in land management (Slovic, 1987). However, Hertwig et al. (2004) found that in the absence of personal experience individuals facing the threat of rare events will frequently overvalue the rare event in what are called "decisions by description," while in contrast, individuals who have experienced rare, damaging events often undervalue the impact of future rare events in what are called "decisions of experience." Hall and Slothower (2009) demonstrated decisions of experience at play in the Oregon Coast Range where individuals who had experienced a fire were less likely to invest in defensible space compared to individuals who had not experienced a fire. Individuals who had experienced a wildfire appeared to believe that the probability of a second rare event was so small that it dd not warrant risk mitigation. Nonetheless, past social and ecological surprises have led to enormous changes in risk management (Kates and Clark, 1996). What is unclear is how modeled characterizations of plausible surprises will or will not translate to investment in risk reduction activities.

Both the probabilistic and surprise assessments illustrate a wildfire future in the Clackamas that is deeply uncertain and speak to the value of robust planning. Robust planning acknowledges uncertainty in future conditions and rather than try to optimize a 
solution based on a probabilistic assessment, instead aims to develop strategies that will facilitate adaptation across the range of plausible futures (Lempert et al., 2006). Our study lays the foundation for future robust decision-making processes by more fully characterizing the nature of contemporary risk exposure and describing a range of possible futures. Decision-makers can use this information to formulate short term strategies to mitigate risk and maximize benefits from potentially surprising events (Lindenmayer et al., 2010). Surprising wildfires, especially extremely large fires and fires that occur unexpectedly close to human communities, can potentially lead to catastrophic negative consequences. For instance, Halofsky et al. (2018) argue that in forests with stand-replacing fire regimes, like the Clackamas and much of western Oregon and Washington, negative impact of inevitable surprising fires on ecosystem services is cause for continued strategic but aggressive suppression policies that reduce the likelihood of a large, damaging fire. In contrast, Barnett et al. (2016) and Thompson et al. (2016) both present methods for potentially benefitting from surprising fires. Depending on the location of the surprise event and the weather conditions under which it occurs, surprise fires may be managed and help advance social and ecological adaptation to new climate conditions.

While adapting Monte Carlo simulation outputs for surprise analysis has obvious merits, there are also some challenges which deserve recognition. In the Clackamas River watershed, climate change is going to increase potential for surprises and change the nature of surprising events. The two climate scenarios are expected to account for the range of possible changes in wildfire frequency and characteristics and, in fact, the results 
illustrate two very different projected futures. Under high climate conditions, surprising fires as defined here, became an order of magnitude more common, at which point it is worth asking, how valuable today's definition of surprise will be by mid-century. It may be a limitation in this study that we used the same definition of surprise for contemporary and mid-century scenarios, when it is possible for definitions of surprise to change after the occurrence of a surprise. For example, the 2019-2020 fire season in Australia exhibited a previously unthinkable level of synchronicity as more than 79,000 square miles burned across a wide swath of the country, replacing the Black Saturday fires as the new standard of a disastrous surprise. However, most of the Clackamas River watershed is a very low frequency fire regime where it is plausible that it will be more than twenty years before the next surprising wildfire, at which point the region would be experiencing mid-century climate conditions but perhaps still operating with the same expectations of surprise. Nonetheless, this study did not attempt to account for future mid-century changes in social values and expectations which are important in complete evaluations of surprise (Lempert et al., 2002). Additionally, our modeling approach did not account for potential changes in mid-century vegetation which could either facilitate surprising events or inhibit them. In this respect, agent-based models, compared to Monte Carlo approaches like FSim, may be useful for studies of surprise and adaptation to surprise over time (i.e. Hulse et al., 2016).

In this study we addressed surprises that result from a relatively narrow range of reducible ignorance, primarily by focusing on how climate change could alter a previously stable fire regime. Using the typology presented in Ascough et al. (2008) as 
well as Thompson and Calkin (2011), our analysis primarily addresses knowledge uncertainty by providing plausible descriptions of how climate change is projected to increase the potential for surprising wildfires. Our analysis provides a foundation on which future work with managers and stakeholders can then begin to reduce decision uncertainty by comparing the results of risk mitigation strategies and to our analysis. However, Kates and Clark (1996) noted that in addition to arising from discontinuities in long term trends, ecological surprises are often the product of additive, convergent events. As of now, our results should not be interpreted as worst-case-scenarios because they do not address the confluence of multiple events such as wildfires coinciding with a volcanic eruption, or a catastrophic wildfire season coinciding with a global pandemic although both are plausible, foreseeable scenarios. Of course, surprises are also symptomatic of irreducible ignorance, which we also did not attempt to address in this study. In that sense, our method does not address black swans or other fundamentally unpredictable events which have the potential to challenge perceptions of reality (Taleb, 2010). There are different points of view about the value of and methods for trying to imagine the unimaginable (Lindaas and Pettersen, 2016). Aven and Krohn (2014) and Lindaas and Pettersen (2016) present different, but similar imaginative processes for trying to "de-blacken" black swan events that they believe lead to resilient solutions and reduced uncertainty. Future risk assessments which combine probabilistic and surprise analyses would benefit from structured engagement with stakeholders to develop plausible worst-case-scenarios which could be incorporated into the modelling or analysis process. 
This paper demonstrates how modeling methods ordinarily utilized to produce probabilistic wildfire risk assessments can also be used to evaluate the frequency and characteristics of wildfires which, today, seem improbable. The definition and evaluation of surprise fires does not replace or detract from probabilistic assessments but should be used in conjunction with evaluations of probabilistic risk. This demonstration of a method for characterizing risk posed by surprising wildfires may be especially useful for non-wildfire professionals who nonetheless are in a position where they need to make decisions informed by an understanding wildfire risk, for instance planners and municipal officials, and those who generally rely on regional probabilistic risk assessments. Quantification and qualitative descriptions of plausible surprise events may help direct wildfire risk mitigation resources towards westside, low-frequency fire regimes where they are needed to develop robust strategies in the face of climate change.

We expect that by defining surprise events based on recent, local fires individuals interpreting this information in the Clackamas will be more adept at including wildfire risk into planning decisions. Referring to actual, observed events will likely help overcome the challenges that representativeness poses in the evaluation of low probabilities (Kahneman and Tversky, 1972). Including surprise analysis in a risk assessment allows assessors to narratively communicate risk and support the narratives with quantifiable, modeled support, a strategy which has been embraced in diverse risk fields (Knoblauch et al., 2018). Our analysis of surprise fires in the Clackamas can serve as the motivation for and foundation of continued risk assessment that seeks to better assess the impact of surprise fires using effects analysis methods described in Thompson 
et al. (2016). Additionally, future work should focus on evaluating the efficacy of modeled surprise events in motivating risk mitigation decisions.

\section{CONCLUSION}

This study was motivated by the growing field of wildfire risk management and the proliferation of probabilistic risk assessments. Risk assessments are incredibly useful tools for identifying wildfire threat and susceptibility as well as for evaluating risk mitigation strategies. Regional and national assessments play an important role in directing resources to enable risk reduction. However, probabilistic risk assessments may not fully characterize sources of uncertainty, especially in the case of low probability, high consequence events.

Our analysis of surprising wildfires presented a novel risk assessment method that helps to identify and characterize low probability, high consequence events in a landscape where large fires are very infrequent. Moreover, our approach was to model future climate scenarios in order to determine how climate change may alter the plausibility of future surprises. The results illustrated a wide range of possible future conditions, all of which are projected to increase the plausibility of consequential, surprising wildfires. The results confirm other similar projections of climate changeinduced changes in fire regimes and illustrate the need for adaptive planning. However, our results also illustrate that future conditions are uncertain and that under one plausible future climate scenario, risk mitigation to prevent surprises may be at odds with strategies that would promote climate adaptation. The range of plausible scenarios and uncertainty 
in future fire regimes supports robust planning methods and the eventual implementation

of risk mitigation strategies that will be resilient under a wide range of conditions.

\section{REFERENCES}

Abatzoglou, J.T., Williams, A.P., 2016. Impact of anthropogenic climate change on wildfire across western US forests. Proc Natl Acad Sci USA 113, 11770-11775. https://doi.org/10.1073/pnas.1607171113

Agee, J.K., 1993. Fire Ecology of Pacific Northwest Forests. Island Press, Washington, D.C.

Archibald, S., Lehmann, C.E.R., Gomez-Dans, J.L., Bradstock, R.A., 2013. Defining pyromes and global syndromes of fire regimes. Proceedings of the National Academy of Sciences 110, 6442-6447. https://doi.org/10.1073/pnas.1211466110

Ascough, J.C., Maier, H.R., Ravalico, J.K., Strudley, M.W., 2008. Future research challenges for incorporation of uncertainty in environmental and ecological decision-making. Ecological Modelling 219, 383-399. https://doi.org/10.1016/j.ecolmodel.2008.07.015

Aven, T., 2013. Practical implications of the new risk perspectives. Reliability Engineering \& System Safety 115, 136-145. https://doi.org/10.1016/j.ress.2013.02.020

Aven, T., Krohn, B.S., 2014. A new perspective on how to understand, assess and manage risk and the unforeseen. Reliability Engineering \& System Safety 121, 110. https://doi.org/10.1016/j.ress.2013.07.005

Bakker, J.D., Jones, E., Sprenger, C.B., 2019. Evidence of a historical frequent, lowseverity fire regime in western Washington, USA. Can. J. For. Res. 49, 575-585. https://doi.org/10.1139/cjfr-2018-0354

Barnett, K., Miller, C., Venn, T.J., 2016. Using Risk Analysis to Reveal Opportunities for the Management of Unplanned Ignitions in Wilderness. Journal of Forestry 114, 610-618. https://doi.org/10.5849/jof.15-111

Barros, A.M., Ager, A.A., Day, M.A., Palaiologou, P., 2019. Improving long-term fuel treatment effectiveness in the National Forest System through quantitative prioritization. Forest Ecology and Management 433, 514-527. https://doi.org/10.1016/j.foreco.2018.10.041

Bowman, D.M.J.S., Williamson, G.J., Abatzoglou, J.T., Kolden, C.A., Cochrane, M.A., Smith, A.M.S., 2017. Human exposure and sensitivity to globally extreme wildfire events. Nat Ecol Evol 1, 0058. https://doi.org/10.1038/s41559-016-0058

Faber, M., Manstetten, R., Proops, J.L.R., 1992. Humankind and the Environment: An Anatomy of Surprise and Ignorance. environ values 1, 217-241. https://doi.org/10.3197/096327192776680089

Fairbrother, A., Turnley, J.G., 2005. Predicting risks of uncharacteristic wildfires: Application of the risk assessment process. Forest Ecology and Management 211, 28-35. https://doi.org/10.1016/j.foreco.2005.01.026 
Finney, M.A., 2005. The challenge of quantitative risk analysis for wildland fire. Forest Ecology and Management 211, 97-108. https://doi.org/10.1016/j.foreco.2005.02.010

Finney, M.A., McHugh, C.W., Grenfell, I.C., Riley, K.L., Short, K.C., 2011. A simulation of probabilistic wildfire risk components for the continental United States. Stoch Environ Res Risk Assess 25, 973-1000. https://doi.org/10.1007/s00477-011-0462-z

Gedalof, Z., Peterson, D.L., Mantua, N.J., 2005. Atmospheric, Climatic, And Ecological Controls on Extreme Wildfire Years in the Northwestern United States. Ecological Applications 15, 154-174. https://doi.org/10.1890/03-5116

Gilbertson-Day, J., Stratton, R.D., Scott, J.H., Vogler, K.C., Brough, A., 2018. Pacific Northwest Quantitative Wildfire Risk Assessment: Methods and Results.

Graves, D., Chang, H., 2007. Hydrologic impacts of climate change in the Upper Clackamas River Basin, Oregon, USA. Clim. Res. 33, 143-157. https://doi.org/10.3354/cr033143

Hall, T.E., Slothower, M., 2009. Cognitive Factors Affecting Homeowners' Reactions to Defensible Space in the Oregon Coast Range. Society \& Natural Resources 22, 95-110. https://doi.org/10.1080/08941920802392187

Halofsky, J.S., Donato, D.C., Franklin, J.F., Halofsky, J.E., Peterson, D.L., Harvey, B.J., 2018. The nature of the beast: examining climate adaptation options in forests with stand-replacing fire regimes. Ecosphere 9, e02140. https://doi.org/10.1002/ecs2.2140

Haugo, R., Zanger, C., DeMeo, T., Ringo, C., Shlisky, A., Blankenship, K., Simpson, M., Mellen-McLean, K., Kertis, J., Stern, M., 2015. A new approach to evaluate forest structure restoration needs across Oregon and Washington, USA. Forest Ecology and Management 335, 37-50. https://doi.org/10.1016/j.foreco.2014.09.014

Hertwig, R., Barron, G., Weber, E.U., Erev, I., 2004. Decisions from Experience and the Effect of Rare Events in Risky Choice. Psychol Sci 15, 534-539. https://doi.org/10.1111/j.0956-7976.2004.00715.x

Hulse, D., Branscomb, A., Enright, C., Johnson, B., Evers, C., Bolte, J., Ager, A., 2016. Anticipating surprise: Using agent-based alternative futures simulation modeling to identify and map surprising fires in the Willamette Valley, Oregon USA. Landscape and Urban Planning 156, 26-43. https://doi.org/10.1016/j.landurbplan.2016.05.012

Jurjevich, J., Proehl, R., Chun, N., Rancik, K., Harada, M., Loftus, D., Morris, R., Rynerson, C., 2017. Coordinated Population Forecast for Clackamas County, its Urban Growth Boundaries (UGB) and Area Outside UGB. Population Research Center, Portland State University, Portland, OR.

Kahneman, D., Tversky, A., 1979. Prospect Theory: An Analysis of Decision under Risk. Econometrica 47, 263. https://doi.org/10.2307/1914185

Kahneman, D., Tversky, A., 1972. Subjective probability: A judgment of representativeness. Cognitive Psychology 3, 430-454. https://doi.org/10.1016/0010-0285(72)90016-3 
Kates, R.W., Clark, W.C., 1996. Environmental Surprise: Expecting the Unexpected? Environment: Science and Policy for Sustainable Development 38, 6-34. https://doi.org/10.1080/00139157.1996.9933458

Knoblauch, T.A.K., Stauffacher, M., Trutnevyte, E., 2018. Communicating LowProbability High-Consequence Risk, Uncertainty and Expert Confidence: Induced Seismicity of Deep Geothermal Energy and Shale Gas: Communicating LPHC Risk, Uncertainty and Expert Confidence. Risk Analysis 38, 694-709. https://doi.org/10.1111/risa.12872

Krawchuk, M.A., Moritz, M.A., Parisien, M.-A., Van Dorn, J., Hayhoe, K., 2009. Global Pyrogeography: the Current and Future Distribution of Wildfire. PLoS ONE 4, e5102. https://doi.org/10.1371/journal.pone.0005102

Kunreuther, H., Novemsky, N., Kahneman, D., 2001. Making Low Probabilities Useful. Journal of Risk and Uncertainty 23, 103-120. https://doi.org/10.1023/A:1011111601406

Lempert, R., Popper, S., Bankes, S., 2002. Confronting Surprise. Social Science Computer Review 20, 420-440. https://doi.org/10.1177/089443902237320

Lempert, R.J., Groves, D.G., Popper, S.W., Bankes, S.C., 2006. A General, Analytic Method for Generating Robust Strategies and Narrative Scenarios. Management Science 52, 514-528. https://doi.org/10.1287/mnsc.1050.0472

Lindaas, O.A., Pettersen, K.A., 2016. Risk analysis and Black Swans: two strategies for de-blackening. Journal of Risk Research 19, 1231-1245. https://doi.org/10.1080/13669877.2016.1153499

Lindenmayer, D.B., Likens, G.E., Krebs, C.J., Hobbs, R.J., 2010. Improved probability of detection of ecological "surprises." Proceedings of the National Academy of Sciences 107, 21957-21962. https://doi.org/10.1073/pnas.1015696107

Littell, J.S., Peterson, D.L., Riley, K.L., Liu, Y., Luce, C.H., 2016. A review of the relationships between drought and forest fire in the United States. Glob Change Biol 22, 2353-2369. https://doi.org/10.1111/gcb.13275

Markley, O., 2011. A new methodology for anticipating STEEP surprises. Technological Forecasting and Social Change 78, 1079-1097. https://doi.org/10.1016/j.techfore.2011.01.008

McKenzie, D., Littell, J.S., 2017. Climate change and the eco-hydrology of fire: Will area burned increase in a warming western USA? Ecological Applications 27, 26-36. https://doi.org/10.1002/eap.1420

Meldrum, J.R., Champ, P.A., Brenkert-Smith, H., Warziniack, T., Barth, C.M., Falk, L.C., 2015. Understanding Gaps Between the Risk Perceptions of WildlandUrban Interface (WUI) Residents and Wildfire Professionals: WUI Residents and Wildfire Professionals. Risk Analysis 35, 1746-1761. https://doi.org/10.1111/risa.12370

Morgan, M.G., Henrion, M., 1990. The nature of uncertainty, in: Uncertainty: A Guide to Dealing with Uncertainty in Quantitative Risk and Policy Analysis. Cambridge University Press, pp. 47-72.

Morris, W.G., 1934. Forest Fires in Western Oregon and Western Washington. Oregon Historical Quarterly 35, 313-339. 
Parisien, M.-A., Dawe, D.A., Miller, C., Stockdale, C.A., Armitage, O.B., 2019. Applications of simulation-based burn probability modelling: a review. Int. J. Wildland Fire 28, 913. https://doi.org/10.1071/WF19069

Probabilistic Wildfire Risk, 2020.

Riley, K., Thompson, M., Scott, J., Gilbertson-Day, J., 2018. A Model-Based Framework to Evaluate Alternative Wildfire Suppression Strategies. Resources 7, 4. https://doi.org/10.3390/resources7010004

Riley, K.L., Loehman, R.A., 2016. Mid-21st-century climate changes increase predicted fire occurrence and fire season length, Northern Rocky Mountains, United States. Ecosphere 7, e01543. https://doi.org/10.1002/ecs2.1543

Sachs, M.K., Yoder, M.R., Turcotte, D.L., Rundle, J.B., Malamud, B.D., 2012. Black swans, power laws, and dragon-kings: Earthquakes, volcanic eruptions, landslides, wildfires, floods, and SOC models. Eur. Phys. J. Spec. Top. 205, 167182. https://doi.org/10.1140/epjst/e2012-01569-3

Sanborn Map Company, 2016. West Wide Wildfire Risk Assessment: Final Report. Oregon Dept. of Forestry.

Scott, J.H., Burgan, R.E., 2005. Standard fire behavior fuel models: a comprehensive set for use with Rothermel's surface fire spread model (No. RMRS-GTR-153). U.S. Department of Agriculture, Forest Service, Rocky Mountain Research Station, Ft. Collins, CO. https://doi.org/10.2737/RMRS-GTR-153

Scott, J.H., Thompson, M.P., Calkin, D.E., 2013. A wildfire risk assessment framework for land and resource management (No. RMRS-GTR-315). U.S. Department of Agriculture, Forest Service, Rocky Mountain Research Station, Ft. Collins, CO. https://doi.org/10.2737/RMRS-GTR-315

Short, K.C., 2017. Spatial wildfire occurrence data for the United States, 1992-2015 [FPA_FOD_20170508] (4th Edition). https://doi.org/10.2737/RDS-2013-0009.4

Simpson, M., 2013. Forest Vegetation Zone Map.

Slovic, P., 1987. Perception of risk. Science 236, 280-285. https://doi.org/10.1126/science.3563507

Slovic, P., Kunreuther, H., White, G., 1974. Decision processes, rationality and adjustment to natural hazards, in: Natural Hazards: Local, National, Global. Oxford University Press, New York, pp. 187-205.

Spies, T.A., Stine, P.A., Gravenmier, R., Long, J.W., Reilly, M.J., Technical Coordinators, 2018. Synthesis of Science to Inform Land Management Within the Northwest Forest Plan Area (General Technical Report No. PNW-GTR-966 Vol. 1). U.S. Department of Agriculture, Forest Service, Pacific Northwest Research Station.

Stavros, E.N., Abatzoglou, J., Larkin, N.K., McKenzie, D., Steel, E.A., 2014. Climate and very large wildland fires in the contiguous western USA. Int. J. Wildland Fire 23, 899. https://doi.org/10.1071/WF13169

Taleb, N.N., 2010. Black Swan: The Impact of the Highly Improbable, Second. ed. Random House Trade Paperbacks, New York. 
Tepley, A.J., Swanson, F.J., Spies, T.A., 2013. Fire-mediated pathways of stand development in Douglas-fir/western hemlock forests of the Pacific Northwest, USA. Ecology 94, 1729-1743. https://doi.org/10.1890/12-1506.1

Thompson, M., Bowden, P., Brough, A., Scott, J., Gilbertson-Day, J., Taylor, A., Anderson, J., Haas, J., 2016. Application of Wildfire Risk Assessment Results to Wildfire Response Planning in the Southern Sierra Nevada, California, USA. Forests 7, 64. https://doi.org/10.3390/f7030064

Thompson, M.P., Calkin, D.E., 2011. Uncertainty and risk in wildland fire management: A review. Journal of Environmental Management 92, 1895-1909. https://doi.org/10.1016/j.jenvman.2011.03.015

Thompson, M.P., Gilbertson-Day, J.W., Scott, J.H., 2016. Integrating Pixel- and Polygon-Based Approaches to Wildfire Risk Assessment: Application to a HighValue Watershed on the Pike and San Isabel National Forests, Colorado, USA. Environ Model Assess 21, 1-15. https://doi.org/10.1007/s10666-015-9469-z

Weisberg, P.J., Swanson, F.J., 2003. Regional synchroneity in fire regimes of western Oregon and Washington, USA. Forest Ecology and Management 172, 17-28. https://doi.org/10.1016/S0378-1127(01)00805-2

Westerling, A.L., 2006. Warming and Earlier Spring Increase Western U.S. Forest Wildfire Activity. Science 313, 940-943. https://doi.org/10.1126/science.1128834 


\section{CONCLUSION}

This thesis demonstrates the value of novel wildfire risk assessment methods for low-frequency fire regimes. Chapter One illustrated that despite significant changes in fire regime characteristics under mid-century climate change, annual probabilities increase but are still generally low. However, quantifying the possible impact over the course of the thirty-year climate period and quantifying the significant increase in potential for extremely large fires helps to give annual hazard metrics more meaning. Likewise, in Chapter Two, the novel application of Monte Carlo simulation results to surprise fire analysis illustrates a replicable framework for adding to probabilistic risk assessments in locations with low annual burn probabilities. This work clearly shows that recent historic and contemporary fire regime characteristics are not an adequate predictor of future wildfire hazard in the Clackamas. Managers and planners can apply these hazard assessments to long term strategies for adapting to climate change, and specifically, to robust planning focused on developing resilient, safe communities while facilitating transitions to climate-adapted landscapes.

The results from both chapters clearly illustrate that climate change is going to alter fire regime characteristics in the Clackamas over the next fifty years. The findings are consistent with other projections of fire regime changes in westside forests. Namely, results from the Clackamas indicate that wildfire will occur more frequently and will impact a larger area over annual and decadal periods which is line with region-wide projections of future wildfire hazard ( i.e. J. E. Halofsky et al., 2018; Sheehan et al., 2015). Related, results from the Clackamas demonstrate that warmer and drier future 
climate conditions are associated with increased hazard to human communities, similar to findings from the southern Willamette Valley in western Oregon (Hulse et al., 2016). Presenting a range of plausible future scenarios is a non-probabilistic method for communicating uncertainty about climate change and the impact on wildfire hazard (Kunreuther et al., 2013). Following the framework of robust planning, my approach was to model and measure a range of projected future climate scenarios so that in future work we can test risk mitigation strategies against a variety of plausible scenarios and develop strategies that minimize negative consequences under all plausible future conditions (Lempert et al., 2006). Other studies have demonstrated that specific GCMs exhibit biases when applied to particular and that GCMs should be selected first on the bases of regional applicability (Vano et al., 2015). I did not consider regional biases when I selected the four GCMs, but three of the four (CNRM-CM5, HadGEM-ES365, and MIROC5) have been ranked in the top 35\% of all CMIP5 GCMs for applications in the Pacific Northwest (Rupp et al., 2013). The fourth GCM, MIROC-ESM-CHEM, appears to have significant biases which limit its application in the Pacific Northwest (Rupp et al., 2013).

Collectively, the methods and analyses in this thesis illustrate an approach to characterizing wildfire hazard which may be particularly useful in low-frequency fire regimes, but they do not fully characterize wildfire risk. The results do not evaluate how changes in either wildfire frequency of characteristics will impact specific HVRAs. Other regional risk analyses have indicated that wildfire occurrence in the Clackamas and across westside forests generally results in negative consequences, but that in some 
locations there actually may be a modest net benefit depending on the intensity of the fire (Gilbertson-Day et al., 2018). The primary benefit of wildfire in westside forests is probably from its effect of forest structure and composition. As a result of intensive and widespread forest management westside forests are dominated by mid-seral structure and lacking late- and early-seral structure compared to historic ranges of variability (Tom DeMeo et al., 2018). Wildfire in certain westside locations could be a sufficient disturbance to alter forest and promote climate-adapted species assemblages post-burn (Tepley et al., 2013). That said, drinking water provision and timber resources are priority HVRAs and are not likely to experience any net benefit from wildfires. From the hazard analyses in this thesis we can reasonably infer that increased wildfire hazard is going to lead to net negative consequences in westside forests, but there may well be localized benefits to increased wildfire activity depending on existing conditions in specific locations and depending on the particular HVRA being considered.

Even though this work does not explicitly address the impact of wildfire on specific HVRAs, it does demonstrate that wildfire is going to be an increasingly common ecological and social disturbance in the Clackamas. Furthermore, this work demonstrates that large, surprising, and consequential wildfires are going to become more plausible. The wildfire hazard assessments in this thesis should be used experimentally to test risk mitigation and climate adaptation strategies that will achieve beneficial results under a range of climate conditions. Halofsky et al. (2018b) suggested that continued strategic, but aggressive fire suppression is advisable considering the negative consequences of wildfire for municipal watersheds like the Clackamas. Future work could build on the 
model outputs presented in this paper by identifying areas in the Clackamas where wildfire may pose a net benefit and where unintentional ignitions could be allowed to burn and achieve benefits without undue risk to other HVRAs (i.e. Thompson et al., 2016). This thesis also demonstrated that wildfire hazard and risk is not only a concern for forested public land in the upper watershed. Future work could evaluate the impact of different land use and development patterns and the ways in which they increase or diminish future wildfire risk.

\section{REFERENCES}

Gilbertson-Day, J., Stratton, R.D., Scott, J.H., Vogler, K.C., Brough, A., 2018. Pacific Northwest Quantitative Wildfire Risk Assessment: Methods and Results.

Halofsky, J.E., Peterson, D.L., Prendeville, H.R., 2018. Assessing vulnerabilities and adapting to climate change in northwestern U.S. forests. Climatic Change 146, 89-102. https://doi.org/10.1007/s10584-017-1972-6

Halofsky, J.S., Donato, D.C., Franklin, J.F., Halofsky, J.E., Peterson, D.L., Harvey, B.J., 2018. The nature of the beast: examining climate adaptation options in forests with stand-replacing fire regimes. Ecosphere 9, e02140. https://doi.org/10.1002/ecs2.2140

Hulse, D., Branscomb, A., Enright, C., Johnson, B., Evers, C., Bolte, J., Ager, A., 2016. Anticipating surprise: Using agent-based alternative futures simulation modeling to identify and map surprising fires in the Willamette Valley, Oregon USA. Landscape and Urban Planning 156, 26-43. https://doi.org/10.1016/j.landurbplan.2016.05.012

Kunreuther, H., Heal, G., Allen, M., Edenhofer, O., Field, C.B., Yohe, G., 2013. Risk management and climate change. Nature Clim Change 3, 447-450. https://doi.org/10.1038/nclimate 1740

Lempert, R.J., Groves, D.G., Popper, S.W., Bankes, S.C., 2006. A General, Analytic Method for Generating Robust Strategies and Narrative Scenarios. Management Science 52, 514-528. https://doi.org/10.1287/mnsc.1050.0472

Rupp, D.E., Abatzoglou, J.T., Hegewisch, K.C., Mote, P.W., 2013. Evaluation of CMIP5 $20^{\text {th }}$ century climate simulations for the Pacific Northwest USA: CMIP5 20th century climate of the PNW. J. Geophys. Res. Atmos. 118, 10,884-10,906. https://doi.org/10.1002/jgrd.50843

Sheehan, T., Bachelet, D., Ferschweiler, K., 2015. Projected major fire and vegetation changes in the Pacific Northwest of the conterminous United States under 
selected CMIP5 climate futures. Ecological Modelling 317, 16-29.

https://doi.org/10.1016/j.ecolmodel.2015.08.023

Tepley, A.J., Swanson, F.J., Spies, T.A., 2013. Fire-mediated pathways of stand development in Douglas-fir/western hemlock forests of the Pacific Northwest, USA. Ecology 94, 1729-1743. https://doi.org/10.1890/12-1506.1

Thompson, M., Bowden, P., Brough, A., Scott, J., Gilbertson-Day, J., Taylor, A., Anderson, J., Haas, J., 2016. Application of Wildfire Risk Assessment Results to Wildfire Response Planning in the Southern Sierra Nevada, California, USA. Forests 7, 64. https://doi.org/10.3390/f7030064

Tom DeMeo, Ryan Haugo, Chris Ringo, Jane Kertis, Steve Acker, Mike Simpson, Mark Stern, 2018. Expanding Our Understanding of Forest Structural Restoration Needs in the Pacific Northwest. Northwest Science 92, 18-35.

Vano, J.A., Kim, J.B., Rupp, D.E., Mote, P.W., 2015. Selecting climate change scenarios using impact-relevant sensitivities: Selecting Scenarios by Impact Sensitivity. Geophys. Res. Lett. 42, 5516-5525. https://doi.org/10.1002/2015GL063208 